\title{
Analogue earthquakes and seismic cycles: experimental modelling across timescales
}

\author{
Matthias Rosenau ${ }^{1}$, Fabio Corbi ${ }^{2,3}$, and Stephane Dominguez ${ }^{3}$ \\ ${ }^{1}$ Helmholtz Centre Potsdam, German Research Centre for Geosciences, GFZ, 14473 Potsdam, Germany \\ ${ }^{2}$ Dipartimento di Scienze, University Roma Tre, 00146 Rome, Italy \\ ${ }^{3}$ University of Montpellier, UMR5243 Geosciences, 34920 Montpellier, France
}

Correspondence to: Matthias Rosenau (rosen@gfz-potsdam.de)

Received: 1 December 2016 - Discussion started: 6 December 2016

Revised: 23 March 2017 - Accepted: 27 March 2017 - Published: 19 May 2017

\begin{abstract}
Earth deformation is a multi-scale process ranging from seconds (seismic deformation) to millions of years (tectonic deformation). Bridging short- and long-term deformation and developing seismotectonic models has been a challenge in experimental tectonics for more than a century. Since the formulation of Reid's elastic rebound theory 100 years ago, laboratory mechanical models combining frictional and elastic elements have been used to study the dynamics of earthquakes. In the last decade, with the advent of high-resolution monitoring techniques and new rock analogue materials, laboratory earthquake experiments have evolved from simple spring-slider models to scaled analogue models. This evolution was accomplished by advances in seismology and geodesy along with relatively frequent occurrences of large earthquakes in the past decade. This coincidence has significantly increased the quality and quantity of relevant observations in nature and triggered a new understanding of earthquake dynamics. We review here the developments in analogue earthquake modelling with a focus on those seismotectonic scale models that are directly comparable to observational data on short to long timescales. We lay out the basics of analogue modelling, namely scaling, materials and monitoring, as applied in seismotectonic modelling. An overview of applications highlights the contributions of analogue earthquake models in bridging timescales of observations including earthquake statistics, rupture dynamics, ground motion, and seismic-cycle deformation up to seismotectonic evolution.
\end{abstract}

\section{Introduction}

Deformation of the Earth involves a large spectrum of timescales: from earthquake rupture of less than $1 \mathrm{~s}$ to days of aftershock activity, and from years of post-seismic relaxation to hundreds of millions of years of deformation related to plate movements (Wilson cycle; e.g. Ben-Zion, 2008). Such a multi-scale process poses major challenges to observation in nature as the instrumental and historical records are too short to capture a significant amount of the evolution with the high resolution and completeness required. Simulation is a way to overcome such limitations. However, our knowledge of the physics of earthquakes and Earth deformation in general is incomplete and poses a strong challenge to set up realistic numerical scenarios. Simplifications and parametrizations of physical laws implemented in numerical models are rarely justified. The non-uniqueness of numerical solutions for typical problems of Earth deformation on various timescales (e.g. inversion of rupture kinematics or mantle rheology from coand post-seismic observations, respectively) is another limitation of computer models. Experimental approaches using physically self-consistent analogue models have been traditionally used to address physical problems like earthquakes for about 1 century and tectonics for about 2 centuries. Bridging the gap between short-term earthquake and long-term tectonic deformation has only recently become possible due to a better understanding of material properties and developments in monitoring techniques. New across-timescale analogue and numerical modelling approaches are an explorative tool nowadays to better understand instrumental or historical observations and paleo-seismological or geological observa- 
tions, both individually as well as their interference, and interpret them in a seismotectonic context.

Reid (1911) with his pioneering jelly experiments was the first to experimentally simulate earthquakes and formulate a theory, the elastic rebound theory, based on his laboratory and field observations following the 1906 San Francisco earthquake. Wondering "What forces could have produced such distortion and displacements in the rock mass of the region" (Wood, 1912), Reid postulated that only elastic forces can do so. He hypothesized that the release of elastic deformation stored due to a slow accumulation of strain in the Earth occurred by fracturing "along an old fault line" (Reid, 1911) that caused vibration and rebound of the elastically strained rock mass in the vicinity of the fracture.

With the rise of plate tectonic theory in the 1960s accompanied by a thriving of seismology and experimental rock mechanics, stick-slip instabilities (the cyclic slow accumulation and sudden release of stress along frictional interfaces) along pre-existing discontinuities, i.e. tectonic faults, have become the most prominent earthquake mechanism (e.g. Brace and Byerlee, 1966; Byerlee, 1970). Today we are aware that the largest earthquakes, as measured by the seismic moment release energy, are exclusively a result of tectonic faulting in the brittle parts of the Earth's crust concentrated along plate boundaries. Smaller events might occur as a result of, e.g., magmatic diking, hydraulic fracturing, landslides, anthropogenic pumping, or nuclear tests. We focus here on the modelling of tectonic earthquakes.

However, the study of earthquakes faces several limiting factors related to the difficulty of accessing the deep source of the earthquake and of integrating the characteristic timescales of deformation processes that extend from seconds to thousands of years. As a consequence, seismic hazard mitigation is inevitably based on incomplete geological datasets and poorly constrained physical parameters.

New technological advances in seismology and geodesy have significantly improved our knowledge of the dynamics of deformation processes associated with earthquakes on all relevant timescales. By substituting space for time, all archetypical phases of the seismic cycle including the coseismic, post-seismic, and inter-seismic phase have been observed in nature (e.g. Klotz et al., 2001; Wang et al., 2012). However, while recent earthquakes are well documented, this is not the case for older events for which historical records are often too short and incomplete to be usable with the required precision. Beyond the last 50 years, only sparse seismological records and kinematic measurements are available. This situation does not allow constraining seismic-cycle dynamics that extend over a time span of 100 to 1000 years. In particular, geodetic data (e.g. GPS - Global Positioning System - and InSAR - interferometric synthetic aperture radar) that only cover a short time span of the interseismic period ( $<30$ years) are typically extrapolated over longer periods using steady-rate assumptions. However, numerous geophysical observations highlight the complexity of the inter-seismic period (e.g. slow earthquakes, periods of seismic quiescence or crisis) suggesting that the steady-state assumption may be an oversimplification. This raises the issue of a period length in the earthquake cycle that is far larger than the duration of most scientific observations.

The scientific exploitation of available earthquake geophysical data mainly utilizes analytical and numerical modelling methods that allow us to obtain complementary information about deformation processes, physical and mechanical properties of faults, and boundary conditions by means of data inversion (e.g. slip at depth, contemporary stress accumulation, stress transfer). Although such approaches allow reproducing and analysing observed surface velocity fields, they face some limitations. On one hand, some important parameters, such as frictional conditions along the fault plane or stress history induced by past seismic cycles are not understood well enough. On the other hand, modelling all seismiccycle phases using a single approach with different processes acting on different time- and space scales is still a difficult goal to achieve numerically.

We present here an overview of the history as far as the state of the art in analogue seismotectonic modelling. We group existing experimental approaches into three categories of increasing complexity and increasing similarity with the natural prototype. The latest development, namely analogue seismotectonic scale models, has a central position here, as seismotectonic scale models have shown great potential for future developments alongside numerical simulations of the earthquake process. We elaborate on the scaling, monitoring, and material characterization and show a brief overview of applications of the various models. Where appropriate, we make links to numerical models and highlight outlooks and challenges. We compiled information into a set of tables which give a quick overview of existing approaches (Table 1), scaling (Tables 2 and 3), materials (Table 4), and monitoring techniques (Table 5). Symbols used in this article are summarized in Table 6. Original data are published as openaccess material in Rosenau et al. (2016).

\section{Experimental approaches overview}

In parallel to the development of analytical and numerical approaches, numerous experimental or analogue models have been developed to investigate the physics of earthquakes, seismic-cycle dynamics, and seismotectonic evolution. Here, we categorize analogue earthquake models into three groups with a decreasing level of abstraction and an increasing applicability (Fig. 1; Table 1):

- "Spring-slider models", in which elastic and frictional elements are physically discrete components of the setup (Sect. 2.1). These models can only be applied conceptually to nature. 
Table 1. Categories of analogue earthquake models (see text for discussion).

\begin{tabular}{|c|c|c|c|c|c|}
\hline Category & Set-up & Materials & References & Numerical simulations & Scope \\
\hline \multirow[t]{3}{*}{$\begin{array}{l}\text { Spring-slider } \\
\text { models (elastic } \\
\text { and frictional } \\
\text { elements } \\
\text { separate) }\end{array}$} & $\begin{array}{l}\text { Spring-slider } \\
\text { sensu stricto }\end{array}$ & & $\begin{array}{l}\text { Burridge and Knopoff (1967), King (1975, 1991, } \\
\text { 1994), Heslot et al. (1994), Popov et al. (2012), } \\
\text { Varamashvili et al. (2008) }\end{array}$ & $\begin{array}{l}\text { Burridge and Knopoff (1967), Erickson et } \\
\text { al. (2011), Cao and Aki (1984), Schmittbuhl et } \\
\text { al. (1996), Carlson and Langer (1989), Carlson et } \\
\text { al. (1991), Gu and Wong (1991), Wang (2012), } \\
\text { Abe and Kato (2013), Mori and Kawamura (2006, } \\
\text { 2008), Narkounskaia and Turcotte (1992), Saito } \\
\text { and Matsukawa (2007), Dieterich (1972a), Aragon } \\
\text { and Jagla (2013), Baumberger et al. (1994) }\end{array}$ & $\begin{array}{l}\text { Statistics, scal- } \\
\text { ing }\end{array}$ \\
\hline & $\begin{array}{l}\text { Direct } \\
\text { shear/ring } \\
\text { shear }\end{array}$ & $\begin{array}{l}\text { Rocks, glass } \\
\text { beads, sand, } \\
\text { gouge, pasta, } \\
\text { wooden rods, } \\
\text { steel bars, } \\
\text { rice, etc. }\end{array}$ & $\begin{array}{l}\text { Knuth and Marone (2007), Anthony and } \\
\text { Marone (2005), Mair and Marone (1999), } \\
\text { Mair et al. (2002), Alshibli and Roussel (2006), } \\
\text { Schulze (2003), Scuderi et al. (2015), Niejmeier } \\
\text { et al. (2008, 2010), Daniels and Hayman (2008), } \\
\text { Nasuno et al. (1998), Jonhson et al. (2013), } \\
\text { Schulze (2003), Rosenau et al. (2009), Reber et } \\
\text { al. (2014), Rubinstein et al. (2012) }\end{array}$ & $\begin{array}{l}\text { Abe and Mair (2009), Abe et al. (2006), Ferdowsi } \\
\text { et al. (2013, 2014, 2015), Mair and Abe (2008), } \\
\text { Mair and Hazzard (2007) }\end{array}$ & $\begin{array}{l}\text { Slip stability, } \\
\text { rate-state } \\
\text { effects, } \\
\text { triggering, } \\
\text { statistics }\end{array}$ \\
\hline & $\begin{array}{l}\text { Deformable } \\
\text { slider spring }\end{array}$ & Carbopol $^{\circledR}$ & Reber et al. (2015) & & $\begin{array}{l}\text { Slip stability, } \\
\text { brittle-ductile } \\
\text { deformation }\end{array}$ \\
\hline \multirow[t]{6}{*}{$\begin{array}{l}\text { Fault block } \\
\text { models (elastic } \\
\text { solid(s) } \\
\text { in frictional } \\
\text { contact) }\end{array}$} & Shear & Foam rubber & $\begin{array}{l}\text { Brune (1973), Brune et al. (1990, 1993) } \\
\text { Anooshehpoor and Brune }(1994,1999,2004) \text {, } \\
\text { Hartzell and Archuleta (1979), Archuleta and } \\
\text { Brune (1975) }\end{array}$ & Weertman (1980), Andrews and Ben-Zion (1997) & $\begin{array}{l}\text { Rupture dy- } \\
\text { namics }\end{array}$ \\
\hline & Compression & $\begin{array}{l}\text { Plexiglas } \\
\text { (homalite, } \\
\text { resin, poly- } \\
\text { carbonate, etc.) }\end{array}$ & $\begin{array}{l}\text { Lu et al. (2009, 2010), Rosakis et al. (1999, } \\
\text { 2007), Rousseau and Rosakis (2009), Cocker et } \\
\text { al. (2005), Gabuchian et al. (2014, 2017), Ru- } \\
\text { binstein et al. (2004), Lykotrafitis et al. (2006), } \\
\text { Nielsen et al. (2010), Wu et al. (1972), Xia et } \\
\text { al. (2004, 2005), Rubino et al. (2015), Schubnel } \\
\text { et al. (2011), Mello et al. (2010, 2014, 2016), de } \\
\text { Joussineau et al. (2001), Bouissou et al. (1998), } \\
\text { Latour et al. (2013a) }\end{array}$ & $\begin{array}{l}\text { Ma and Beroza (2008), Ampuero and Ben- } \\
\text { Zion (2008), Brietzke et al. (2007, 2009), Tem- } \\
\text { pleton et al. (2009), Kaneko and Ampuero (2011), } \\
\text { Gabuchian et al. (2017) }\end{array}$ & $\begin{array}{l}\text { Rupture dy- } \\
\text { namics }\end{array}$ \\
\hline & Compression & Rock & $\begin{array}{l}\text { Zang et al. (1998), Kwiatek et al. (2014), Stierle } \\
\text { et al. (2016), Lockner et al. (1991), Zang et } \\
\text { al. (2000), Thompson et al. (2009), Passelègue } \\
\text { et al. (2013, 2016), Brace and Byerlee (1966), } \\
\text { Brace (1972), McLaskey and Glaser (2011), } \\
\text { McLaskey et al. (2012), Blanpied et al. (1991, } \\
\text { 1995), McLaskey and Kilgory (2013), Lei and } \\
\text { Ma (2014), Dieterich (1978a), Okubo and Di- } \\
\text { eterich (1984), Ohnaka and Shen (1999), Johnson } \\
\text { et al. (1973) }\end{array}$ & $\begin{array}{l}\text { Ben-Zion and Rice (1997), Lapusta and } \\
\text { Liu (2009), Yoshida et al. (2004), Ben-Zion (2001) }\end{array}$ & $\begin{array}{l}\text { Rupture dy- } \\
\text { namics }\end{array}$ \\
\hline & Shear & Rubber & $\begin{array}{l}\text { Hamilton and McCloskey }(1997,1998) \text {, Schalla- } \\
\text { mach (1971) }\end{array}$ & & $\begin{array}{l}\text { Rupture dy- } \\
\text { namics }\end{array}$ \\
\hline & Shear & Salt & $\begin{array}{l}\text { Voisin et al. (2007, 2008), Zigone et al. (2011), } \\
\text { Mair et al. (2006), Renard et al. (2012) }\end{array}$ & & Slip instability \\
\hline & Shear & Hydrogels & $\begin{array}{l}\text { Corbi et al. (2011), Rubio and Galeano (1994), } \\
\text { Baumberger et al. (2003), Namiki et al. (2014), } \\
\text { Latour et al. (2013b), Yamaguchi et al. (2011) }\end{array}$ & & $\begin{array}{l}\text { Rupture dy- } \\
\text { namics, slip } \\
\text { instability, } \\
\text { statistics }\end{array}$ \\
\hline \multirow{5}{*}{$\begin{array}{l}\text { Seismotectonic } \\
\text { scale models } \\
\text { (elasto-visco- } \\
\text { plastic solids } \\
\text { and fluids with } \\
\text { similarity to } \\
\text { prototype) }\end{array}$} & Megathrust & Gelatine & Corbi et al. (2013) & $\begin{array}{l}\text { Van Dinther et al. (2013a, b), Herrendörfer et } \\
\text { al. (2015), Kaneko et al. (2010) }\end{array}$ & $\begin{array}{l}\text { Rupture } \\
\text { dynamics, } \\
\text { seismic cycle }\end{array}$ \\
\hline & Megathrust & $\begin{array}{l}\text { Rubber/granular } \\
\text { /silicone }\end{array}$ & $\begin{array}{l}\text { Rosenau et al. (2009, 2010), Rosenau and } \\
\text { Oncken (2009) }\end{array}$ & Pipping et al. (2016), Kaneko et al. (2010) & $\begin{array}{l}\text { Seismotectonic } \\
\text { evolution, } \\
\text { seismic cy- } \\
\text { cle, statistics, } \\
\text { tsunami gene- } \\
\text { sis }\end{array}$ \\
\hline & Megathrust & Foam/silicone & Dominguez et al. (2015) & Pipping et al. (2016), Kaneko et al. (2010) & Seismic cycle \\
\hline & $\begin{array}{l}\text { Thrust/normal } \\
\text { fault }\end{array}$ & Foam & Brune (1996), Brune and Anooshehpoor (1999) & $\begin{array}{l}\text { Shi et al. (1998, 2005), Oglesby et al. (1998, } \\
\text { 2000a, b), Ma and Beroza (2000), Nielsen (1998) }\end{array}$ & $\begin{array}{l}\text { Rupture } \\
\text { dynamics, } \\
\text { ground motion }\end{array}$ \\
\hline & Strike slip & Foam & $\begin{array}{l}\text { Caniven et al. (2015), Brune and Anoosheh- } \\
\text { poor (1998), Day et al. (2008) }\end{array}$ & $\begin{array}{l}\text { Ben-Zion and Rice (1997), Lapusta and } \\
\text { Rice (2003), Tullis et al. (2012a, b), Day et } \\
\text { al. (2008) }\end{array}$ & $\begin{array}{l}\text { Seismic cy- } \\
\text { cle, rupture } \\
\text { dynamics, } \\
\text { ground motion }\end{array}$ \\
\hline
\end{tabular}


Table 2. Dimensionless numbers used in analogue earthquake models (see text for discussion).

\begin{tabular}{llll}
\hline Regime & Number & Equation & Meaning \\
\hline Quasi-static & Smoluchowski & $S m=\rho g l / C$ & Gravitational-stress-brittle-strength relation \\
& Ramberg & $R a=\rho g l /(\eta v / l)$ & Gravitational-stress-viscous-strength relation \\
& Stokes & $S t=\Delta P /(\eta v / l)$ & Pressure-viscosity relation \\
\hline \multirow{2}{*}{ Dynamic } & Reynolds & $R e=\rho v l / \eta$ & Inertia-viscosity relation \\
& Froude & $F r=v /(g l) 1 / 2$ & Inertia-gravity relation \\
& Cauchy & $C a=\rho v^{2} / B$ & Inertia-elasticity \\
\hline
\end{tabular}

(a)

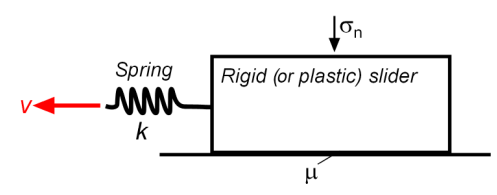

(b) Fault block model

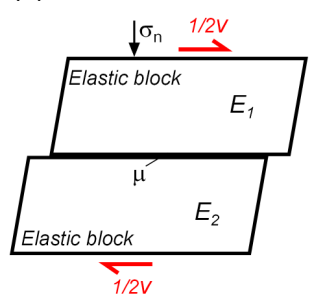

(c) Seismotectonic scale model

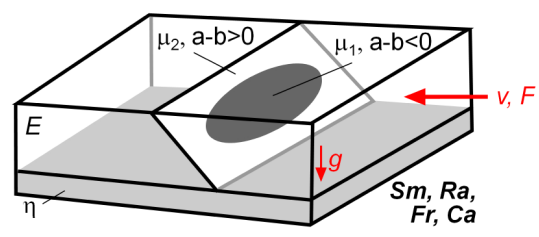

Figure 1. Analogue model categories: (a) spring-slider model ( $v$ is velocity, $k$ is spring constant, $\sigma_{\mathrm{n}}$ is normal load, $\mu$ is friction coefficient); (b) fault block model ( $E$ is Young's modulus); (c) seismotectonic scale model ( $a-b$ is rate-state parameter, $\eta$ is viscosity, $g$ is gravitational acceleration, $\mathrm{F}$ is force, $\mathrm{Sm}, \mathrm{Ra}, \mathrm{Fr}$ and $\mathrm{Ca}$ are dimensionless numbers used for scaling; see Table 2).

- "Fault block models", in which two elastic blocks, with similar or different elastic properties, are in frictional contact (Sect. 2.2). Observations from these models can be qualitatively extrapolated to nature.

- "Seismotectonic scale models", in which a distinct tectonic setting is realistically simulated on a small scale and with boundary conditions mimicking as closely as possible the natural prototype (Sect. 2.3). These models can be directly and often quantitatively upscaled to nature.

\subsection{Spring-slider models}

Following Reid's initial idea of earthquakes reflecting the release of elastic deformation energy stored in the Earth by a mechanical instability, fairly simple spring-slider models (Figs. 1a, 2) have been employed both in seismology and experimental rock mechanics. The spring-slider system is mathematically modelled using a single differential equation that describes the slider motion as a function of the relevant forces acting on it:

$m a(t)+A v(t)+f(v, x, t, \ldots)+k(x-v t)=0$,

where $m$ is slider mass; $x$, an, and $v$ are location, acceleration, and velocity; $t$ is time; $A$ is the damping factor; $f$ is friction force; and $k$ is the spring constant (force over length). Numerous solutions, developments, and applications exist (e.g. Burridge and Knopoff, 1967; Cao and Aki, 1984; Schmittbuhl et al., 1996; Carlson and Langer, 1989; Carlson et al.,
1991; Gu and Wong, 1991; Mori and Kawamura, 2006, 2008; Wang, 2012; Erickson et al., 2011; Abe and Kato, 2013; Aragon and Jagla, 2013). Burridge and Knopoff (1967) developed the simple spring-slider model into one- and twodimensional models, both experimentally and numerically. They established the concept of a chain of coupled springslider systems being able to mimic earthquake occurrence and mechanisms realistically, which revolutionized statistical seismology.

The original Burridge and Knopoff model featured a velocity-weakening friction law as the key non-linearity controlling complexity in earthquake pattern (Carlson and Langer, 1989; Carlson et al., 1991). Schmittbuhl et al. (1996) and Mori and Kawamura $(2006,2008)$ investigated the control of details of the velocity-dependent friction law to earthquake characteristics. Several authors implemented different forms of the friction laws, e.g. time dependence (Dieterich, 1972a), displacement dependence (Cao and Aki, 1984), and rate and state dependence ( $\mathrm{Gu}$ and Wong, 1991; Erickson et al., 2011; Abe and Kato, 2013). Several developments were aimed at including additional effects such as seismic waves (Wang, 2012) or stress relaxation (Aragon and Jagla, 2013). These models succeeded in simulating the variety of seismicity pattern, including Gutenberg-Richter frequency distributions, as well as details of the stick-slip process including pre-seismic quiescence, creep, and aftershocks.

While laboratory spring-slider models have been used widely for teaching basic earthquake phenomena, few have been used to scientifically approach earthquake dynamics. One of the few is that of King $(1975,1991,1994)$, who 


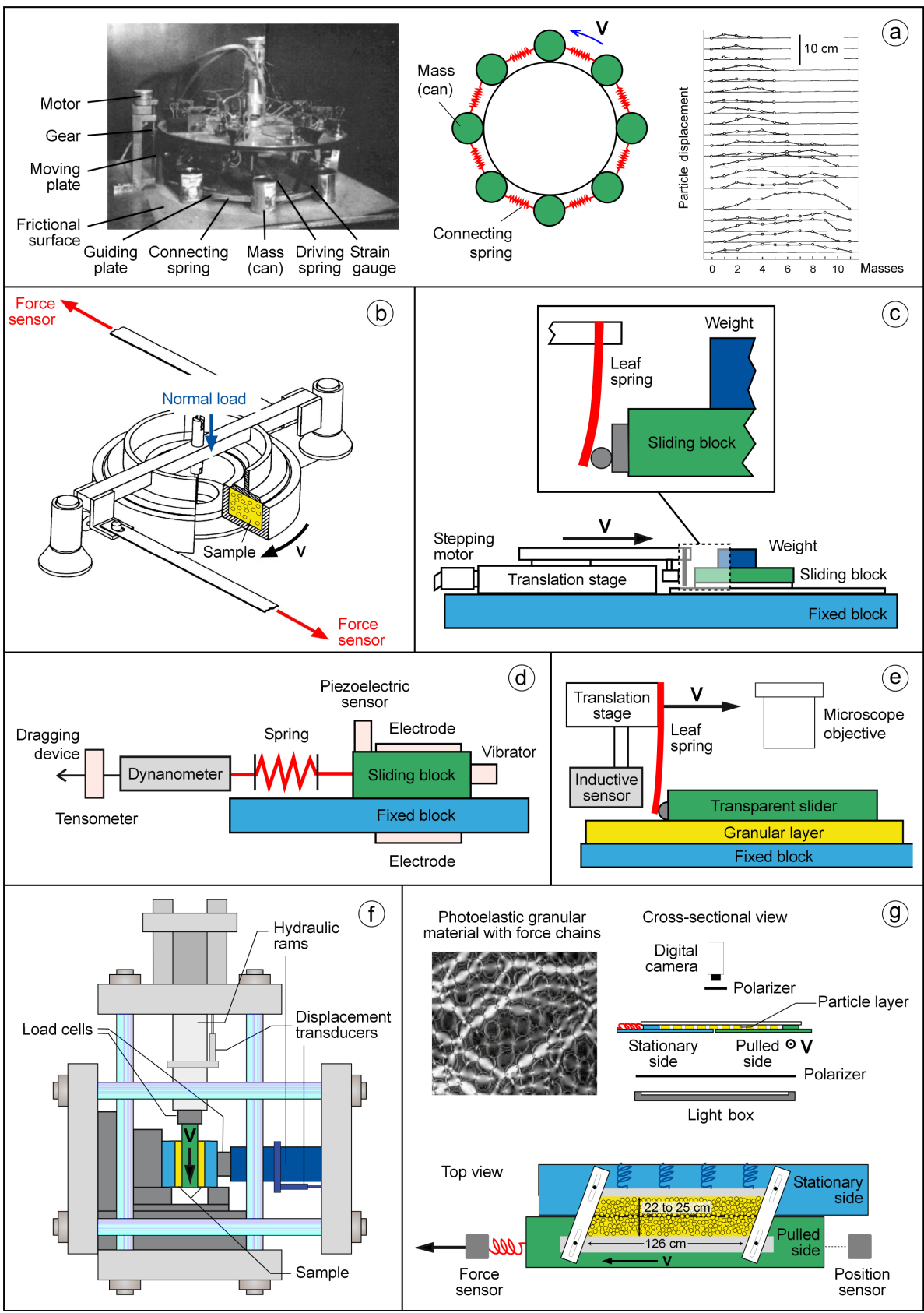

Figure 2. Examples of spring-slider models: (a) King's circular-chain, multiple spring-slider set-up and example of rupture (modified after King 1975, 1991, 1994, reproduced and adapted with permission from Springer); (b) Schulze ring-shear tester used to characterize frictional properties of granular materials in this study (modified after Schulze, 1994); (c) spring-slider set-up after Heslot et al. (1994) (adapted with permission from Heslot et al. (1994), copyrighted by the American Physical Society); (d) spring-slider set-up used by Varamashvili et al. (2008) (modified from there); (e) set-up of see-through experiments by Nasuno et al. (1998) (adapted with permission from Nasuno et al. (1998), copyrighted by the American Physical Society); (f) double-direct shear configuration used to shear rods in various configurations by Knuth and Marone (2007) (modified from there); (g) simple shear set-up and visualization of force bridges in granular media by seethrough experiments of Daniels and Hayman (2008) (modified from there).

employed a circular chain of spring sliders to study earthquake predictability and slip variability over various cycles (Fig. 2a). Heslot et al. (1994) performed spring-slider experiments to illuminate the dependence of frictional stability on the fundamental parameters spring stiffness, loading velocity, and slider mass (Fig. 2c). More recent studies have been realized by Varamashvili et al. (2008) to study the effect of 
external forcing (Fig. 2d) and by Popov et al. (2012) to study the onset of frictional instability.

Brace and Byerlee (1966) were the first amongst a number of other rock mechanics experimentalists of the late 1960s (see references in Brace, 1972) to reproduce stick-slip instabilities by biaxial compression of cylindrical rock samples. The loading machines used were usually designed to be as stiff as possible (in any case stiffer than the rock sample) but were compliant enough to store and release elastic deformation energy. Therefore, such tests can be considered to be a type of spring-slider experiment. Both intact and precut samples were used to generate stress drops associated with stickslip instability in the order of kilobars. In a large number of experiments, the role of mineralogy, porosity, pressure, water, temperature, gouge thickness, and stiffness of the loading system on stick-slip was established first (as summarized in Brace, 1972).

Since these pioneering experiments, stick-slip as an analogue mechanism of earthquakes has been studied using axial testing machines but also direct and rotary or ring-shear testers (see relevant references in Table 1). It is not within the scope of this paper to review the literature of rock mechanics experimental work done on stick-slip deformation in the last half century. Here we focus on those approaches using analogue rock materials instead of rock samples. Knuth and Marone (2007), for example, used rods of different materials in a double-direct shear device in different configurations to study the mechanisms of sliding, rolling, and dilation as well as stick-slip (Fig. 2f). A large body of works exists on granular shear experiments using glass beads and other synthetic fault gouges in shear, rotation, and axial compression apparatuses, some with a focus on stick-slip (e.g. Anthony and Marone, 2005; Mair et al., 2002; Alshibli et al., 200; Schulze, 2003; Scuderi et al., 2015; Rubinstein et al., 2012; Nasuno et al., 1998; Fig. 2e). These experiments were accompanied by numerical models mainly using the discrete element method (e.g. Abe and Mair, 2009; Abe et al., 2006; Ferdowsi et al., 2013, 2014, 2015; Mair and Abe, 2008; Mair and Hazzard, 2007). The shearing of optically clear acrylic or polymeric spheres and discs (e.g. Nasuno et al., 1998; Daniels and Hayman, 2008; Reber et al., 2014) provided insights into the dynamics of stick-slip in granular media by means of 2-D "seethrough" experiments (Fig. 2e and g).

Several studies which focus on the frictional behaviour of granular rock analogue materials (e.g. sand, glass beads; e.g. Schulze, 2003; Ritter et al., 2016; Klinkmüller et al., 2016; Panien et al., 2006; Lohrmann et al., 2003) at low loads (kPa) used a Schulze ring-shear tester (Schulze, 1994; Fig. 2b), which serves here as an example of a spring-slider device used to generate analogue earthquakes. The ring-shear tester consists of a $4 \mathrm{~cm}$ high annular shear cell made of stainless steel holding approximately $1 \mathrm{~L}$ of the sample material. A ring-shaped lid is placed on the filled cell. The lid is subjected to a normal force in order to control normal load on the sample. While the cell is rotated at velocities ranging from 0.5 to $500 \mu \mathrm{m} \mathrm{s}^{-1}$, the lid is prevented from rotating by two tie rods connected to a crossbeam. The force necessary to shear the material is measured continuously. To ensure shearing inside the material and prevent slip between the lid and the granular material, the lid has 20 vanes protruding $4 \mathrm{~mm}$ into the material. The loading system is compliant enough $\left(\sim 1.3 \mathrm{kN} \mathrm{mm}^{-1}\right)$ to generate stick-slip in a variety of materials at loads below $20 \mathrm{kPa}$. Results of this set-up are presented on several occasions in this paper (see Sects. 4.2.2 and 6.2; data in Rosenau et al., 2016).

The main limitation of the classical, simple spring-slider set-up stems from the general rigidity of the slider. A rigid slider distributes shear stress evenly across the frictional interface. Therefore, both loading and release are unrealistically homogenous resulting in fairly periodic and characteristic (similar slip magnitudes), system-sized events. Slip distributions of earthquakes in nature usually show complexity, with areas of high and low energy release (asperities and barriers, respectively; e.g. Aki, 1984). Such heterogeneity might be a stationary feature through subsequent seismic cycles or transient and related to variably frictional properties and/or the slip history of the fault. In any case it also reflects heterogeneous loading as well as heterogeneous release. Multiple spring-slider systems (e.g. Burridge-Knopoff, 1967; King, 1991, 1994) aimed to overcome this limitation and succeeded in generating a more complex slip and recurrence pattern (see Sect. 6.1).

A special type of spring-slider set-ups currently under development may be called "deformable slider spring"; in this, the slider is not rigid but plastic. While elasticity is still controlled by a separate spring, the frictional element can be replaced by different plastic rheologies, e.g. a Bingham fluid (Reber et al., 2015).

\subsection{Fault block models}

In addition to multiple spring-slider models, fault block models have been developed to circumvent the strong assumption of uniform loading and release inherent simple spring-slider models. They allow investigating different aspects of earthquake dynamics on the scale of an analogue fault plane. Unlike spring-slider models, in which the system is provided with elasticity through a spring, in fault block models the elastic strain is stored within the sample volume (Figs. 1b, 3) mimicking the behaviour of the fault-bounded crustal blocks. The first experiments by Reid (1911) were jelly block experiments used to demonstrate the distortion and displacement phenomena seen during the 1906 San Francisco earthquake. This set-up also allows small- (partial) and large- (complete) scale failures to occur in a less segmented fashion compared to multiple spring sliders bearing the potential to generate more realistic frequency size distributions.

Fault block models share the same common characteristic: they are composed by two blocks which are uniformly loaded normal to their interface and sheared against each other. They 

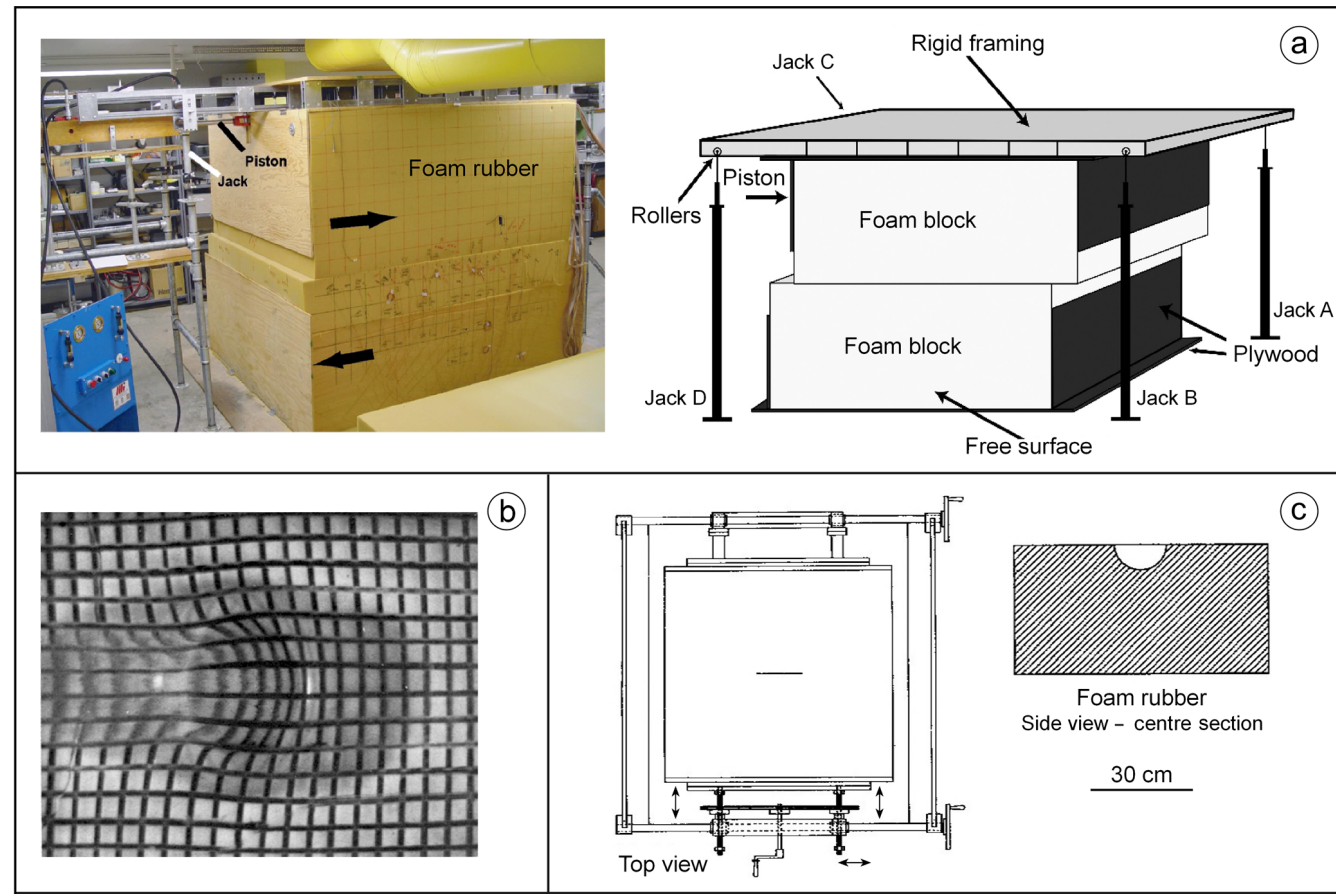

(b)

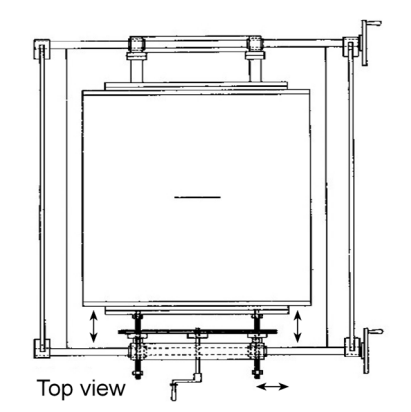

(C)

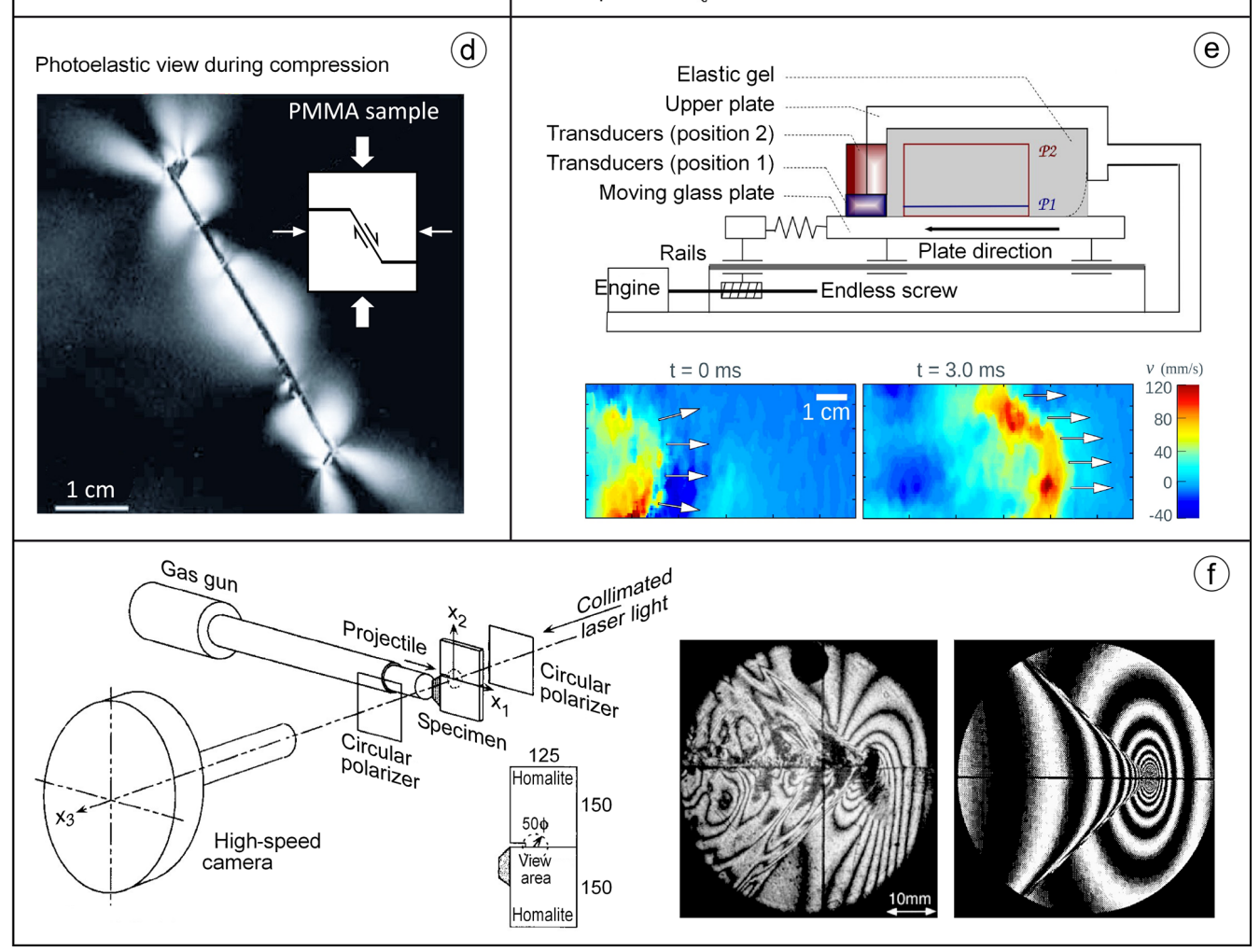

Figure 3. Examples of fault block models: (a) Brune's foam block model as used in Brune et al. (1993), Anooshehpoor and Brune (2004) and Day et al. (2008) (image courtesy of Anooshehpoor and Brune, 2004; sketch modified from Day at al., 2008); (b) "Schallamach wave" pattern as seen in sliding rubber block experiments by Schallamach (1971) (image reproduced with permission from Elsevier); (c) foam rubber set-up after Archuleta and Brune (1975) (modified from there); (d) PMMA block set-up and photoelastic pattern visualizing stress in the vicinity of a crack from De Joussineau et al. (2001) (image reproduced with permission from Elsevier); (e) gel block set-up and resulting rupture pattern from Latour et al. (2013b) (modified from there); (f) homalite block set-up and photoelastic fringe pattern associated with rupture in experiments of Rosakis et al. (1999) (reproduced with permission from the American Association for the Advancement of Science). 
are equivalent to a slip surface embedded in an elastic solid. The slow shearing motion imposed on the system mimics the tectonic loading. Two loading configurations can be differentiated: shear, including direct shear, ring shear, and Couette shear (e.g. Brune, 1973; Archuleta and Brune, 1975; Schallamach, 1971; Latour et al., 2013b; Fig. 3a-c, e), and (biaxial) compression (e.g. de Joussineau et al., 2001; Bouissou et al., 1998; Rosakis et al., 1999; Fig. 3d and f). Earthquakes may nucleate spontaneously and repeatedly or through external forcing, i.e. impact (e.g. Xia et al., 2004).

The two blocks and the interface between them are the analogues of rock volume and an embedded fault of finite dimensions, respectively. Edge effects, artificial reflections and free-surface effects are usually unavoidable in fault block models (e.g. Scholz et al., 1972). The two blocks may be of the same material (e.g. foam rubber: Brune, 1973; Archuleta and Brune, 1975; rock: Lockner et al., 1991; Lei et al., 2000; Zang et al., 2000; Thompson et al., 2005, 2006, 2009) or materials with different compliances (e.g. gel sliding on glass: Baumberger et al., 2003; rubber on rough substrate: Hamilton and McCloskey, 1997, 1998; Schallamach, 1971). Different materials have been adopted depending on the desired rheological response of the system; ranging from purely elastic (e.g. rubber: Schallamach, 1971; Plexiglas: Rosakis et al., 2007, and references therein) to viscoelastic (e.g. polyvinilalcool - PVA: Namiki et al., 2014). The use of softer materials allows us to slow down the rupture process and make it more accessible by means of monitoring. This has been exploited by, e.g., Baumberger et al. (2003), Yamaguchi et al. (2011), and Latour et al. (2013b) using gel sliders (Fig. 3e).

\subsection{Seismotectonic scale models}

With the advent of high-resolution strain monitoring such as digital image correlation (e.g. Adam et al., 2005), it became possible to measure small-scale deformation increments (i.e. scaling from decimetres to metres in nature) corresponding to single earthquake displacements. This unlocked the possibility to realize analogue seismotectonic scale models of earthquakes (Figs. 1c, 4). Modern seismotectonic scale models feature realistic non-linear frictional properties of materials. They are able to mimic the coseismic dynamic weakening that in nature happens for various reasons (e.g. frictional melting, thermal pressurization, chemical effects). A second feature is a properly scaled elasticity of the model. Classical analogue models of tectonic processes use sand or other rigid particles to study long-term fault kinematics in the brittle regime. However, their elastic moduli appear to be too high (GPa; e.g. Klinkmüller et al., 2016) to be used to simulate elastic deformation realistically. To model earthquakes and seismic cycles, scaling rules impose a decrease in the elastic moduli of the model by several orders of magnitude. This can be achieved by adding elastic particles (e.g. rubber pellets) or by using compliant solids (e.g. gelatine, foam rubber). In contrast to fault block models, seismotectonic scale models make a realistic depth-dependent pressurization of the faults (i.e. lithostatic pressure) possible. Loading conditions that mimic tectonic forcing are realized by applying pure or simple shear boundary conditions, for example.

In the context of earthquakes and seismic cycles, seismotectonic scale models are used to study seismogenic fault behaviour over many orders of magnitude in timescales. They allow us to simulate multiple seismic cycles in threedimensional models with fully dynamic ruptures including the interaction between seismic and aseismic fault areas, offfault deformation in the brittle upper crust, and viscoelastic relaxation in the lower crust and mantle. Therefore, despite their simplicity, they are the preferred scientific tool to overcome the limitations in natural observations by means of sufficiently long and well enough resolved time series of deformation.

From an observational point of view, the main challenges of analysing analogue earthquake models are the elastic nature of deformation as well as the very small displacements on various timescales, especially with regard to the interseismic stage. Because earthquake cycles are dominated by elastic deformation, the deformation fields are characterized by velocity reversals and alternations between slow strain accumulation (loading) and fast release (earthquake). Due to the high variability in strain rates only quasi-continuous or highly resolved incremental monitoring provides accurate quantification. Moreover, in seismotectonic scale models, incremental displacements of interest are necessarily very small as decimetres to metres in nature scale down to micrometres in laboratory seismotectonic scale models. Finally, deformation increments occur on a wide range of timescales (seconds to thousands of years in nature, milliseconds to minutes in laboratory models) resulting in strongly variable velocities that vary by more than 12 orders of magnitude in nature. Thanks to non-linear timescaling (see Sect. 3), the latter can be reduced to about 3 orders of magnitude in analogue models.

There have been several seismotectonic scale model approaches in the recent past (Table 1; Fig. 4). Viscoelastic seismotectonic scale models (e.g. Corbi et al., 2013; Fig. 4a) were used to study rupture dynamics and elastic coseismic deformation of the forearc wedge. In these models, a gelatine wedge (analogue of the overriding plate) is underthrust by a $10^{\circ}$ dipping, planar, and rigid aluminium plate (analogue of the subducting slab). Plate convergence is imposed kinematically. A UV light sheet is used to illuminate fluorescent markers along a central section of the model. The experiments are monitored in side view using digital image correlation techniques. The subducting plate embeds a "seismogenic" velocity-weakening zone limited by velocity strengthening areas at its updip and downdip limits. Frictional instabilities (the analogue earthquakes) nucleate and propagate along the gelatine-aluminium interface. Viscoelastic models feature the following characteristics that make them useful in the investigation of different aspects of the seismic cycle: 


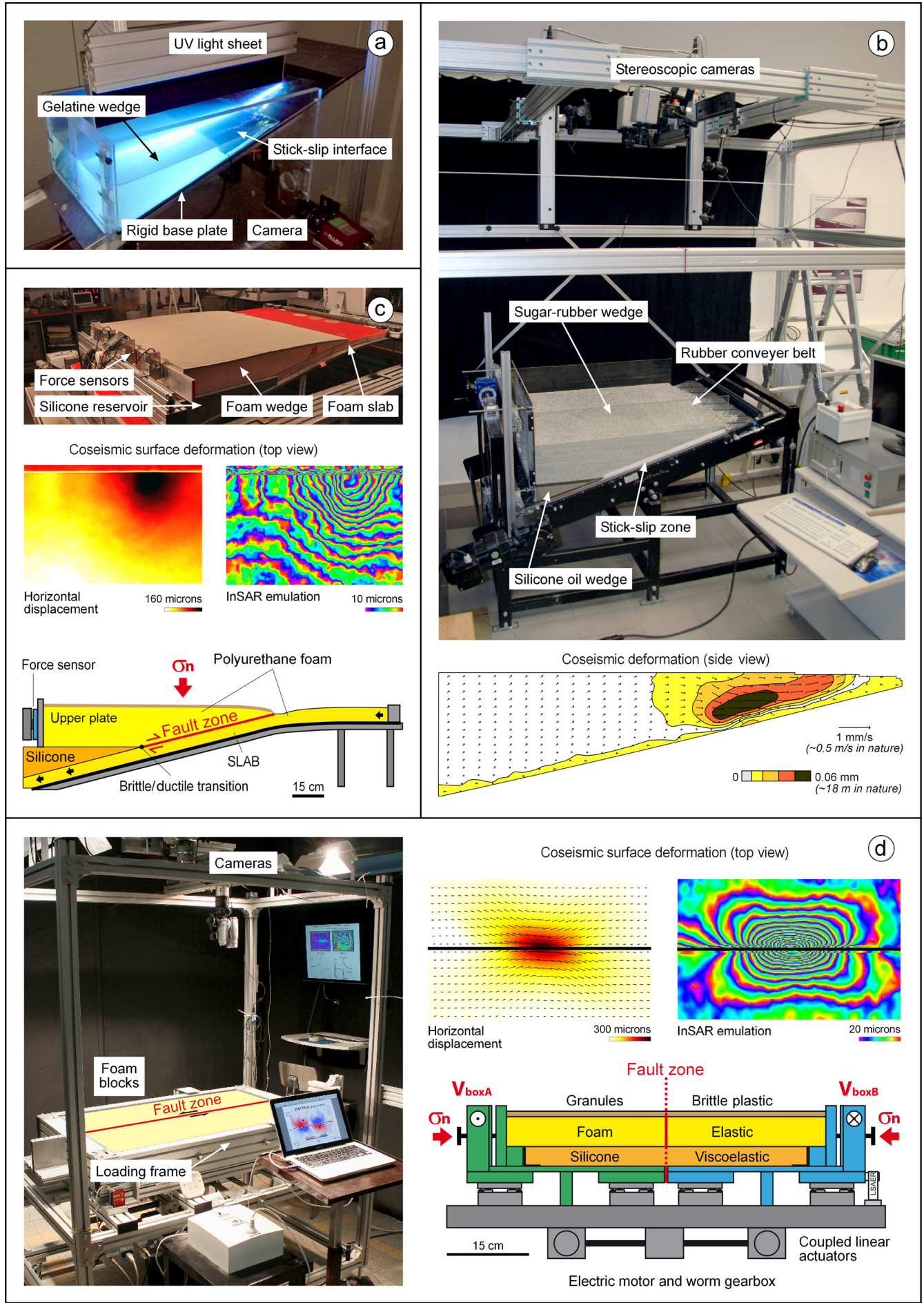

Figure 4. Examples of seismotectonic scale models: (a) viscoelastic gelatine wedge set-up used by Corbi et al. (2013) to study subduction megathrust earthquakes (modified from there); (b) elastoplastic granular wedge set-up used in this study to simulate subduction megathrust seismotectonic evolution, which is developed from a similar set-up used by Rosenau et al. (2009, 2010), and the resulting earthquake deformation pattern (side view, modified after Rosenau et al., 2009); (c) layered elastic-viscoelastic foam rubber-silicone wedge set-up used by Dominguez et al. (2015) to study subduction megathrust earthquakes and the resulting earthquake deformation pattern (top view; left: displacement; right: pseudo-InSAR fringe pattern); (d) layered elastic-viscoelastic foam rubber-silicone strike-slip set-up used by Caniven et al. (2015) and the resulting earthquake deformation pattern (top view; left: displacement; right: pseudo-InSAR fringe pattern) (modified from Caniven et al., 2015). 
(a) the earthquake process lasts for a few seconds, allowing us to capture the nucleation process, the propagation, and the arrest of the rupture; (b) the rheology of the material can be tuned depending on the desired experimental requirements. The analogue models of Corbi et al. (2013) have been tested against numerical models using the finite-element technique (van Dinther et al. 2013a, b). An extensive benchmark has been carried out analysing a set of parameters that are characteristic of both the inter-seismic and coseismic stages (i.e. recurrence time, coseismic displacement, rupture duration, rupture velocity, slip rate, rupture width, and hypocentre location). A robust fit has been obtained for the majority of the investigated parameters of the reference model (van Dinther et al., 2013a). In particular, the mean of individual source parameters of the numerical model falls systematically within the standard deviation of the same parameter of the analogue models. The largest discrepancies between the two modelling techniques are observed for rupture width and hypocentre location and are attributed to a difference in boundary conditions (i.e. the aseismic part of the megathrust does not create stress build-up in the analogue models) and sampling rate, respectively.

A similar set-up has been used by Rosenau et al. (2009) but with a granular, elastoplastic wedge on top of a less compliant conveyer plate or belt (Fig. 4b). This set-up, in combination with digital image correlation based optical strain analysis allows us to simulate and monitor the seismotectonic evolution of subduction forearcs and thus bridge the short- to long-term processes of earthquakes and tectonic evolution, respectively. Because of the opacity of the models, strain monitoring was restricted to side views through glass walls or stereoscopic top views of the surface deformation in 2-D and 3-D experiments, respectively. Seismogenic zones at the base of the wedge were defined through the use of a velocity-weakening material (i.e. rice). Compared to the viscoelastic wedges of Corbi et al. (2013), elastoplastic wedges were stiffer. Consequently the rupture velocity was higher, while the deformations were smaller. From a scaling point of view, this is more appropriate; however, it poses limitations on the observability of analogue earthquakes, i.e. a lower bound of about $M 8$ events. The analogue models of Rosenau et al. $(2009,2010)$ have been cross-validated using finite-element models (Pipping et al., 2016). The numerical model of Pipping et al. (2016) replicated the laboratory results by means of the general deformation pattern of the wedge through seismic cycles, the recurrence behaviour (recurrence times and periodicity), and principal source parameters (slip distribution). Using numerical simulation, the frictional properties of the analogue model material were validated and augmented if not measured physically. Moreover the numerical model provided a highly resolved image of the rupture dynamics beyond what was observed in the analogue model (see, e.g., animation of analogue vs. numerical subduction earthquake cycles in Rosenau et al., 2016). Vice versa, the laboratory example served as an object for testing the general performance of the numerical modelling scheme and for the verification of the effectiveness and reliability of the algorithm for frictional contact modelling introduced there.

Most recently, Caniven et al. (2015) have developed an experimental approach allowing us to simulate strike-slip fault earthquakes and seismic cycles in a brittle-ductile crust (Fig. 4d). One of the remarkable points of this study is the use of an analogue model consisting of an elastic block (polyurethane foam) floating on viscoelastic (silicone oil) material and covered by brittle plastic (silica-powdergraphite mix) analogue material. This multi-layer approach takes into account, at first order, the crust rheology and its mechanical behaviour. This is a crucial point to allow the simulation of brittle-ductile couplings and post-seismic deformation. Following the approach of Caniven et al. (2015), a set-up for 3-D subduction megathrust experiments was developed by Dominguez et al. (2015) (Fig. 4c). In both settings, the use of a multi-layered model allows us to reproduce the complete seismic cycles, including for the first time realistic post-seismic deformation. Post-seismic deformation in the model is driven by relaxation due to the same mechanisms as in nature, namely after slip along the fault and viscoelastic relaxation of the underlying substrate. The scaling of experimental earthquakes has been shown to be satisfactory in terms of stress drop and associated deformation. The evolution of model kinematics is monitored using a digital image correlation technique at sub-pixel accuracy and resolution mimicking a very dense GPS network, and this allows us to emulate an InSAR-like fringe pattern (Fig. $4 \mathrm{c}$ and d). The rigorous implementation of numerical inversion and modelling tools in the approach provides key direct and indirect observables such as surface and volumetric strain and stress as well as the slip distribution and stress changes along the fault plane. Optical measurements are complemented by strain gauges to measure far-field strain evolution and earthquakeinduced stress drops. Acoustic sensor measurements are also being developed to study background seismicity and coseismic event signatures. The analogue models generate a broad variability of earthquake-like slip events constituting large data catalogues that can be used to study earthquake scaling and statistics as well as rupture dynamics. As the model generates tens of successive seismic cycles, these provide the potential to study the short-term and long-term evolution of strain and stress fields. Cross-validation with numerical models is ongoing.

Some general model limitations apply to all of the seismotectonic scale model mentioned here; they are related to principal space and resolution restrictions. For example, the minimum size of events simulated is in the order of magnitudes 7-8 which so far has prevented us from studying preand aftershock activity in detail. The size of the models is generally large enough to realistically simulate near-field deformation on a local to regional scale. Continental-scale farfield phenomena like mantle relaxation in subduction zones 
are currently beyond the limit of such studies. Finally, fluids, poroelasticity, and temperature effects are not simulated, and, consequently, the role of metamorphism and associated changes in rock properties in earthquake and seismic-cycle dynamics cannot be evaluated.

\section{Scaling and similitude}

Scaling laboratory-scale observations to nature is a central issue in analogue earthquake modelling, especially for seismotectonic scale models. To be representative of a natural system, a small-scale model should share geometric, kinematic, and dynamic similarity with its prototype (Hubbert, 1937). This condition is termed similitude and requires that all lengths, time, and forces scale down from the prototype in a consistent way dictated by scaling laws. The latter are derived either from an analytic approach (e.g. Weijermars et al., 1993) or from dimensional analysis and the formulation of dimensionless numbers (Buckingham, 1914; Table 2).

The large range of velocities to be captured in an analogue earthquake model poses practical challenges: first, to conduct experiments in a reasonable time frame and second, to observe (monitor) analogue earthquakes. If the total runtime of an experiment simulating thousands to millions of years in nature is on a reasonable scale (of hours), the episodically recurring earthquakes are captured only with very high speed monitoring techniques $(\mathrm{MHz})$ or the earthquakes are slowed down to a reasonable speed (to be captured by 1$100 \mathrm{~Hz}$ monitoring), in which case a model run would take weeks.

From a scaling point of view, however, the range in velocities in the model can be significantly reduced through the use of non-linear timescaling, which considers different timescales for co- and inter-seismic deformation periods. Rosenau et al. (2009) introduced a "dyadic" timescale that recognizes two dynamically distinct regimes of the seismic cycle: the quasi-static inter-seismic regime, where inertial effects are negligible due to the slow deformation rates and the dynamic coseismic regime, which is controlled by inertial effects. Consequently, two different temporal scales are applied. This way, the earthquake rupture can be virtually slowed down while the loading phase is sped up, keeping dynamic similarity in both stages. In a typical application $0.1 \mathrm{~s}$ may correspond to a quarter century of inter-seismic loading and about $1 \mathrm{~min}$ of rupture time.

The transition from non-inertial, quasi-static to inertial, dynamic deformation can be defined kinematically. Based on theoretical considerations using a spring-slider system, Roy and Marone (1996) suggest that the transition occurs at a critical velocity, which is a function of extrinsic and intrinsic frictional properties and mass. By contrast, Latour et al. (2013a), basing their findings on empirical results and theory, equate the transition from quasi-static to dynamic deformation with the transition from exponential growth to power law growth of the rupture length. They suggest that elastic and frictional properties control the transition. In practice a velocity threshold is defined that also depends on the temporal resolution to differentiate between the quasi-static and dynamic regime. With better spatial and temporal resolution in future, this issue will certainly be re-visited in detail.

The scaling for the short and long term, or inter- and coseismic phases is elaborated in Sect. 3.1 and 3.2, respectively. Dimensionless numbers and scaling relations are summarized in Tables 2 and 3.

\subsection{Quasi-static regime: scaling the inter-seismic phase}

In the non-inertial, quasi-static regime of the inter-seismic phase, scaling is identical to the common scaling of longterm processes to the lab. For long-term tectonic studies involving materials that deform brittle or viscous material, two dimensionless numbers, the Smoluchowski and Ramberg numbers, are of interest according to the deformation regime (Weijermars and Schmeling, 1986; Brun, 2002; Pollard and Fletcher, 2005).

In the case of brittle deformation characterized by cohesion and a pressure-dependent frictional strength, the ratio between gravitation (or overburden stress) and the material strength, labelled the Smoluchowski number, is commonly used to ensure dynamic similarity. It is defined as

$S m=\frac{\rho g l}{C}=\frac{\text { gravitational stress }}{\text { brittle strength }}$,

where $\rho$ is density $\left(\mathrm{kg} \mathrm{m}^{-3}\right), g$ gravitational acceleration $\left(\mathrm{m} \mathrm{s}^{-2}\right), C$ cohesion $(\mathrm{Pa})$, and $l$ a characteristic length. In the viscous deformation regime, the ratio of gravitation and viscous flow strength is used and has been labelled the Ramberg number:

$R a=\frac{\rho g l}{\eta v / l}=\frac{\text { gravitational stress }}{\text { viscous strength }}$,

where $\eta$ is viscosity (Pas) and $v$ a characteristic velocity (Ramberg, 1967). Note that the Ramberg number is derived from the Stokes number (Table 2), which characterizes more generally slow, non-inertial (small Reynolds numbers, $R e<<1$; Table 2) flow typical of tectonic applications. To achieve similitude these numbers have to be the same in the model as in the prototype. For a given length scale (usually suitably chosen for handling the model in a lab), Sm and $R a$ dictate the stress scaling in the brittle and viscous regimes, respectively.

According to Eq. (2), for a brittle sandbox model under normal gravity (i.e. $g^{\text {model }}=g^{\text {prototype }}$ such that $g^{\text {model }} / g^{\text {prototype }}=1$, where superscript "model" and "prototype" indicate the respective values), we find that the cohesion should scale according to the density and length scale following the scaling law:

$C^{*}=\rho^{*} L^{*}$. 
Table 3. Typical scales, scaling relations, and factors in seismotectonic scale models (see text for discussion).

\begin{tabular}{|c|c|c|c|c|c|c|c|}
\hline Regime & Parameter & Symbol & Dimension & Model value & $\begin{array}{l}\text { Prototype } \\
\text { value }\end{array}$ & Scaling relation & $\begin{array}{l}\text { Scaling } \\
\text { factor }\end{array}$ \\
\hline \multirow{8}{*}{$\begin{array}{l}\text { Inter-seismic } \\
\text { (quasi-static } \\
\text { regime) }\end{array}$} & Length & $l$ & $\mathrm{~L}$ & $\mathrm{~mm}$ to $\mathrm{dm}$ & $1-1000 \mathrm{~km}$ & $L^{*}=L^{\text {model }} / L^{\text {prototype }}$ & $10^{-5}-10^{-6}$ \\
\hline & Time & $t$ & $T$ & $\mathrm{~s}$ to $\mathrm{h}$ & Years to millions of years & $T^{*}=T^{\text {model }} / T^{\text {prototype }}$ & $10^{-10}$ \\
\hline & Density & $\rho$ & $\mathrm{M} \mathrm{T}^{-3}$ & $1000-2000 \mathrm{~kg} \mathrm{~m}^{-3}$ & $2500-3000 \mathrm{~kg} \mathrm{~m}^{-3}$ & $\rho^{*}=\rho^{\text {model }} / \rho^{\text {prototype }}$ & $1 / 3 \ldots 1$ \\
\hline & Mass & $m$ & M & $\mathrm{kg}$ & Tera- to petatons & $M^{*}=\rho^{*} L^{*^{3}}\left(\right.$ for $\left.g^{*}=1\right)$ & $10^{-15}-10^{-18}$ \\
\hline & Gravity & $g$ & $\mathrm{LT}^{-2}$ & $9.81 \mathrm{~m} \mathrm{~s}^{-2}$ & $9.81 \mathrm{~m} \mathrm{~s}^{-2}$ & $g^{\text {model }}=g^{\text {prototype }}$ & 1 \\
\hline & Recurrence time & $T_{\text {rec }}$ & $T$ & $\mathrm{~s}$ & Centuries & $T^{*}=T^{\text {model }} / T^{\text {prototype }}$ & $10^{-10}$ \\
\hline & $\begin{array}{l}\text { Maxwell relaxation } \\
\text { time }\end{array}$ & $T_{\mathrm{m}}$ & $T$ & $0.1 \mathrm{~s}$ & Decades & $T^{*}=T^{\text {model }} / T^{\text {prototype }}$ & $10^{-10}$ \\
\hline & $\begin{array}{l}\text { Tectonic loading } \\
\text { velocity }\end{array}$ & $V_{0}$ & $\mathrm{LT}^{-1}$ & $\mathrm{~mm} \mathrm{~s}^{-1}$ & $\mathrm{~mm} \mathrm{yr}^{-1}$ & $V^{*}=L^{*} / T^{*}$ & $10^{4}-10^{5}$ \\
\hline \multirow{9}{*}{$\begin{array}{l}\text { Coseismic } \\
\text { (dynamic } \\
\text { regime) }\end{array}$} & Length & $l$ & $\mathrm{~L}$ & $\mu \mathrm{m}$ to $\mathrm{mm}$ & $\mathrm{cm}$ to $\mathrm{m}$ & $L^{*}=L^{\text {model }} / L^{\text {prototype }}$ & $10^{-5}-10^{-6}$ \\
\hline & Time & $t$ & $T$ & $\mathrm{~s}$ & $\mathrm{~s}$ to $\min$ & $T^{*}=\left(L^{*}\right)^{1 / 2}$ & $10^{-3}$ \\
\hline & Mass & $m$ & M & $\mathrm{kg}$ & Tera- to petatons & $M^{*}=L^{*^{3}}\left(\right.$ for $\left.g^{*}=1\right)$ & $10^{-15-}-10^{-18}$ \\
\hline & Acceleration & $\tilde{a}$ & $\mathrm{LT}^{-2}$ & $1 \mathrm{~ms} \mathrm{~s}^{-2}$ & $1 \mathrm{~ms}^{-2}$ & $\tilde{\mathrm{a}}^{\text {model }}=\tilde{\mathrm{a}}^{\text {prototype }}$ & 1 \\
\hline & Rupture duration & $T_{\text {rup }}$ & $T$ & $\mathrm{~ms}$ to $\mathrm{s}$ & $\mathrm{s}$ to $\min$ & $T^{*}=\left(L^{*}\right)^{1 / 2}$ & $10^{-3}$ \\
\hline & Rupture velocity & $V_{\text {rup }}$ & $\mathrm{LT}^{-1}$ & $\mathrm{~ms}^{-1}$ & $\mathrm{~km} \mathrm{~s}^{-1}$ & $V^{*}=T^{*}=\left(L^{*}\right)^{1 / 2}$ & $10^{-3}$ \\
\hline & Slip velocity & $V$ & $\mathrm{LT}^{-1}$ & $\mathrm{~mm} \mathrm{~s}^{-1}$ & $\mathrm{~ms}^{-1}$ & $V^{*}=T^{*}=\left(L^{*}\right)^{1 / 2}$ & $10^{-3}$ \\
\hline & Seismic moment & $M_{0}$ & $\mathrm{ML}^{2} \mathrm{~T}^{-2}$ & $0.1-1 \mathrm{Nm}$ & $10^{21}-10^{23} \mathrm{Nm}$ & $M_{0}^{*}=M^{*} L^{*}\left(\right.$ for $\left.g^{*}=1\right)$ & $10^{-21}-10^{-23}$ \\
\hline & Moment magnitude & $M_{\mathrm{W}}$ & - & -7 to -5 & $8-9.5$ & $M_{\mathrm{W}}^{\text {prototype }}=M_{\mathrm{W}}^{\text {model }}-2 / 3 \log \left(M_{0}^{*}\right)$ & $\mathrm{n} / \mathrm{a}$ \\
\hline
\end{tabular}

The asterisks denote the model / prototype ratios also known as the scaling factors (i.e. $C^{*}=C^{\text {model }} / C^{\text {prototype }}, \rho^{*}=$ $\left.\rho^{\text {model }} / \rho^{\text {prototype }}, L^{*}=L^{\text {model }} / L^{\text {prototype }}\right)$. Inserting typical numbers for the scaling factors for density and cohesion of a brittle analogue rock material like sand $\left(C^{*} \sim 10^{-6}\right.$, $\rho^{*} \sim 0.6$; e.g. Klinkmüller et al., 2016) into Eq. (3) yields typical length scales $L^{*}$ of $10^{-5}$ to $10^{-6}$; i.e. $1 \mathrm{~cm}$ in the model equals $1-10 \mathrm{~km}$ in nature. Note that all quantities with the unit of stress, in particular all strengths, share the same scaling and are substitutes for cohesion in Eq. (4).

As cohesion and elastic moduli also share the same dimension $(\mathrm{Pa})$, elastic moduli should scale with the same scaling factor (e.g. $E^{*}=E^{\text {model }} / E^{\text {prototype }}=C^{*}$ ). For typical values of tens of gigapascal elastic moduli in nature, analogue rock material should be typically fairly soft, i.e. tens of kilopascal, like foam rubber (see Sect. 4.1.2).

For a viscous model under normal gravity we find from Eq. (3) that the stress $\sigma$ should scale according to the viscosity scale and strain rate scale following the scaling law:

$\sigma^{*}=\eta^{*}(\mathrm{~d} \varepsilon / \mathrm{d} t)^{*}$.

Importantly, implementing a viscous rheology in analogue models sets a long-term timescale by combining Eqs. (4) and (5):

$T^{*}=\frac{\eta^{*}}{\sigma^{*} L^{*}}$.

Inserting typical numbers for the scaling factors for viscosity of an analogue material like silicone (Sect. 4.3.2: $\eta^{*}$ $\sim 10^{-15}-10^{-16}$ ) and densities and using the length scale derived from the above yields typical timescales $T^{*}$ of $10^{-9}$ $10^{-10}$; i.e. $1 \mathrm{~s}$ in the model represents about $30-300$ years in nature. Regarding analogue earthquake models, the typical scaling of recurrence time is shown in Fig. 5a. Accordingly, recurrence times of tens of seconds scale to hundreds to thousands of years in nature (Rosenau et al., 2010; Caniven et al., 2015).

\subsection{Dynamic regime: scaling the coseismic phase}

For the coseismic stage inertia controls the dynamics, so that the Froude number can be used to reach dynamic similarity and find an appropriate short-term timescaling (Rosenau et al., 2009):

$F r=v / \sqrt{g l}=\frac{\text { inertia }}{\text { gravitation }}$.

Froude scaling sets the important constraint that the timescale of the model should be the square root of the length scale:

$T^{*}=\sqrt{L^{*}}$.

As a consequence, all accelerations are the same in the model as in the prototype. Regarding the stress scale in the dynamic regime, the Cauchy number can be used (Rosenau et al., 2009):

$C a=\frac{\rho v^{2}}{B}=\frac{\text { inertia }}{\text { elasticity }}$,

where $B$ is the bulk modulus or an equivalent elastic modulus. If frictional or viscous strength is set as the denominator in Eq. (9), it can be generalized to define brittle and viscous scaling in the dynamic regime, respectively. The latter is equivalent to the Reynolds number (Table 2). Importantly, the stress scale derived by Cauchy scaling in the dynamic 

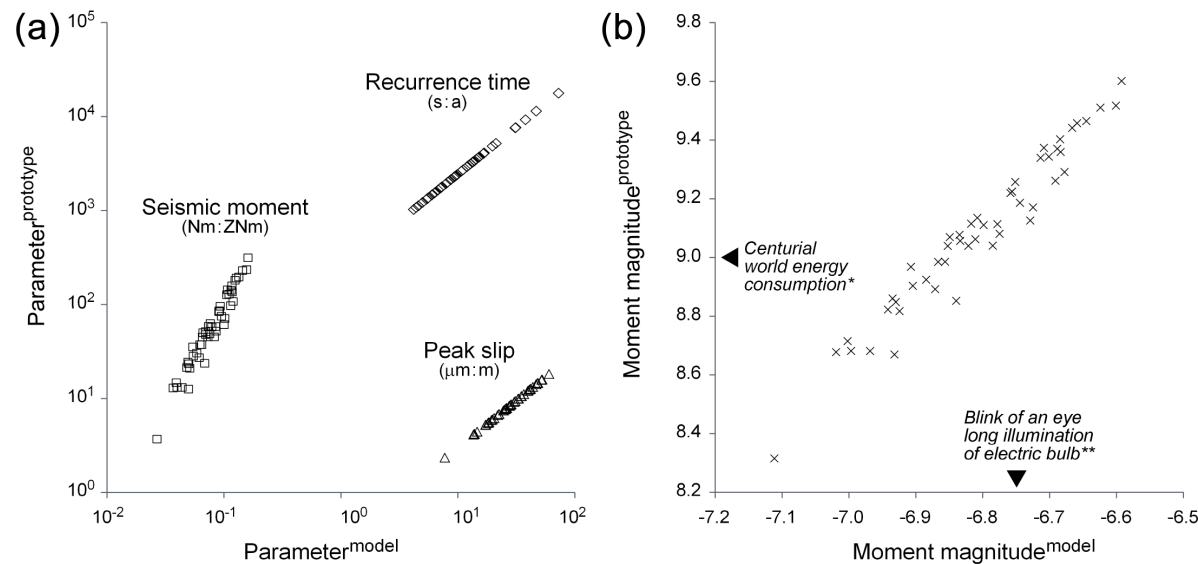

Figure 5. Scaling of parameters from laboratory (model) to nature (prototype). (a) Scaling for peak slip, recurrence time, and seismic moment (the unit relation given in parentheses corresponds to the dimensional mapping of the respective axis); (b) scaling for moment magnitude (* based on the year 2000; ** $10 \mathrm{~W}$ bulb, ca. $0.1 \mathrm{~s}$ ). Data and methodological details are published as open-access material in Rosenau et al. (2016).

regime is consistent with the stress scale derived by Smoluchowski scaling the in the quasi-static regime.

A theoretical conflict arises, however, when viscous forces in the dynamic regime are considered: these should be scaled using the Reynolds number. For various reasons the similarity requirements posed by the Froude and Reynolds numbers can typically not be satisfied simultaneously. In our application, both the Reynolds and Froude number can be preserved simultaneously only if we use a viscous material that hardens dramatically (by 3 orders of magnitude or so) coseismically or assume that the mantle weakens accordingly. In practice, assuming that viscous flow plays a limited role in the coseismic stage, which is dominated by elastic deformation, nonconservation of the Reynolds number through the coseismic phase seems acceptable.

Apart from the dimensionless numbers introduced above, all model parameters without a dimension should be preserved, e.g. Poisson's ratio $v$, the friction coefficient, the friction rate and state parameters $a$ and $b$, and the stress exponent in the viscous regime. An exception to this general scale independence of dimensionless parameters is the moment magnitude $M_{\mathrm{w}}$ that is related to the seismic moment (unit $\mathrm{Nm}$ ) but defined as being dimensionless:

$M_{\mathrm{w}}=\frac{2}{3} \log M_{0}-10.7$

The scaling factor for seismic moment $M_{0} *=$ $M_{0}^{\text {model }} / M_{0}^{\text {prototype }}$ can be derived in a straightforward fashion from the scaling rules for length and stress as it is defined as the product of the rigidity of the Earth, mean coseismic slip, and rupture area. Accordingly, typical analogue earthquake events with less than $1 \mathrm{Nm}$ scale up by more than 20 orders of magnitude up to $10^{22} \mathrm{Nm}$ in strike-slip experiments (Caniven et al., 2015) and $>10^{23} \mathrm{Nm}$ in subduction megathrust experiments (Rosenau et al., 2009; Fig. 5a).

As an example to illustrate this massive scaling, the energy of an analogue earthquake is about the energy needed to illuminate a $10 \mathrm{~W}$ electric light bulb for the duration of an analogue event that is similar to the blink of an eye (ca. $100 \mathrm{~ms}$ ). In contrast the energy of a $M_{\mathrm{w}}=9$ earthquake released over several minutes equals 100 years of the world's energy consumption (based on the year 2000).

As Eq. (10) is not a product of dimensional parameters but a sum of two dimensionless terms one of which includes a logarithm of a dimensional parameter, the standard method of applying scaling rules for the dimensions involved fails. Consequently, a scaling factor for moment magnitude does not exist. We can, however, scale up analogue earthquake moment magnitude non-linearly by applying the scale factor of seismic moment $M_{0} *$ and defining the following scaling rule:

$M_{\mathrm{W}}^{\text {prototype }}=M_{\mathrm{w}}^{\text {model }}-\frac{2}{3} \log M_{0}^{*}$.

Typically this results in magnitudes of analogue earthquakes in the range of -6 to -7 , which correspond to earthquakes of $M_{\mathrm{w}}=8-9$ (Fig. 5b).

\section{Analogue rock rheology}

This section reviews the history of analogue rock materials used in laboratory modelling of earthquakes and seismic cycles. They fall into three groups according to the dominant rheology: elastic, (frictional-)plastic, and viscoelastic. They are described in Sect. 4.1, 4.2 and 4.3. Moreover, the model materials are divided into soft and stiff materials in terms of everyday experience. Stiff materials (e.g. Plexiglas, 
Table 4. Mechanical properties of selected rock analogue materials under typical laboratory conditions (see text for discussion).

\begin{tabular}{|c|c|c|c|c|c|c|c|}
\hline Rheology & Material & Source & Rheological model & & Constitutive $\mathrm{p}$ & rameters & \\
\hline \multirow{6}{*}{ Elastic } & & & & $\begin{array}{r}E \\
(\mathrm{kPa}) \\
\end{array}$ & $v$ & $\begin{array}{r}V_{\mathbf{s}} \\
\left(\mathrm{m} \mathrm{s}^{-1}\right) \\
\end{array}$ & $\left(\mathrm{kg} \mathrm{m}^{-3}\right)$ \\
\hline & Homalite-100 & [1] & Linear elastic & $3860 \times 10^{3}$ & 0.35 & 1200 & 1230 \\
\hline & Polycarbonate & [1] & Linear elastic & $2480 \times 10^{3}$ & 0.38 & 960 & 1129 \\
\hline & Foam & [2] & Linear elastic & $10-100$ & $0.1-0.3$ & $10-100$ & 40 \\
\hline & Rubber (EPDM) & [3] & Linear elastic & $100-10.000$ & 0.5 & $1-100$ & 1600 \\
\hline & Gelatine $(<10 \%)$ & [4], [5] & Linear elastic & $1-10$ & $0.45-0.5$ & $0.5-2$ & $1000-1100$ \\
\hline \multirow{6}{*}{ Frictional-plastic } & & & & $\begin{array}{r}C \\
(\mathrm{~Pa})\end{array}$ & $\mu$ & $a-b$ & $\left(\mathrm{~kg} \mathrm{~m}^{-3}\right)$ \\
\hline & Rice & [6] & $\begin{array}{l}\text { High friction, } \\
\text { velocity weakening }\end{array}$ & $10-100$ & 0.7 & -0.015 & 900 \\
\hline & Sugar & [6] & $\begin{array}{l}\text { High friction, } \\
\text { velocity strengthening }\end{array}$ & $10-100$ & 0.7 & +0.015 & 900 \\
\hline & Foam (coated) & [2] & $\begin{array}{l}\text { High friction, } \\
\text { velocity weakening }\end{array}$ & Not specified & 0.65 & -0.017 & 40 \\
\hline & Gelatine on sandpaper & [7] & $\begin{array}{l}\text { Low friction, } \\
\text { velocity weakening }\end{array}$ & Not specified & 0.15 & -0.028 & 1000 \\
\hline & Gelatine on plastic & [7] & $\begin{array}{l}\text { Low friction, } \\
\text { velocity strengthening }\end{array}$ & Not specified & 0.05 & +0.027 & 1000 \\
\hline \multirow{7}{*}{ Viscoelastic } & & & & $\begin{array}{r}\eta \\
(\mathrm{kPa} \mathrm{s}) \\
\end{array}$ & $n$ & $\begin{array}{l}T_{\mathrm{m}} \\
(\mathrm{s})\end{array}$ & $\left(\mathrm{kg} \mathrm{m}^{-3}\right)^{\rho}$ \\
\hline & Silicone oil (PDMS) & [8] & Maxwell & 30 & $1-2$ & $0.1-0.2$ & 970 \\
\hline & Silicone-plasticine $(4: 1)$ & [9] & Maxwell & $6.000 \times 10^{3}$ & 2.8 & 30 & 1000 \\
\hline & Gelatine $(<10 \%)$ & [5], [10] & $\begin{array}{l}\text { Maxwell }(>3 \%) / \\
\text { bi-viscous }(<3 \%)\end{array}$ & $0.05-10$ & 5 & $0.1-1$ & $1000-1100$ \\
\hline & Natrosol HH & [11] & Burgers & $0.02-3$ & $1-2$ & $1-12$ & $1000-1010$ \\
\hline & Carbopol $^{\circledR}$ & {$[12]$} & Herschel-Buckley & $0.01-10$ & $1.6-3.4$ & 0.1 & $1000-1030$ \\
\hline & Kaolin (wet) & [13] & Burgers & $1-10 \times 10^{3}$ & Not specified & $100-1000$ & $1600-1700$ \\
\hline
\end{tabular}

wood) are used mainly in the fault block model category to model earthquakes under near-natural pressures (MPa) in rock mechanics deformation rigs, while for seismotectonic scale models the materials are generally soft or weak. This is because scaling laws dictate that the models deform in response to forces many orders of magnitude smaller than in nature. In particular, forces driving tectonic faults are in the order of teranewton per metre fault length, while in the lab only a few newton should be enough to deform the material. The latter is typically realized by using bulk solids (e.g. loose sand), foam rubber, or silicone oil. Most of the materials (e.g. gelatine) exhibit two or even all three rheologies under different conditions. Key material properties of the most commonly used rock analogues are summarized in Table 4.

\subsection{Elasticity}

\subsubsection{Hooke's Law, crack growth, and elastic dislocations}

Rocks at low temperature, pressures, and strains behave elastically, that is, they deform when a force is applied and return to their original shape when the force is released. In linear elastic solids, as in springs, elastic strain $\varepsilon_{i j}$ is generally linearly related to the applied stress $\sigma_{i j}$ in the same direction (Fig. 6):

$E=\frac{\mathrm{d} \sigma_{i j}}{\mathrm{~d} \varepsilon_{i j}}$,

which is a differential version of Hooke's Law. Moreover, elastic materials are conveniently treated as isotropic, that is, the mechanical property is independent of the direction and there are no preferred directions. Five elastic parameters exist, three of which have the dimension of stress (Young's modulus $E$, bulk modulus $B$, shear modulus $G$ ) and two are dimensionless (Lamé constant $\lambda$ and Poisson's ratio $v$ ). This set of parameters is dependent such that two need to be defined to derive the others. The moduli $E, K$, and $G$ describe the strain-stress relationship under different loading conditions (respectively, axial, volumetric, and shear). The elastic moduli of rocks are in the order of 10 to $100 \mathrm{GPa}$ (e.g. Turcotte and Schubert, 2002, Appendix 2, Sect. F). Poisson's ratio, which describes the relation between axial and transverse strain, varies between 0.1 and 0.4 for rocks (Turcotte and Schubert, 2002). 


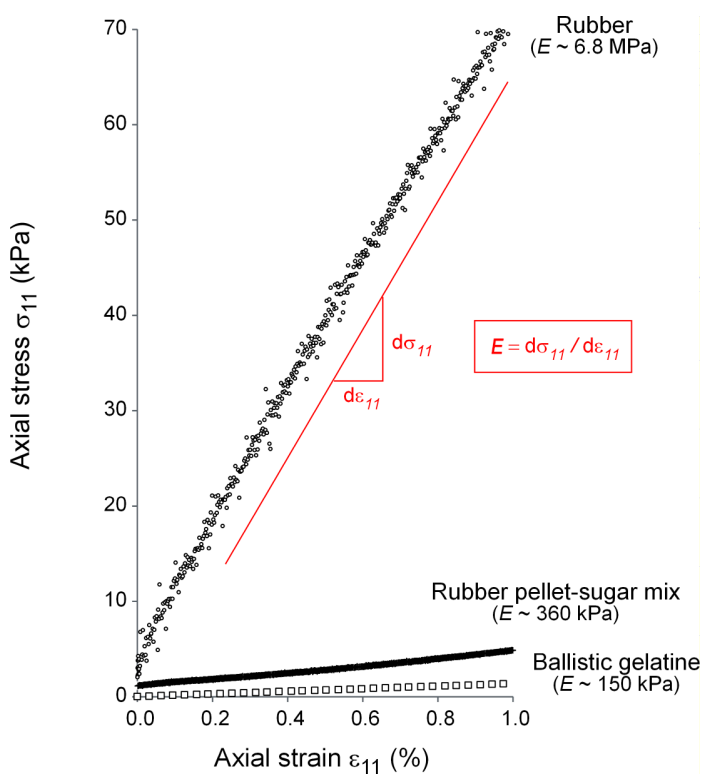

Figure 6. Elastic moduli of selected rock analogue materials as measured in an axial tester. Data and methodological details are published as open-access material in Rosenau et al. (2016).

Crack growth is intrinsically related to the elastic moduli. In the simplest case of a "penny-shaped" crack in which the slip is driven by a uniform stress drop $\Delta \sigma$, slip $S_{x}$ alongstrike of the fault ( $x$ coordinate) is given by Eq. (13):

$S_{x}(x)=\frac{24}{7 \pi} \frac{\Delta \sigma}{G} \sqrt{\frac{1}{4} L^{2}-x^{2}}$,

in which $L$ is the length of the crack (Eshelby, 1957; Scholz, 2002). For a uniform initial shear stress, slip on a pennyshaped crack shows the typical elliptical shape in which slip at a location is inversely proportional to the shear modulus (Fig. 7a). The rupture velocity of cracks is also typically considered to be limited by the shear wave velocity $V_{\mathrm{s}}$ that is given by Eq. (14):

$V_{\mathrm{s}}=\sqrt{G / \rho}$.

Therefore, the speed of the analogue earthquake process, which generally poses resolution limits on observations, is critically controlled by the stiffness of the rock analogue material used.

Elastic deformation in the solid surrounding the crack is usually described by elastic dislocation theory (e.g. Pollard and Segall, 1987). Since the Earth's surface is considered mechanically a free surface, i.e. no shear and normal stresses are transmitted across it (to the atmosphere), so-called "half-space" models are applied. Additionally, because the characteristic lengths of static and dynamic deformations (e.g. stress shadows, seismic waves) associated with earthquakes are usually regional scale, both small-scale topography and large-scale Earth curvature are often neglected and the surface is modelled as a plane. Analytical solutions to the problem of shear-crack-induced surface and internal deformations in homogenous elastic half-space are given by Okada $(1985,1992)$ and applied in numerous studies (e.g. King et al., 1994; Toda and Stein, 2002; Lin and Stein, 2004). A convenient MATLAB ${ }^{\circledR}$-based tool ("Coulomb") based on these solutions has been developed by the USGS (Toda et al., 2011).

Both crack growth as well as elastic dislocation predictions are superb benchmarks for seismotectonic scale models. Simplified versions of the surface deformation induced by vertical strike-slip dislocations in elastic half-space exist both for the case of inter-seismic and coseismic stages of the seismic cycle: inter-seismic surface velocities $V_{x}$ parallel to a strike-slip fault as a function of fault-perpendicular distance $y$ can be calculated using the following Eq. (15):

$V_{x}(y)=\frac{V_{0}}{\pi} \arctan \left(y / D_{\mathrm{L}}\right)$,

where $V_{0}$ is the far-field loading velocity, $D_{\mathrm{L}}$ is the locking depth (Savage and Burford, 1973). Similarly, Reid's coseismic rebound of the sidewalls of strike fault can be calculated using Eq. (16):

$U_{x}(y)=\frac{S_{x}}{\pi} \arctan \left(D_{\mathrm{S}} / y\right)$,

where $U_{x}$ is the fault-parallel surface displacement, $S_{x}$ is fault slip, and $D_{\mathrm{S}}$ the depth to which slip extends (Chinnery, 1961). Figure $7 b$ and $c$ show the predictions for inter- and coseismic surface deformation across a strike-slip fault, respectively. In the case where $D_{\mathrm{L}}$ equals $D_{\mathrm{S}}$, the sum of the interseismic deformation and the coseismic deformation produce a set function of the tectonic velocity.

\subsubsection{Elastic rock analogue materials}

While in spring-slider set-ups, mechanical springs or the effective stiffness of the testing machine controls the elasticity of the system, a variety of analogue rock materials have been used that can be classified as linear, isotropic, elastic solids up to few percent of strain, similar to the Earth on relevant scales. Elastic rock analogues are classified as relatively stiff (e.g. Plexiglas) and soft (gelatine, rubber, foam). Stiff materials are used exclusively in spring-slider and block models, while soft materials also find application in seismotectonic scale models for which scaling rules dictate their Young's moduli in the order of $1-1000 \mathrm{kPa}$.

Examples of stiff elastic materials are "homalite-100" and polycarbonate as used in the studies shown by Rosakis et al. (2007). These materials show enhanced photoelasticity compared to other transparent stiff materials like PMMA (polymethyl methacrylate). They are characterized by a Young's modulus value in the order of a few gigapascal, a Poisson's ratio value of ca. 0.35-0.4, and a shear wave speed of ca. $1000 \mathrm{~km} \mathrm{~s}^{-1}$ (Rosakis et al., 2007). 


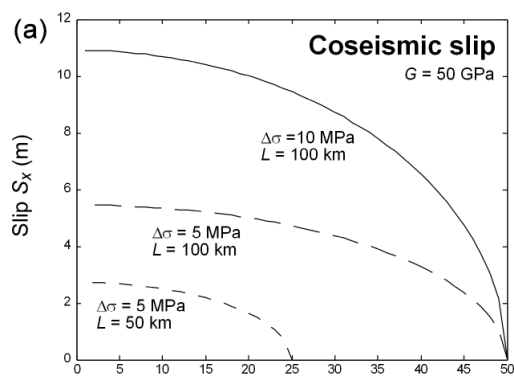

Distance from crack centre $x(\mathrm{~km})$

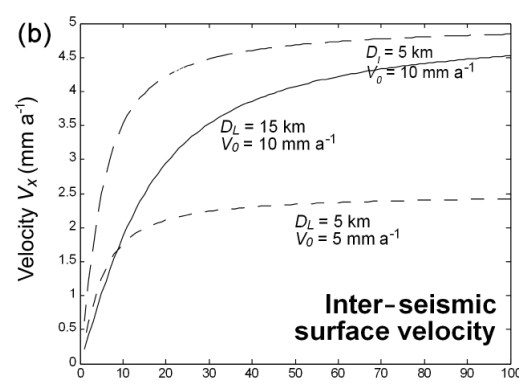

Distance from fault line $y(\mathrm{~km})$

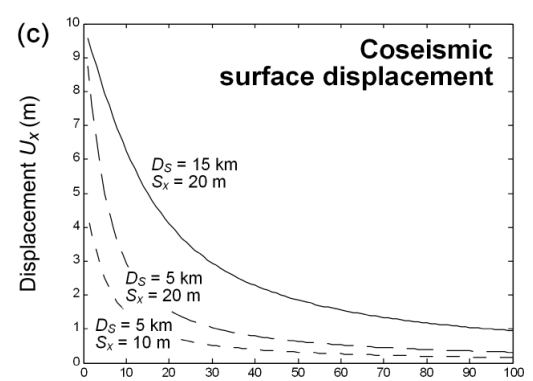

Distance from fault line $y(\mathrm{~km})$

Figure 7. Predictions from analytical elastic models: (a) coseismic slip $S_{x}(x)$ along a penny-shaped crack for different crack length $L$ (50 and $100 \mathrm{~km})$ and stress drop $\Delta \sigma(5$ and $10 \mathrm{MPa})$ according Eq. (13); (b) surface velocity $V_{x}(y)$ away from a locked fault represented by a deep dislocation simulating inter-seismic loading velocity $V_{0}\left(5\right.$ and $\left.10 \mathrm{~mm} \mathrm{a}^{-1}\right)$ of a fault locked to depth $D_{\mathrm{L}}(5$ and $15 \mathrm{~km})$ according Eq. (15); (c) surface displacement $U_{x}(y)$ away from a slipped fault simulated by a shallow dislocation with fault slip $S_{x}$ (10 and $\left.20 \mathrm{~m}\right)$ down to a depth $D_{\mathrm{S}}(5$ and $15 \mathrm{~km})$ according Eq. (16). Note that only one half of the mirror-symmetric solutions are shown.

Examples of soft elastic materials include gelatine. Gelatine is the common name for animal and plant viscoelastic biopolymers, which have been adopted for analogue modelling (see Di Giuseppe et al., 2009; Kavanagh et al., 2008, 2013; van Otterloo and Cruden, 2016, for a complete rheological characterization of a wide range of gelatines). The shear modulus of gelatine is controlled by its concentration. Low-concentration $(<10 \%)$ gelatine has a Young's modulus value of a few kilopascal, while high-concentration $(>10 \%$, "ballistic") gelatine has a Young's modulus value of a few hundred kilopascal (Fig. 6). Because it consists mainly of water, gelatine has a density of around $1000 \mathrm{~kg} \mathrm{~m}^{-3}$ and a Poisson's ratio value of $0.45-0.5$. The latter poses some limitations on the similarity of stress orientations in analogue models using gelatine, which are, however, not yet well constrained. Gelatine can more completely be described as viscoelastic and is therefore described with regard to the respective properties in Sect. 4.3.2.

Foam rubbers are a soft elastic solid which is used often, i.e. foam polymers (e.g. PU - polyurethane; PVC - polyvinyl chloride) that come in a variety of densities and elasticities. Those used in analogue modelling are usually light (e.g. density ca. $20-40 \mathrm{~kg} \mathrm{~m}^{-3}$; used by Anooshehpoor and Brune, 1999; Day et al., 2008; Caniven et al., 2015) and have a Young's modulus value ranging from 10 to $100 \mathrm{kPa}$. Poisson's ratios range between 0.1 and 0.3 (Brune, 1973; Caniven et al., 2015) and shear wave velocities are in the order of 10$100 \mathrm{~m} \mathrm{~s}^{-1}$. Attenuation properties of foam correspond to a low $Q$ of 10, similar to shallow crustal layers (e.g. Brune and Anooshehpoor, 1998). The damping cannot be controlled. This limits the use of foam in simulating seismic wave propagation to the near field. On the other hand, it minimizes undesired reflection from the model boundaries. The low density of foam poses additional limitations on its use in seismotectonic scale models as a realistic pressure gradient cannot be established. The presence of material non-linearities (both kinematic and constitutive) as well as the high friction coef- ficient of foam rubber interfaces has raised some concerns about the scalability of these models (Rosakis, 2007). One of these limitations, i.e. the high friction coefficient, has been overcome by Caniven et al. (2015) by coating the foam rubber with epoxy resin.

Rubber (e.g. EPDM - ethylene propylene diene monomer) has been used both as a solid (Schallamach, 1971; Hamilton and McCloskey, 1997, 1998) as well as in the form of pellets (Rosenau et al., 2009, 2010; Rosenau and Oncken, 2009). It comes in wide range of densities and elasticities. Rubber is characterized by a Young's modulus value of several megapascal (Fig. 6) and a Poisson's ratio value of 0.5. The bulk of EPDM pellets shows a much reduced Young's modulus in the order of $0.1 \mathrm{MPa}$. They can be mixed with more rigid particles (e.g. sugar grains) to reach the desired elasticity (Rosenau et al., 2009). The density of rubber ranges between 900 and $>2000 \mathrm{~kg} \mathrm{~m}^{-3}$.

\subsection{Frictional plasticity}

\subsubsection{Mohr-Coulomb plasticity, Byerlee's Law, and frictional instability}

Once the forces acting on a rock sample exceed a certain threshold or yield strength, brittle failure (of intact rock) or frictional sliding (of faulted rock) will occur at low confining pressure and temperature, while ductile flow may occur at higher temperature and pressure (Sect. 4.3.1). Both deformation mechanisms cause permanent (irreversible) deformation.

Brittle rock deformation as it occurs at shallow to intermediate crustal levels is characterized by a cohesion- and pressure-dependent frictional strength (Mohr-Coulomb type behaviour). The latter is, in its simplest case, described by a linear relation between applied normal load $\sigma_{\mathrm{n}}$ and shear strength $\tau$ in a Mohr diagram, the slope of which is the friction coefficient $\mu$ and the $y$-axis intercept is the cohesion $C$ 

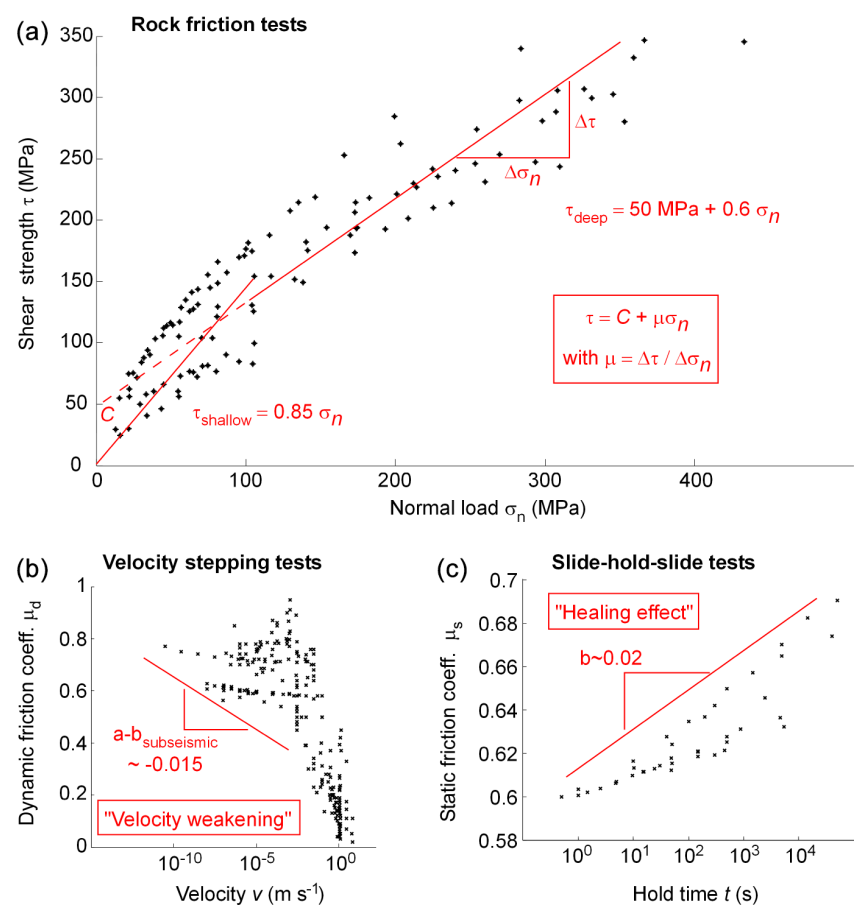

Figure 8. Rock friction data: (a) data from rock friction tests in a Mohr-Coulomb plot showing the pressure dependence of frictional strength ("Byerlee's law", data as compiled by Ritter et al., 2016, and references therein). The slope corresponds to the friction coefficient, the $y$-axis intercept to the cohesion of the rock and rock interfaces. (b) Data from velocity stepping tests (as compiled by Marone, 1998; Spagnulo et al., 2016, and references therein) indicating the velocity-weakening behaviour of rock interfaces. The slope is proportional to the parameter $(a-b)$ in the RSF friction law. (c) Data from slide-hold-slide test (data as compiled by Marone, 1998, and references therein) demonstrating healing of rock interfaces. The slope is proportional to the parameter $b$ in the RSF law. Data plotted here are published as open-access material in Rosenau et al. (2016).

(Fig. 8a):

$\tau=C+\frac{\Delta \tau}{\Delta \sigma_{\mathrm{n}}} \sigma_{\mathrm{n}}$.

While the Mohr-Coulomb criterion originally describes frictional faulting of an intact rock, the same graphical method can be applied to describe frictional sliding on pre-existing faults and retrieve the respective set of parameters (Byerlee's Law). Accordingly, fault rocks at very shallow crustal levels $\left(\sigma_{\mathrm{n}}<100 \mathrm{MPa}\right)$ have virtually no cohesion and a relatively high friction coefficient of 0.85 , while at deeper levels rock appears cohesive $(C \sim 50 \mathrm{MPa})$ and has a friction coefficient of ca. 0.6 (Byerlee, 1978).

In the context of analogue earthquakes, slip stability on pre-existing faults is key. Whether slip is stable or unstable depends on three parameters: the stiffness of the system, the dynamic weakening of the frictional interface (either proportional to slip or velocity) and the applied normal load. Only if the system is soft enough to allow the frictional strength to fall faster than the system can respond, will the force imbalance cause slip instability to occur. This is described by the condition for slip instability following Eq. (18):

$\frac{\left(\mu_{\mathrm{s}}-\mu_{\mathrm{d}}\right) \sigma_{n}}{D_{\mathrm{c}}}>K$

(Scholz, 2002), where $\mu_{\mathrm{s}}$ and $\mu_{\mathrm{d}}$ are static and dynamic friction coefficients, $D_{\mathrm{c}}$ is the characteristic distance over which friction decreases (slip weakening), $\sigma_{\mathrm{n}}$ is the normal load, and $K$ is system stiffness. Accordingly, a stiff system tends to slip stably, while any weakening over short distances and high loads assists instability.

Frictional instability is described nowadays either in terms of static and dynamic friction or in terms of the rate- and state-dependent friction (RSF) theory (Dieterich, 1972b, 1978b; Ruina, 1983; summarized in, e.g., Scholz, 1998, 2002). RSF constitutive laws consider time- and slipdependent re-strengthening and variations in friction with slip rate and can reproduce the entire suite of slip phenomena.

RSF theory states that a change in slip velocity from $V$ to $V^{\prime}$ causes a change in the dynamic friction according to Eq. (19):

$\Delta \mu_{\mathrm{d}}=(a-b) \ln \left(V^{\prime} / V\right)$

(e.g. Scholz, 2002). If $a-b$ is negative, the behaviour is said to be velocity weakening, which is a prerequisite for frictional instability. If $a-b$ is positive, the frictional interface is said to be velocity strengthening and slips stably. The parameters $a$ and $b$ can be independently derived from velocity stepping tests and slide-hold-slide test, respectively. In velocity stepping tests slip velocity is changed systematically and the frictional response is measured (Fig. 8b). The data are then evaluated using the Eq. (20):

$\frac{\Delta \mu_{\mathrm{d}}}{\Delta \log (V)}=(a-b) \ln (10)$

(Marone, 1998), which is the slope of the regression to data in Fig. 8b. Its value is in the order of a few percent only up to sub-seismic sliding velocities of centimetres per second (shallower slope in Fig. 8b). At seismic speeds it may increase dramatically due to dynamic effects like thermal pressurization or flash melting (Spagnuolo et al., 2016, and references therein).

In slide-hold-slide tests, deformation is halted for various periods (allowing the sample to heal) and then restarted. The static friction during reactivation, i.e. the peak friction to overcome when restarting, is measured and scales in the presence of healing with the length of the preceding hold period $T_{\text {hold }}$ (Fig. 8c). The data are then evaluated using the following Eq. (21):

$$
\frac{\Delta \mu_{\mathrm{s}}}{\Delta \log }=b \ln (10)
$$


(Marone, 1998), which is the slope of the regression to data in Fig. 8c. By replacing $\mu_{\mathrm{s}}-\mu_{\mathrm{d}}$ in Eq. (18) with $a-b$, Eq. (18) can be rewritten in terms of RSF for a velocity-weakening frictional material to Eq. (22):

$$
\frac{-(a-b) \sigma_{\mathrm{n}}}{D_{\mathrm{c}}}>K
$$

(e.g. Scholz, 1998; Marone, 1998). Equations (18) and (22) can be considered slip-weakening and velocity-weakening formulations of the instability criterion.

This allows us to define three stability regimes: the stable regime, in which $a-b$ is positive (velocity strengthening) and slip always aseismic; the unstable regime, in which $a-$ $b$ is negative (velocity weakening) and slip always seismic; and the conditionally stable regime, in which $a-b$ is negative but Eq. (22) is not fulfilled either because the system is too stiff or the normal load too low such that slip is stable unless triggered by a velocity jump. Consequently, earthquakes can nucleate only in the unstable regime but can propagate into the conditionally stable regime and will stop in the stable regime. All three regimes have been realized in analogue models.

\subsubsection{Frictional-plastic rock analogue materials}

A large variety of materials (both solids and bulk materials) show the characteristic rate- and state-dependent frictional response to velocity steps and variable hold times in the respective tests (e.g. Dieterich and Kilgore, 1994; Schulze, 2003). Most granular material like quartz sand or glass beads has similar friction coefficients to rocks $(\mu \sim 0.4-0.6)$ and a properly scaled cohesion in the order of a few tens to hundreds of pascal (e.g. Krantz, 1991; Lohrmann et al., 2003; Panien et al., 2006; Klinkmüller et al., 2016; Ritter et al., 2016; Abdelmalak et al., 2016).

In contrast to sand, which shows no measurable velocitydependence of friction (Fig. 9a), many granular materials of organic origin show rate- and state-dependent friction: rice, salt, starch flour, and polenta for example show velocity weakening, while sugar shows velocity strengthening (Fig. 9a). Schulze (2003) demonstrated velocityweakening behaviour for limestone powder and wheat flour and velocity-strengthening behaviour for PE (polyethylene) powder. Healing (i.e. strengthening in static contact) of frictional interfaces is also minor in sand but evident for several materials including wheat flower, cocoa (Fig. 9b), PE powder, and limestone powder (e.g. Schulze, 2003).

Gelatine and foam rubber both show stick-slip behaviour along precut surfaces controlled by rate- and state-dependent friction. Foam on foam contacts show unrealistically high friction coefficients ( $\mu>1$; Brune and Anooshehpoor, 1997). However, coated foams show values similar to rock $(\mu=0.6)$ and velocity-weakening behaviour (Caniven et al., 2015). Gelatine (pig skin $2.5 \%$ ) shows velocity weakening in contact with sandpaper but velocity strengthening when in con- tact with a plastic sheet (Corbi et al., 2013). In both cases the gelatine contact shows a small friction coefficient $(\mu \sim 0.1)$ similar to rock interfaces at high fluid pressures.

The slip-weakening distance $D_{\mathrm{c}}$ is strongly scale dependent: it is in the order of decimetres to metres for natural earthquake slip events and millimetres in rock mechanics experiments (e.g. Hirose and Shimamoto, 2005, and references therein). In studies using rock analogue materials, $D_{\mathrm{c}}$ scales down to micrometres, consistent with typical length scales derived from applying Eq. (4) (e.g. Mair and Marone, 1999; Rosenau et al., 2009).

The $a-b$ values of rock analogue materials are in the order of a few percent per decade change in slip velocity (e.g. Mair and Marone, 1999; Rosenau et al., 2009; and Fig. 9a), similar to rock (e.g. Scholz, 1998; Dieterich, 2007). As a consequence of velocity weakening, stick-slip occurs in analogue rock materials. Figure 10 shows regular stick-slip behaviour as exemplified by various granular rock analogue materials in a Schulze ring-shear tester (Schulze, 1994). This apparatus allows us to simulate faulting in granular materials at loads and velocities typical of analogue models (Klinkmüller et al., 2016; Ritter et al., 2016; Panien et al., 2006; Lohrmann et al., 2003). For analogue rock materials exhibiting unstable slip behaviour under laboratory conditions (i.e. at normal loads of up to few tens of kilopascal), stick-slip events are typically characterized by partial (10-30\%) stress drops of a few kilopascal that increase consistently in size and recurrence period with loading rate.

\subsection{Viscoelasticity}

\subsubsection{Newtonian vs. non-Newtonian and viscoelastic models}

Rocks at higher temperature and pressure deform in a ductile manner, that is elasto(frictional)plasticity is replaced by viscoelasticity. Depending on the timescale of the applied forces and strain rate, the deformation is dominantly elastic (on short timescales, e.g. coseismic) or viscous (on long timescales, e.g. inter-seismic).

On long timescales viscoelastic materials show a strainrate-dependent strength. In this case stress in the deforming material is a function of strain rate, i.e. $\sigma_{i j}\left(\mathrm{~d} \varepsilon_{i j} / \mathrm{d} t\right)$, with the indices $i j$ indicating the component of the stress or strain tensor. The ratio between the stress and strain rate for a given tensor component is defined as the viscosity $\eta$ (unit $\mathrm{Pa} \mathrm{s}$ ):

$\eta=\sigma_{i j} /\left(\mathrm{d} \varepsilon_{i j} / \mathrm{d} t\right)$.

$\eta$ is generally assumed to be isotropic. If the relation is strictly linear, the material is said to be Newtonian. If it is non-linear, the material is said to be non-Newtonian (either strain-rate thickening or thinning). With respect to ductile rock deformation, Newtonian and shear-rate thinning behaviour is relevant: at low strain rates and high temperatures the dominant crystal plastic deformation mechanism is diffu- 
(a)

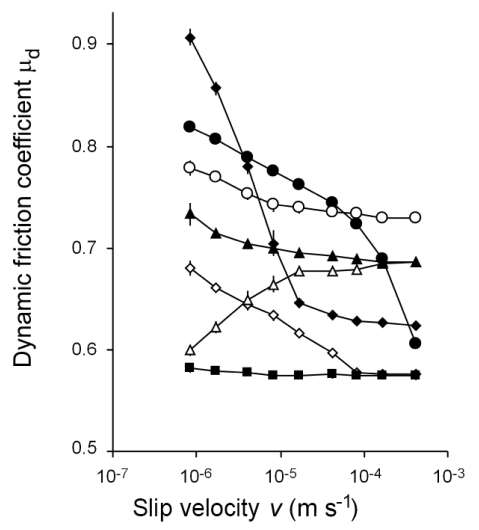

(b)

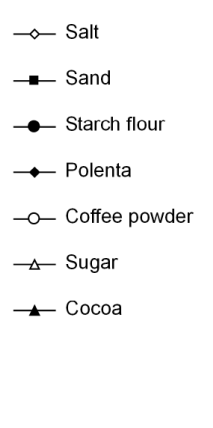

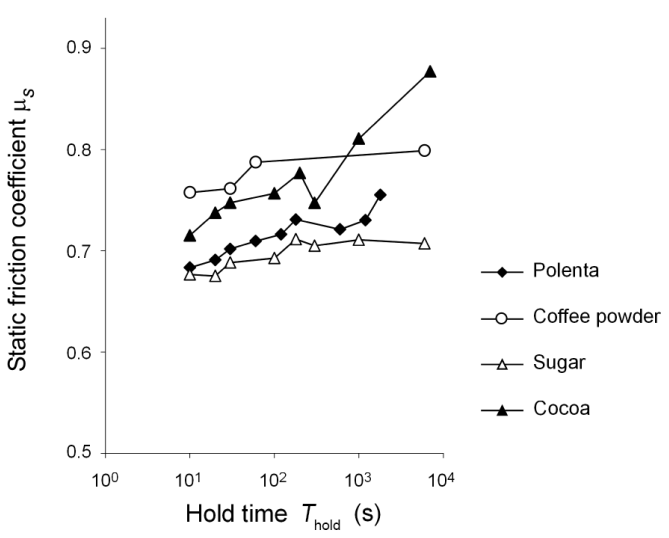

Figure 9. Rate and state effects on friction of selected analogue rock materials: (a) rate effect ( $v$ strengthening versus $v$ weakening) from velocity stepping tests, (b) state effect (healing) from slide-hold-slide tests. Results from tests using a Schulze ring-shear tester RST-01 (Schulze, 1994; Fig. 2b). Data and methodological details are published as open-access material in Rosenau et al. (2016).

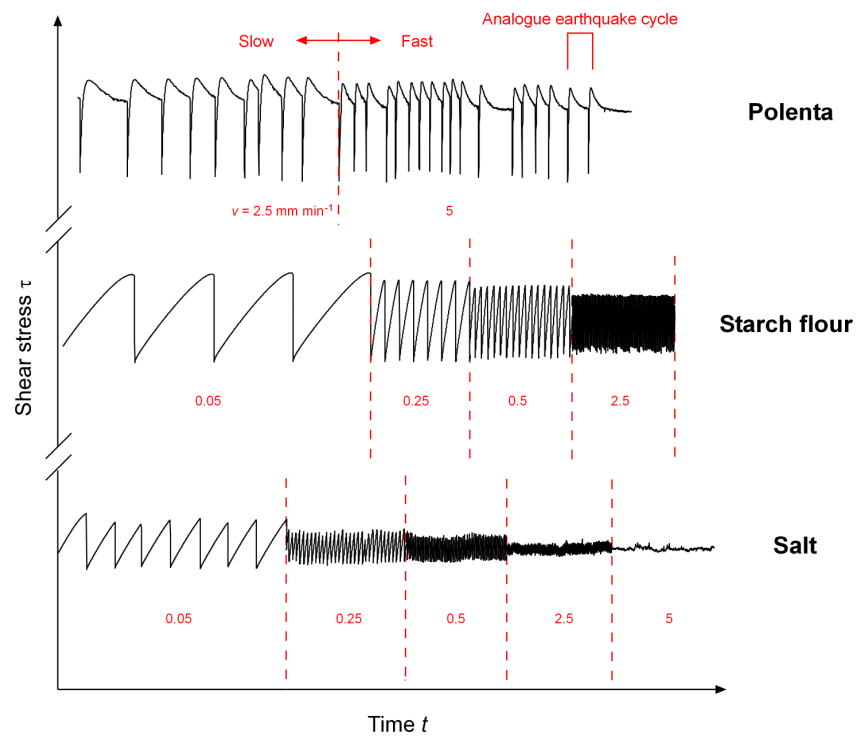

Figure 10. Systematics of stick-slip in selected analogue rock materials. Results from ring-shear tests using a Schulze ring-shear tester (Schulze, 1994; Fig. 2b). Data and methodological details are published as open-access material in Rosenau et al. (2016).

sion creep (Newtonian), while at higher strain rates and/or lower temperatures dislocation creep (non-Newtonian) occurs (e.g. Bürgmann and Dresen, 2008). The latter is usually described by a power law constitutive law where the power law (or stress) exponent $n$ describes the decrease in viscosity with strain rate (Pollard and Fletcher, 2005). Typical values for $n$ in the Earth are 3-4. Such a pronounced shear-rate thinning behaviour is believed to control strain localization in the ductile regime. High strain rates are typically reached in coto post-seismic phases where shear rate thinning then overlaps with elastic effects. (a)
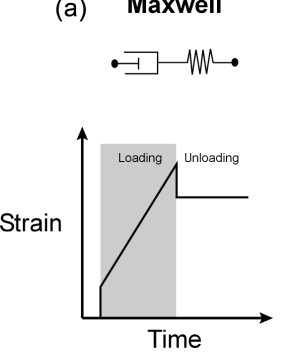

(b)
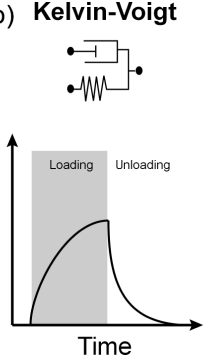

(c) Burgers
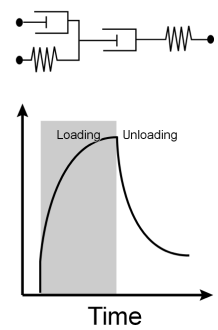

Figure 11. Rheological models represented as spring and dashpots under loading and unloading with their relative strain-time curve: (a) Maxwell model; (b) Kelvin-Voigt model; (c) Burgers model. See text for discussion.

On short timescales viscoelastic materials show a delayed, time-dependent, response when stress is applied and/or removed. The classic example is that of a sample where deformation is recoverable but strain accumulation and release are delayed due to the coexistence of both elastic and viscous behaviour. The rheological behaviour of viscoelastic material is therefore commonly described using the analogy to physical models of a spring (responsible for the elastic behaviour) and a dashpot (responsible for the viscous behaviour).

The simplest rheological models describing viscoelastic behaviour are obtained from a combination of spring and dashpot elements in parallel (Kelvin-Voigt model) or in serial configuration (Maxwell model). A way to distinguish between the two rheological models is by performing a series of low-stress creep-recovery tests with a rheometer. The test consists of applying a constant shear stress to the sample for a given time interval. The instrument records the strain in the loading phase and in the following recovery phase. Different shapes of the strain-time curve are then observable depending on the rheological model of the sample (Fig. 10). 
The deformation of a sample that follows the Maxwell model shows an instantaneous elastic response followed by linearly viscous flow. When the load is removed the elastic component is recovered instantaneously, while a fraction of the deformation linked to the dashpot is not recoverable (Fig. 10a). The constitutive equation for the Maxwell model can be expressed as follows:

$$
\frac{\mathrm{d} \varepsilon_{i j}}{\mathrm{~d} t}=\frac{\sigma_{i j}}{\eta}+\frac{1}{E} \frac{\mathrm{d} \sigma_{i j}}{\mathrm{~d} t}
$$

where $\varepsilon_{i j}$ is a strain tensor component, $\sigma_{i j}$ is the corresponding stress tensor component, $\eta$ is the viscosity of the material, $E$ is the shear modulus of the material, and $t$ is time.

The deformation of a sample that follows the Kelvin-Voigt model is slowed down by the piston component both in the loading phase and when the load is removed (Fig. 10b). Such a slow-down effect is highlighted by the curved path of strain as a function of time in both the loading and in the recovery phases. Sample deformation is fully recoverable when the load is removed. The constitutive equation for the KelvinVoigt model is expressed as follows:

$\sigma_{i j}=E \varepsilon_{i j}+\eta \frac{\mathrm{d} \varepsilon_{i j}}{\mathrm{~d} t}$.

In Earth science the Maxwell model is considered the more relevant compared to the Kelvin-Voigt model. In the case of an earthquake stress drop (which can be viewed as a largescale creep test), this is because the Earth shows the instantaneous coseismic and transient post-seismic deformation characteristic of a slowly relaxing Maxwell body. A KelvinVoigt body would show no instantaneous elastic response to sudden loading but a transient response.

A Maxwell body possesses a relaxation time $T_{\mathrm{m}}$, defined as the time required for the viscous strain to become equal to the elastic strain. $T_{\mathrm{m}}$ is given by the ratio of viscosity $\eta$ and the shear modulus $G$ :

$T_{\mathrm{m}}=\eta / G$.

This allows us to differentiate between relatively short timescales dominated by elasticity and relatively long timescales dominated by viscosity. Applied to the Earth, taking as typical values $\eta \sim 10^{19}-10^{20} \mathrm{~Pa}$ s and $G \sim 10$ $100 \mathrm{GPa}$ one obtains $T_{\mathrm{m}} \sim 3-300$ years.

A more elaborate viscoelastic rheology is the Burgers model, which shows a mixture of the responses of the Kelvin-Voigt and Maxwell models (Fig. 10c). In particular, it features the instantaneous elastic response as well as the transient creep of the Kelvin-Voigt model. It has recently found application in earthquake studies because it allows us to fit time series of post-seismic deformation with a single set of parameters. Thanks to the increasing number of geodetic studies of convergent margins, it has been pointed out that Earth's mantle response after large earthquakes is characterized by two timescales: a shorter one for the transient viscos- ity and a longer one for the steady-state viscosity (e.g. Wang et al., 2012, and references therein).

\subsubsection{Viscoelastic rock analogue materials}

Most viscous materials used in analogue modelling of seismotectonic processes (silicones, honey, etc.) can be described by the Maxwell model at least under certain conditions. The proper rheological model as well as the constitutive parameters like viscosity, elasticity, and the Maxwell relaxation time are inferred from a series of oscillatory and rotational tests in a rheometer (e.g. Rudolf et al., 2016a; Di Giuseppe et al., 2009; ten Grotenhuis et al., 2002; Boutelier et al., 2008, 2016; van Otterloo and Cruden, 2016).

Polydimethylsiloxane (PDMS), mostly referred to as silicone or silicone oil, is one of the most common viscoelastic materials used in analogue modelling. The rheology of PDMS can be described by a Maxwell model including linear Newtonian viscosity of about $10^{4} \mathrm{~Pa}$ s at low strain rates $\left(<10^{-2} \mathrm{~s}^{-1}\right)$, shear rate thinning (stress exponent $\left.n=1-2\right)$ above, and a Maxwell relaxation time $T_{\mathrm{m}}$ of $0.1-0.2 \mathrm{~s}$ (e.g. Rudolf et al., 2016a). The power law exponent can be raised from 1 to $\sim 3$ by using mixtures of high-viscosity silicone and plasticine (Boutelier et al., 2008). Considering the scaling laws for viscosity and timescales above, $T_{\mathrm{m}}$ of silicone scales to tens to hundreds of years in nature. These are typical relaxation times in nature, and silicone is therefore a suitable material to simulate seismic cycles, especially the postseismic phase (e.g. Caniven et al., 2015).

Hydrogels or suspensions, made of aqueous solutions of polymers used for the thickening and stabilization of viscous fluids in the cosmetic and food industry, have found widespread applications in analogue modelling. Gelatine has been used in analogue earthquake models, both in fault block models (Corbi et al., 2011) and seismotectonic scale models (Corbi et al., 2013). Gelatine rheology varies as a function of composition, concentration, temperature, and ageing. At concentrations $>3 \%$ the viscoelastic behaviour of gelatine can be described by a Maxwell model $\left(T_{\mathrm{m}}=0.1-1 \mathrm{~s}\right)$, while for $<3 \%$ concentrations the rheology of gelatine can be described by a bi-viscous model combining a Kelvin-Voigt element in series with a second viscous element (van Otterloo and Cruden, 2016). The rheological properties of gelatine can be modified by adding electrolytes, phosphate, and non-electrolytes. In particular, the addition of $\mathrm{NaCl}$ has been shown to weaken the gelatine structure (Brizzi et al., 2016).

Hydrogels made of Natrosol, a cellulose polymer, similarly show a Burgers rheology and Maxwell relaxation times in the order of seconds (Boutelier et al., 2016). Another polymeric viscoelastic material that has found application in analogue modelling of earthquakes by means of deformable slider-spring models is $\mathrm{Carbopol}^{\circledR}{ }^{\circledR}$ (Reber et al., 2015). As with gelatine, Carbopol ${ }^{\circledR}$ rheology depends on its concentration but also additionally on $\mathrm{pH}$. It is very shear thinning and has a yield strength of up to a few hundred pascal (Di 
Giuseppe et al., 2015). It is consequently rheologically modelled as a Herschel-Buckley fluid. It can more generally be described as a brittle-ductile material. The Maxwell relaxation time of $\mathrm{Carbopol}^{\circledR}$ is in the order of $0.1 \mathrm{~s}$.

While hydrogels have complex rheologies with a high potential in analogue modelling, care must be taken during preparation and experimenting. This is because they are generally very sensitive to temperature and concentration and thus require careful handling, following strict protocols, and rigorous characterization of the individual rheology. Also, storage is usually limited due to a pronounced sample aging.

Wet kaolin has recently been recovered as a suitable analogue material with some potential in modelling short and long-term deformation. It shows the more complex Burgers rheology controlled by the water content (Cooke and van der Elst, 2012). With viscosities in the range of $10^{6}-10^{7} \mathrm{~Pa}$ and elasticities in the order of $10 \mathrm{kPa}$, relaxation times are rather long (up to $15 \mathrm{~min}$ ) compared to the previously discussed materials limiting the applicability in seismotectonic scale models of seismic cycles.

\section{Analogue earthquake monitoring techniques}

Advances in analogue rock material characterization have been paralleled by the development of new monitoring techniques allowing high-resolution quantitative measurements of the deformation of analogue models. Monitoring techniques as applied in analogue earthquake models can be grouped into local (at a point in space), regional (mapping an area), and global (integrating over an area or volume) techniques. They are described in Sect. 5.1, 5.2, and 5.3. They differ in their temporal and spatial resolution as well as the coverage. They may further be differentiated into direct and indirect observation methods. The main monitoring techniques used in analogue earthquake modelling are summarized in Table 5.

Local monitoring techniques (Sect. 5.1) provide time series of point measurements and include quasi-seismological and quasi-geodetic techniques. They use accelerometers, acoustic sensors, strain gauges, or laser interferometry, which provide temporally high-resolution time series of displacement at a single location. Most of these techniques can be considered indirect as they do not observe the process directly but inversion techniques are required to describe the analogue earthquake source. In contrast, regional techniques (Sect. 5.2) map surface deformation and are therefore also called "full-field" techniques. They include photoelastic and digital image correlation techniques and allow high coverage and full-field, stress, and strain monitoring of the model surface and fault at high spatial but generally lower temporal resolution compared to local and global monitoring techniques. Global methods (see Sect. 5.3) are those providing a kinematic or dynamic measurement of an average value integrated across a surface area or volume, e.g. the motion of one side of a sample or the loading stress. Those measurements are necessarily indirect but can usually be inverted easily using geometric tools to a direct measure of interest (e.g. fault slip, stress drop).

\subsection{Local monitoring techniques}

Johnson et al. (1973), Wu et al. (1972), and Hamilton and McCloskey (1998) used an array of strain gauges to monitor model motion at up to a few hundred hertz. Brune et al. (1990) in his foam block models used an instrumentation of digital velocity transducers and accelerometers as well as microphones embedded in the foam block and along its surface. Absolute stress and stress drop have been measured using an in-line hydraulic pressure gauge (Brune et al., 1990). All embedded sensors were designed with a low mass and high dynamic range to allow measuring acceleration up to hundreds of $g$ as expected in the foam models. Brune and Anooshehpoor $(1998,1999)$ used ultralight accelerometers with a dynamic range of $\pm 1000 \mathrm{~g}$ and a flat response between $1 \mathrm{~Hz}$ and $20 \mathrm{kHz}$. To additionally reduce mass loading effects, they mounted the accelerometers on Styrofoam disks.

Optical techniques exploiting brightness changes between successive images of a target have also been developed since the beginning of analogue earthquake modelling. Deformation along the analogue fault in foam was detected by Brune et al. (1973) using a photocell focussing on a blackand-white target along the analogue fault line. Hartzell and Archuleta (1979) developed a new optical monitoring technique using a light-sensitive field effect transistor and an analogue-to-digital recorder to measure particle motions in the near and far field of an analogue fault embedded in a foam block. Brune and Anooshehpoor $(1998,1999)$ experimented with a telescopic, two-axis position-sensing detector that was focused on a small light-emitting diode (LED) embedded in the foam. They report a resolution of $0.1 \mathrm{~mm}$.

Nowadays, digital displacement and force sensors as well as accelerometers in the form of ultralight microelectromechanical systems (MEMSs) are available. Sampling rates are typically kilohertz to megahertz. For example, Dieterich (1978a) and Ohnaka and Kuwahara (1990) used semiconductor strain gauges to monitor analogue earthquakes in granite in a block model set-up. Pressure gauges have been used by Niewland et al. (2000) to measure stress in situ in analogue models potentially useful for analogue earthquake models in future. Arrays of accelerometers have been used, e.g. by Day et al. (2008), to infer rupture dynamics in foam block models.

Acoustic sensors have been widely applied to study analogue earthquakes: Johnson et al. (1973), Wu et al. (1972), and Okubo and Dieterich (1984) used piezoelectric transducers to estimate slip rate and rupture speed in stick-slip experiments on precut rock and rock analogue materials. Lockner et al. (1991), Zang et al. (2000), and Thompson et al. (2005, 
Table 5. Monitoring techniques used in analogue earthquake models (see text for discussion).

\begin{tabular}{|c|c|c|c|c|c|c|}
\hline Category & Technique & Observables & Indirect observable & Precision & $\begin{array}{l}\text { Spatial } \\
\text { resolution }\end{array}$ & $\begin{array}{l}\text { Temporal } \\
\text { resolution }\end{array}$ \\
\hline \multirow{8}{*}{ Local } & Strain gauge & Strain & Rupture kinematics & Medium & Low & $100 \mathrm{~Hz}$ \\
\hline & Velocity transducer & Velocity & Rupture kinematics & High & Low & $\mathrm{kHz}$ \\
\hline & Accelerometer & Acceleration & Rupture kinematics & High & Low & $\mathrm{kHz}$ \\
\hline & Microphone & Acceleration & Rupture kinematics & Medium & Low & $\mathrm{kHz}$ \\
\hline & Pressure gauge & Pressure & Absolute stress, stress drop & Medium & Low & $\mathrm{kHz}$ \\
\hline & Photocell & Velocity & Rupture kinematics & Medium & Low & $\mathrm{kHz}$ \\
\hline & Acoustic emission & Acceleration & Rupture kinematics & High & Low & $10^{2} \mathrm{kHz}$ \\
\hline & Laser velocimetry & Velocity & Rupture kinematics & High & Low & $10^{9} \mathrm{kHz}$ \\
\hline \multirow[t]{2}{*}{ Regional } & Photoelasticity & Stress & Strain, rupture kinematics & Medium & Ca. $100 \mathrm{px}^{2}$ & $\mathrm{kHz}$ \\
\hline & Digital image correlation & Velocity, strain rate & Stress & $10^{-3} \mathrm{px}$ & Ca. $10 \mathrm{px}^{2}$ & $\mathrm{kHz}$ \\
\hline \multirow[t]{3}{*}{ Global } & Strip chart recorder & Displacement & Fault slip & Low & Low & Continuous \\
\hline & Odometer & Displacement & Fault slip & Micrometre & Low & $\mathrm{kHz}$ \\
\hline & Force sensor & Force, stress & Absolute stress, stress drop & $\mathrm{mN}$ & Low & $10^{2} \mathrm{kHz}$ \\
\hline
\end{tabular}

2006, 2009) used acoustic emissions to monitor localization, precursory phenomena, and stick-slip ruptures in rock specimens. Varamashvili et al. (2008) and Zigone et al. (2011) used acoustic emission to characterize the stick-slip process in a spring-slider and salt-slider set-up (Fig. 2d), respectively. Zang et al. (1998), Kwiatek et al. (2014), and Stierle et al. (2016) used acoustic emissions to further constrain the source of laboratory earthquakes in loaded rock specimen by means of the seismic moment tensor and $b$ value. Acoustic sensors usually have high sampling rates $(\mathrm{kHz})$ and work for accelerations up to several $g$. A thorough review of the large body of literature on acoustic emission as a seismological tool in laboratory earthquake studies is given by Lei and Ma (2014).

Most recently, laser velocimetry based on interferometric techniques has been used to obtain displacement time series at selected points on the surface of the specimen (e.g. Lykotrafitis et al., 2006; Rubino et al., 2015; Caniven et al., 2015). The instruments record a specific component of the velocity field at up to $10 \mathrm{~m} \mathrm{~s}^{-1}$ at a picosecond temporal resolution. Usually, a set of instruments is distributed across the surface of interest.

\subsection{Regional monitoring techniques}

\subsubsection{Photoelasticity}

In many earthquake studies using fault block models (Rubio and Galeano, 1994; Rosakis et al., 1999; Xia et al., 2004; Lu et al., 2009, 2010; Mello et al., 2010; Schubnel et al., 2011, Nielsen et al., 2010; De Joussineau et al., 2001, Bouissou et al., 1998), photoelasticity combined with high speed photography is used to monitor the transient deformation and stresses associated with earthquake-like slip events (Fig. 3d and f). Based on the photoelastic effect, Daniels and Hayman (2008) visualized the dynamics of force chains in sheared granular media undergoing stick-slip (Fig. $2 \mathrm{~g}$ ).

Photoelasticity provides not only a visualization of smallscale deformation but a direct and quantitative measurement of stress in suitable materials (e.g. Jessop and Harris, 1960). Photoelasticity is physically based on the fact that, when polarized light passes through a stressed birefringent material, the light separates into two wave fronts travelling at different velocities. Each wave front is oriented parallel to a direction of principal stress in the material, i.e. perpendicular to each other. Different values of the refraction index are assigned to two components that are out of phase when leaving the birefringent material. This difference in optical path can be measured by interferometry and visualized using a second polarizer. The resulting fringe patterns correspond to isocontours of maximum shear stress. This assembly forms the base of the so-called "polariscope".

In analogue earthquake studies, light sources like laser beams or floodlights are used to illuminate the transparent model made, e.g., of homalite, polycarbonate or gelatine. A pair of linear or circular polarizers, one in front and one behind the model, forms the basis of the experimental polariscope assembly. Usually, the light path and therefore the viewing perspective is parallel to the fault plane and normal to the rupture direction.

Photoelasticity is able to monitor the distribution of maximum shear stress in the model at full coverage and high resolution. However, the absolute values of the principal stress components remain unknown. The temporal resolution is only limited by the sampling rate of the employed digital cameras, which is generally flexible and can be adapted to the expected rupture velocity. In particular, while rupture monitoring in rigid materials requires high-speed cameras (kHz imaging), commercial video cameras with $25 \mathrm{~Hz}$ imaging are sufficient in soft gelatine model approaches as the 
Table 6. Symbols and their meaning as used in this article.

\begin{tabular}{|c|c|c|}
\hline Symbol & Definition & Unit \\
\hline$l$ & (Characteristic) length & $\mathrm{m}$ \\
\hline$D_{\mathrm{S}}$ & Depth of coseismic slip & $\mathrm{m}$ \\
\hline$D_{\mathrm{L}}$ & Inter-seismic locking depth & $\mathrm{m}$ \\
\hline$L$ & Crack length & $\mathrm{m}$ \\
\hline$R$ & Crack radius & $\mathrm{m}$ \\
\hline$S_{x}$ & Fault slip & $\mathrm{m}$ \\
\hline$U_{x}$ & Fault-parallel coseismic surface displacement & $\mathrm{m}$ \\
\hline$x$ & $x$ coordinate & $\mathrm{m}$ \\
\hline$y$ & $y$ coordinate & $\mathrm{m}$ \\
\hline$t$ & Time & $\mathrm{s}$ \\
\hline$T_{\text {hold }}$ & Hold time & $\mathrm{s}$ \\
\hline$T_{\text {rup }}$ & Rupture duration & $\mathrm{s}$ \\
\hline$T_{\mathrm{rec}}$ & Recurrence time & $\mathrm{s}$ \\
\hline$v$ & (Characteristic) velocity & $\mathrm{ms} \mathrm{s}^{-1}$ \\
\hline$V_{0}$ & Far-field (tectonic) loading velocity & $\mathrm{ms} \mathrm{s}^{-1}$ \\
\hline$V_{\text {rup }}$ & Rupture velocity & $\mathrm{ms} \mathrm{s}^{-1}$ \\
\hline$V^{1}$ & Slip velocity & $\mathrm{ms} \mathrm{s}^{-1}$ \\
\hline$V_{x}$ & Fault-parallel inter-seismic surface velocity & $\mathrm{ms} \mathrm{s}^{-1}$ \\
\hline$\tilde{\mathrm{a}}$ & Acceleration & $\mathrm{ms} \mathrm{s}^{-2}$ \\
\hline$g$ & Gravitational acceleration & $\mathrm{ms} \mathrm{s}^{-2}$ \\
\hline$m$ & Mass & $\mathrm{kg}$ \\
\hline$\varepsilon_{i j}$ & Strain tensor component & - \\
\hline$f$ & Friction force & $\mathrm{N}$ \\
\hline$F$ & Force & $\mathrm{N}$ \\
\hline$P$ & Pressure & $\mathrm{Pa}$ \\
\hline$\Delta \sigma$ & Stress drop & $\mathrm{Pa}$ \\
\hline$\sigma_{i j}$ & Stress tensor component & $\mathrm{Pa}$ \\
\hline$\sigma_{\mathrm{n}}$ & Normal stress & $\mathrm{Pa}$ \\
\hline$\tau$ & Shear stress (or strength) & $\mathrm{Pa}$ \\
\hline$M_{0}$ & Seismic moment & $\mathrm{Nm}$ \\
\hline$M_{\mathrm{W}}$ & Moment magnitude & - \\
\hline$a$ & Friction rate parameter & - \\
\hline$A$ & Damping factor & - \\
\hline$b$ & Friction state parameter & - \\
\hline$B$ & Bulk modulus & $\mathrm{Pa}$ \\
\hline$C$ & Cohesion & $\mathrm{Pa}$ \\
\hline$D_{\mathrm{c}}$ & Characteristic distance & $\mathrm{m}$ \\
\hline$E$ & Young's modulus & $\mathrm{Pa}$ \\
\hline$\eta$ & Viscosity & $\mathrm{Pas}$ \\
\hline$G$ & Shear modulus & $\mathrm{Pa}$ \\
\hline$k$ & Spring constant & $\mathrm{Nm}^{-1}$ \\
\hline$K$ & System stiffness & $\mathrm{Pam}^{-1}$ \\
\hline$n$ & Power law (stress) exponent & - \\
\hline$v$ & Poisson's ratio & - \\
\hline$\lambda$ & Lamé constant & - \\
\hline$\mu$ & Friction coefficient & - \\
\hline$\mu_{\mathrm{d}}$ & Dynamic friction coefficient & - \\
\hline$\mu_{\mathrm{s}}$ & Static friction coefficient & - \\
\hline$Q$ & Attenuation factor & - \\
\hline$\rho$ & Density & $\mathrm{kg} \mathrm{m}^{-3}$ \\
\hline$T_{\mathrm{m}}$ & Maxwell relaxation time & $\mathrm{s}$ \\
\hline$V_{\mathrm{s}}$ & Shear wave velocity & $\mathrm{ms} \mathrm{s}^{-1}$ \\
\hline $\mathrm{Ca}$ & Cauchy number & - \\
\hline$F r$ & Froude number & - \\
\hline$R a$ & Ramberg number & - \\
\hline$R e$ & Reynolds number & - \\
\hline$S m$ & Smoluchowski number & - \\
\hline St & Stokes number & - \\
\hline $\mathrm{CV}$ & Coefficient of variation & - \\
\hline $\mathrm{pH}$ & Potential of Hydrogen & - \\
\hline
\end{tabular}

rupture velocity is drastically reduced. Photoelasticity works best in quasi two-dimensional models providing plane strain deformation fields. A thorough review of dynamic photoelastic applications in fault block models is given by Rosakis et al. (2007).

\subsubsection{Image correlation techniques}

Image correlation techniques aim at retrieving the shape and 2-D or 3-D deformation of a surface or volume from digital images (e.g. Sutton et al., 2009). In the framework of experimental deformation monitoring, successive optical images are usually analysed to quantify incremental displacements, from which strain rates can be calculated (e.g. Adam et al., 2005, 2013). A variety of digital image correlation algorithms exists. They generally make use of successive monochromatic digital images in which a pattern of a few pixels can be tracked at sub-pixel accuracy. Given modern image resolutions of up to $30 \mathrm{MPx}$ and 16 bit, monochromatic colour depth allows us to track millimetre-sized features on the micrometre displacement scale. In combination with high-speed cameras, this technique provides dynamic deformation monitoring options of unprecedented accuracy and precision. Commercial and noncommercial software packages are on the market including LaVision's Strainmaster ${ }^{\circledR}$, Correlated Solutions Inc.'s VIC $^{\mathrm{TM}}$, open-source software MicMac (Galland et al., 2016), MATLAB ${ }^{\circledR}$-based open toolboxes MatPIV (Sveen, 2004), PIVlab (Thielicke and Stamhuis, 2014), and TecPIV (Boutelier, 2016), and COSI-Corr (Leprince et al., 2007).

The latest developments in strain monitoring using image correlation techniques include a coupling of strain monitoring of the experiment with analytical or numerical elastic dislocation modelling (EDM). For example Rosenau et al. $(2009,2010)$ used elastic EDM to differentiate between elastic and plastic deformation inherent in their elastoplastic models. Rubino et al. (2015) used EDM to invert strain for stress, applying a linear constitutive behaviour (Hild and Roux, 2006). Caniven et al. (2015) used EDM to invert surface deformation for fault slip distribution and depth of locking. The rigorous use of inversion and visualization techniques along with proper scaling in the models of Caniven et al. (2015) and Dominguez et al. (2015) allows for direct comparisons between model and natural observations that include surface deformation measured by geodesy (e.g. pseudo-GPS and InSAR displacement fields; Fig. 4c and d) and fault slip distribution and stress drop deduced from seismological and geodetic records. Their approach allows them to monitor a few microns of horizontal surface displacement at a spatial resolution of a few millimetres. Considering model scaling characteristics, the acquired measurements can be directly compared to a $1 \mathrm{~km}$ spacing of a dense GPS network and allow emulating an InSAR-like fringe pattern. 


\subsection{Global monitoring techniques}

Brune et al. (1990) used a pen attached to one foam block of their fault block models moving over a strip chart recorder to derive the displacement time function of one side of the fault. Similar data were obtained by Rosenau et al. (2009) using a high-resolution electronic odometer allowing us to monitor motion on the micrometre scale and $\mathrm{kHz}$ sampling rate and to derive the displacement time function of the rigid basal plate simulating subduction.

Force sensors at sampling rates up to $\mathrm{kHz}$ are routinely used to monitor the forces acting on one side or across an area of a sample in all kinds of deformation apparatuses (e.g. in a Schulze ring-shear tester; data in Fig. 10) including spring-slider (Fig. 2) and fault block set-ups (e.g. Corbi et al., 2011). Several studies used force sensors to measure the force exerted by a backwall in sandbox experiments of strike slip (Tchalenko, 1970) and thrusting (e.g. Cruz et al., 2010; Souloumiac et al., 2012; Herbert et al., 2015). While they show the long-term stress drop associated with fault formation in a slip-weakening material (e.g. sand), the technique also has the potential to detect stress drops associated with individual slip instabilities (analogue earthquakes)(e.g. Rosenau et al., 2016; Rudolf et al., 2016b)

\section{Applications}

\subsection{Earthquake statistics}

Earthquake statistics deals with the probabilistic treatment of the size and frequency of earthquakes by means of frequency-size distributions, probability distribution functions (pdfs), $b$ values, and coefficients of variation.

The iconic Gutenberg-Richter distribution is by far the most prominent result of earthquake statistics. It is a cumulative frequency plot of earthquakes occurring generally in a large area over a long period. It shows a negative log-linear correlation with a slope (" $b$ value") of -1 , i.e. a power law distribution. It is considered evidence of the self-similarity of earthquakes. The $b$ value, describing the relative amount of large versus small events, might change, however, depending on fault orientation and stressing level (e.g. Schorlemmer et al., 2005).

The original Burridge-Knopoff model (Burridge and Knopoff, 1967) was able to mimic the self-similarity of earthquakes. Accordingly, two types of events can be distinguished: local events that smooth existing stress heterogeneities and that obey a Gutenberg-Richter distribution and system-sized events that recur more regularly. This has been reproduced by the experiments of King (1991, 1994), who showed that large events tend to roughen the stress distribution while small events smooth them. Moreover, he found that large events are dissimilar (i.e. not characteristic) and that rupture nucleation is not where peak slip accumulates.
The frequency-size distributions found by King $(1991,1994)$ were Gutenberg-Richter-like except for the system-sized events which recur approximately time-predictably. Similarly, Hamilton and McCloskey (1997), when investigating the frequency-size distribution in a simple fault block model, found a power law behaviour up to analogue earthquakes approximately the size of the smallest dimension of the setup. Larger events occurred more often than predicted by extrapolation of the power law. They concluded that a break in the slope of the Gutenberg-Richter distribution is due to the change in rupture mechanism from truly two-dimensional to quasi one-dimensional once the earthquake ruptured the whole seismogenic width.

A simple measure of periodicity is the coefficient of variation (CV) of recurrence intervals. It is defined as the standard deviation divided by the mean recurrence interval. Recurrent events with a $\mathrm{CV}<50 \%$ can be considered quasi-periodic as their frequencies follow a normal pdf. $\mathrm{CV}>50 \%$ is considered aperiodic. Aperiodic events may follow an exponential pdf $(\mathrm{CV}=1)$, indicating random occurrence, or a longtail pdf (e.g. gamma pdf with $\mathrm{CV}=2$ ), indicating clustering. In their foam models, Brune et al. (1990) found a high periodicity of recurring characteristic stick-slip events with a CV $\sim 10 \%$. Similarly, elastic sliders by Corbi et al. (2011) or stick-slip of granular materials as shown in Fig. 10 generally display regular stick-slip with minimal variability in size and frequency given that extrinsic factors (load, loading rate) are kept constant. This regularity can be understood by means of system-sized characteristic events that rupture the whole fault area resulting in very homogenous stress release. Slightly more complexity is introduced in seismotectonic scale models, allowing the rupture to propagate more freely and introducing spatially more heterogeneous stress drops. The subduction earthquake models by Rosenau et al. (2009) and Corbi et al. (2013), for example, generate sequences of stick-slip events with a CV of 20-30\%. The breakdown of quasi-periodic behaviour controlled by the seismogenic patch size and slip heterogeneity has also been numerically simulated and studied more systematically by, e.g., Nielsen et al. (2000) and Herrendörfer et al. (2015).

Allowing earthquake interactions by means of static stress coupling or off-fault plasticity seems critical in controlling earthquake recurrence behaviour. In particular, static stress transfer between two seismogenic patches results in a switch from periodic to random behaviour, rarely synchronized (Sugiura et al., 2014; Varamashvili et al., 2008), as suggested by numerical models (e.g. Kaneko et al., 2010; Tullis et al., 2012a, b) and experimental results from the Rosenau et al. (2010) set-up shown in Fig. 12. This is consistent with simple spring-slider experiments (e.g. Burridge and Knopoff, 1967; King, 1991, 1994) and fault block models (e.g. Rubio and Galeano, 1994; Yamaguchi et al., 2011), where complexity emerges naturally.

Interaction with plastic deformation, i.e. faulting, of the hanging wall in the subduction earthquake models of Rose- 
(a)

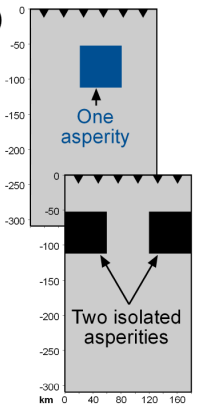

(b)

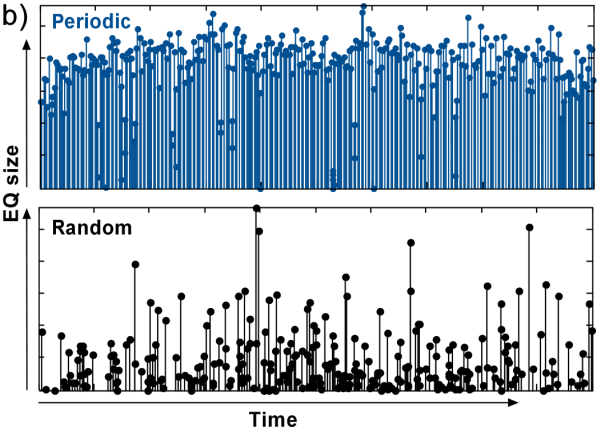

(c)

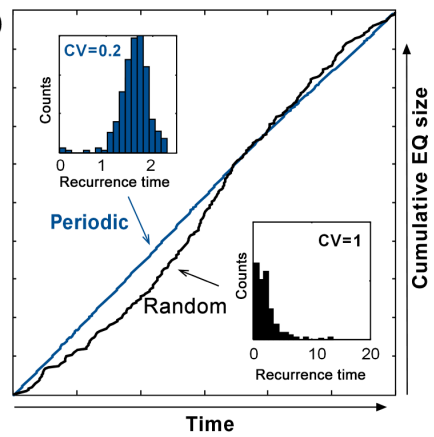

Figure 12. Periodic vs. random rupture behaviour as exemplified by seismotectonic scale models. (a) Model set-up: blue - one asperity; black - two asperities. (b) Analogue earthquake catalogues generated by blue and black models. (c) Cumulative plot of analogue earthquakes sequences and histograms of frequencies. Data and methodological details are published as open-access material in Rosenau et al. (2016).

(a)

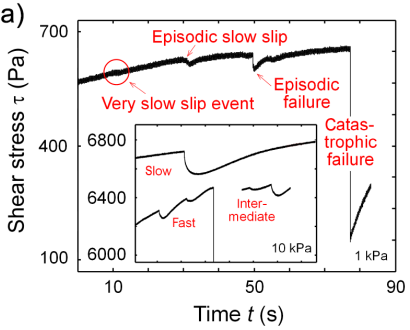

(b)

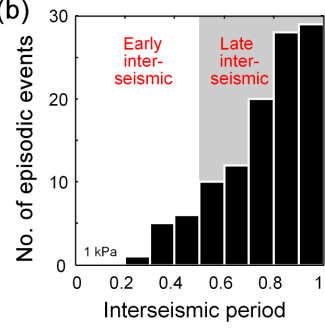

Figure 13. Seismic vs. aseismic slip in a ring-shear test using rice. (a) Slip styles ranging from slow to fast earthquake slip. (b) Systematic increase in slip events towards the end of an analogue seismic cycle. The $x$ axis is a unit interval. Results from ring-shear tests using a Schulze ring-shear tester RST-01 (Schulze, 1994; Fig. 2b). Data and methodological details are published as open-access material in Rosenau et al. (2016).

nau and Oncken (2009) resulted similarly in a more randomized recurrence of analogue earthquakes. The situation is similar with viscoelastic wedge models: while pure gelatine models (Corbi et al., 2013) display a very regular stick-slip (characteristic earthquakes) modified gelatine models tend to show more random behaviour (Brizzi et al., 2016). The rheological properties of gelatine in the latter have been modified by adding $\mathrm{NaCl}$, which caused an increase in viscoelastic behaviour. This increase in turn affected analogue earthquake statistics and widened the range of earthquake magnitudes, recurrence times, and rupture durations by a factor of 2 .

Quasi-periodic events can be potentially described by slip-predictable and time-predictable recurrence models (e.g. Weldon et al., 2004): in slip-predictable models the amount of slip depends on the duration of the previous inter-seismic period, while in time-predictable models the duration of the inter-seismic period depends on the size of the last event. However, no indication of such a predictability has been found in nature or in analogue earthquake models (e.g Rubinstein et al., 2012) except for spring-slider models (e.g. King, 1991, 1994). Nevertheless, a distinctive bimodal distribution

of slip events in models by Hamilton and McCloskey (1998) as well as in the models of Rosenau et al. (2009) emerges where smaller (but still large) events follow a distinctly different, though well-defined, frequency distribution than larger events. In contrast spring-slider models by Burridge and Knopoff (1967) and King (1994) as well as some fault block models (e.g. Rubio and Galeano, 1994) show a more random behaviour.

\subsection{Seismic versus aseismic faulting}

Tectonic faults are known to accumulate slip unsteadily at a wide range of rates: from sudden, seismic-wave-releasing slip instability at speeds of $\mathrm{m} \mathrm{s}^{-1}$ to slow, aseismic creep around the tectonic loading rate at $\mathrm{mm} \mathrm{yr}^{-1}$. Only if active faults become partially locked, that is, no or very little slip (less than loading rate) occurs across the fault interface, is elastic energy re-stored in fault-bounded blocks effectively. We are now aware that stick-slip is only one endmember of the cyclic storage and release of elastic energy known as "seismic cycles", while continuous (secular) creep at loading rate is the other endmember. A wide variety of slip transients (slow or silent earthquakes, non-volcanic tremors, very lowfrequency earthquakes) occur in between these endmembers (e.g. Peng and Gomberg, 2010). Understanding the physical foundations that govern the transition between the two dynamical regimes is pivotal for seismic hazard assessment as it may allow us to distinguish between "quiet" faults and hazardous ones.

Sliding in spring-slider and fault block models may occur both through a typical see-saw profile of stress reflecting phases of accumulation (i.e. stick phase) alternating with sudden drops (i.e. slip phase) or through smooth and continuous motion. The first regime, also known as "stick-slip", represents the basic physical model for the seismic cycle, while the second, also known as "stable sliding", is the analogue of creeping.

Spring-slider set-ups in which stiffness and loading velocity were varied reproduced a wide variety of slip styles (Lee- 


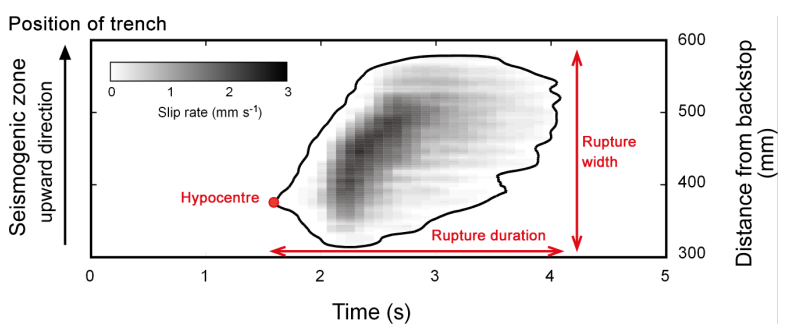

Figure 14. Rupture dynamics as observed in the subduction zone megathrust models of Corbi et al. (2013): slip evolution of a cracklike analogue subduction megathrust earthquake propagating upwards and downwards in the seismogenic zone (modified from Corbi et al., 2013).

man et al. 2016; Kaproth and Marone, 2013). The deformable slider-spring set-up of Reber et al. (2015) is used to study transients in the brittle-ductile regime. The latter is defined as a two-mineral-phase regime where one phase deforms in a brittle manner, while the other is ductile (e.g. feldspar vs. quartz). In the experiments by Reber et al. (2015), viscoelastic material is used to induce both creep and fracture. The observation of slip transients at various speeds in such experiments may be equivalent to tremors and slow slip phenomena (Peng and Gomberg, 2010). Similar variability of slip styles can be simulated using spring-slider set-ups in which stiffness and shear velocity were varied for artificial and natural fault gouge (Leeman et al. 2016; Kaproth and Marone, 2013) or using rice in a ring-shear tester set-up (Fig. 13). Here shear and normal stress are the controlling factors.

Fault block models have been specifically designed to investigate frictional dynamics as a function of the system loading rate, material rheology, and interplate roughness. In general, a bifurcation from stick-slip to stable sliding is observed as the system loading rate increases (e.g. Baumberger et al., 1994). A similar transition from potentially seismic to aseismic behaviour has been speculatively applied to subduction megathrusts, where the observed earthquake magnitude decreases with depth and the subsequent switch off at the downdip limit of the seismogenic zone may be explained by a progressive decrease in the viscosity of the upper plate (Namiki et al., 2014) or by the progressive smoothing of the interplate roughness (Voisin et al., 2008; Corbi et al., 2011).

\subsection{Rupture dynamics}

Rupture dynamics, which includes the study of earthquake nucleation, the transition to dynamic rupturing, and its arrest, has by far the broadest range of applications of the phenomena that can be studied by analogue experiments. We can only give a small overview here of the vast amount of existing knowledge, highlighting the experimental contributions using analogue earthquake models. The latter include mainly fault block models where a precut surface in rock or rock analogue material is stressed by the application of far-field compressive or shear forces.

The nucleation of an earthquake, i.e. the onset of frictional instability, has been investigated with a variety of analogue models. It was studied experimentally using fault block models using precut rock (e.g. Dieterich, 1978a; Okubo and Dieterich, 1984; Ohnaka and Shen, 1999; McLaskey and Kilgore, 2013; McLaskey and Glaser, 2011; McLaskey et al., 2012) as well as rock analogues, e.g. polycarbonate (e.g. Nielsen et al., 2010; Rosakis et al., 2007, and references therein). Accordingly, the onset of frictional instability is characterized by quasi-static creep up to loading velocity, acceleration, and dynamic propagation. Based on theoretical considerations using a spring-slider system, Roy and Marone (1996) suggest that the transition occurs at a critical velocity that is a function of extrinsic and intrinsic frictional properties and mass. On the basis of empirical results using a fault block model and theory, Latour et al. (2013a) in contrast equate the transition from quasi-static to dynamic rupture with the transition from exponential growth to power law growth of the rupture length. They suggest that elastic frictional properties control the transition.

Regarding rupture propagation, two main mechanisms can be distinguished, depending on slip duration at a single point along the fault with respect to total rupture duration. In the "crack model", slip at a point is continuous for about the entire rupture duration, while in the "pulse model", slip occurs only for a small fraction of the rupture duration (e.g. Heaton, 1990). Understanding what governs the duration of slip at a point is crucial for earthquake hazard assessment because the two models predict different degrees of strong motions with distance from the nucleation site (Marone and Richardson, 2006).

Brune et al. (1993) were amongst the first to find slip pulses travelling along interfaces of foam and relate them to earthquake dynamics. They argued that normal vibrations reduce the load on the fault at the rupture tip and thereby allow the rupture to propagate in a self-sustained, wrinklelike manner and slip to occur at very low friction. Similarly, Schallamach (1971) and Rubinstein et al. (2004) reported detachment waves in experiments using rubber on hard ground and between PMMA blocks, respectively (Fig. 3b). Slip pulses were also found as the main rupture mechanism by later studies in different materials (e.g. Lykotrafitis et al., 2006; Nielsen et al., 2010). Lu et al. (2010) suggested that a low stress level along faults may support pulse-like behaviour. The role of slip pulses as an earthquake mechanism was studied more systematically using foam block models in order to explain the heat flow paradox associated with the San Andreas Fault (Anooshehpoor and Brune, 1994).

Using the same experimental technique Anooshehpoor and Brune (1999) verified theoretical predictions of Weertman (1980) and Andrews and Ben-Zion (1997) regarding the directivity and speed of slip pulses travelling along contact interfaces between differentially compliant media. Key find- 
ings were that slip pulses propagate into the direction of the particle motion in the more compliant medium at a rupture velocity close to the shear wave velocity of the more compliant medium. Similar results were found by Xia et al. (2005) using much stiffer, bi-material interfaces (homalite). The role of the bi-material character of fault interfaces was studied in depth numerically in recent times (e.g, Ma and Beroza, 2008; Ampuero and Ben Zion, 2008; Brietzke et al., 2007, 2009).

Consistent with the above and with Rosakis et al. (1999), who found that cracks can move at velocities faster than shear wave speed ("super-shear" ruptures), Lykotrafitis et al. (2006) found that pulses are generally characterized by a slower propagation velocity than cracks. Accordingly, the origin of the two different types of rupture modes depends on the strength of the initial forcing. Similarly, Xia et al. (2004) found that in their experimental set-up, the sub-shear to super-shear transition depends on the dynamic loading conditions.

The control of parameters other than the rupture mechanism on rupture velocity has been studied by a variety of approaches. Using precut Columbia Resin, Wu et al. (1972) found that propagation velocity can range in general from sub-shear to $110 \%$ of the shear wave velocity. Using precut rock specimens, Johnson et al. (1973) found that particle velocity and rupture speed increase with stress drop, consistent with theoretical predictions. Okubo and Dieterich (1984) showed that rupture velocities along a simulated fault in granite are lower on rough faults than on smooth fault. Fault block models have also been developed to investigate how different configurations of roughness affect the rupture propagation. It has been found that a single linear barrier may both accelerate and decelerate a rupture, while a large heterogeneous barrier slows down the rupture (Latour et al., 2013b). Rousseau and Rosakis (2009) investigated the effect of more complex fault geometries including kinking and branching on rupture propagation in a homalite material. At the same time, Templeton et al. (2009) were able to simulate experimental results numerically. The control on rupture velocity in general and super-shear ruptures specifically is a very active field in analogue earthquake studies (e.g Lu et al., 2009; Schubnel et al., 2011; Mello et al., 2010, 2014, 2016; Passelègue et al., 2013, 2016).

Recently, seismotectonic scale models have become available that allow us to study rupture dynamics in a subduction setting (Corbi et al., 2013). Because of the slowness of the earthquake process in viscoelastic gelatine models, rupture dynamics can be studied at high resolution. Key characteristics of earthquake ruptures in viscoelastic subduction zone models of Corbi et al. (2013) regarding rupture nucleation, directivity and mechanism are as follows:

1. Hypocentres concentrate near the base of the seismogenic zone (Fig. 14). This is consistent with numerical simulations (Das and Scholz, 1983; van Dinther et al., 2013a, b, Pipping et al., 2016). In nature, the spatial re- lation between the hypocentre and the rupture area is less clear: the hypocentres of the 2004 M9.2 Sumatra and $2010 M 8.8$ Chile earthquakes were located in the deepest part of the rupture (Rhie et al., 2007; Moreno et al., 2010), probably aided by the lithostatic pressure and locking gradient. On the basis of observations of 12 finite-source rupture models of megathrust earthquakes, Mai et al. (2005) suggested that hypocentres tend to concentrate in the along-dip centre of the fault. Similarly, the hypocentre of the 2011 M9.0 Tohoku-Oki earthquake was located in the along-dip centre of the rupture (Lee et al., 2011).

2. Ruptures propagate bilaterally with a preference for the updip direction (Fig. 14) in the viscoelastic models of Corbi et al. (2013). This behaviour is consistent with previous analogue models of interplate seismicity performed with foam rubber (Brune, 1996) and elastoplastic materials (Rosenau et al., 2009) and numerical simulations (van Dither et al., 2013a, b; Pipping et al., 2016). The most likely explanation for the preferential earthquake migration to shallow levels is that the rupture follows the lithostatic pressure gradient that results from the thrust geometry (Das and Scholz, 1983). Also, the material compliancy difference between gelatine and aluminium favours the upward migration direction. Such a bi-material contrast may be active also in nature where the overriding plate is expected to be the more compliant than the subducting one (e.g. Ma and Beroza, 2008).

3. The majority of ruptures are crack-like as they display a minimum duration of slip at a point larger than $1 / 10$ of the entire rupture duration. The spatio-temporal cumulative slip distribution also seems to support the idea of the growth of the rupture as a crack (Fig. 14). A detailed study based on numerical modelling highlights the occurrence of both cracks and pulses and that the largest stress drops are associated with cracks (Herrendorfer et al., 2015).

The characteristics shown by the viscoelastic seismotectonic scale models by Corbi et al. (2013) are consistent with observations in the experiments with elastoplastic models of Rosenau et al. (2009). However, in the latter the rupture process is far less well resolved as the models were stiffer, speeding up the process, while the monitoring resolution was limited.

\subsection{Ground motion}

Pioneering work by Archuleta and Brune (1975) using foam block models (Fig. 2c) to study ground motion have been followed by a number of similar studies which helped in interpreting seismological observations and improving numerical predictions. King and Brune (1981) summarized the modelling approach by stating that "The foam model acts 
as an analogue computer that automatically accounts for the diffraction, refraction, reflection, and conversion phenomena that occur when seismic waves interact with an attenuative, linear-elastic soil structure".

Foam rubber models were for example amongst the first to explain the strong asymmetry in particle motion and associated ground motion across dipping faults. Brune (1996) investigated the dynamics of seismogenic thrusting using a wedge-shaped foam block. He found a pronounced amplification of particle and ground motion in the hanging wall. He explained this by considering static and dynamic effects: the free-surface effect, as predicted by analytical dislocation models, allows higher static particle motions in the hanging wall because of the possibility of the material to be lifted up. Additionally, seismic energy is reflected by the fault and the free surface and becomes trapped in the hanging wall wedge, increasing its coseismic motion. Shi et al. (1998) and Shi and Brune (2005) were able to reproduce and refine the experimental results numerically. Several numerical studies confirmed their results (Oglesby et al., 1998, 2000a, b; Ma and Beroza, 2008; Nielsen, 1998; Gabuchian et al., 2017). Gabuchian et al. $(2014,2017)$ most recently revisited this issue by means of experiments using homalite as a rock analogue. Beside the free-surface effects they focused on rupture velocity as a controlling factor for ground motion.

Brune and Anooshehpoor (1999) showed the dynamic effect of normal fault geometry and a low stress level at a shallow level. They found systematically lower accelerations of the model surface near the normal faults when compared to strike-slip faults. Similar results have been obtained with numerical models (Shi et al., 2003; Oglesby et al., 1998, 2000a, b). The effect of a shallow weak and creeping zone on ground motions from strike-slip earthquakes has been studied quantitatively using foam models by Brune and Anooshehpoor (1998).

A co-genetic though more engineering-type approach has been used to study site effects due to topography (Anooshehpoor and Brune, 1989), sedimentary basins (King and Brune, 1981), and the response of buildings and other structures, such as dams, to earthquakes (e.g. Brune and Anooshehpoor, 1991a; Anooshehpoor and Brune, 1989). Brune and Anooshehpoor (1991b) simulated a large-scale seismic experiment in order to help interpret the seismic data obtained in nature. In such studies, geometric-scale models made from foam rubber were used. Excitation of the model was by impulses or vibrations using plate and line sources simulating the horizontally and vertically incident polarized seismic shear waves picked up at model sites by accelerometers.

These studies demonstrated, for example, the sensitivity of seismic shear wave amplification to the incidence direction in the presence of topography as well as resonance characteristics of, e.g., basins, alluvial fans, and constructions. Comparison to natural observations and theoretical predictions validated the experimental approach, which was used in the following to study more complex scenarios beyond existing the- oretical and (generally 2-D) numerical models. In addition to the strong damping of the foam used (Brune and Anooshehpoor, 1998), some limitations specific to this modelling approach were recognized by Brune and Anooshehpoor (1991), such as edge reflections, imperfect or contaminated input signals, and non-linearities related to imperfect boundary conditions (e.g. bonding of foam blocks to the foundation).

\subsection{Seismic-cycle deformation}

Since Reid's formulation of the elastic rebound theory following the 1906 San Francisco earthquake (Reid, 1911) seismic cycles in various settings are seen as recurring, more or less sudden releases of stress or elastic strain energy that slowly accumulated in the period before. The term cycle by no means implies a regularity of the recurring events but rather describes the succession of the archetypical stages. Accordingly, a full seismic cycle consists primarily of the inter-seismic period (years to millennia) and the coseismic rupture (seconds). Precursors, post-seismic relaxation, and inter-seismic transients may complete the seismic cycle. Traditionally, the seismic cycle has been considered to be purely elastic (e.g. Klotz et al., 2001) and modelled accordingly using elastic models (e.g. Fig. 7b, c). The recognition of interand post-seismic viscoelastic relaxation phenomena in the ductile lower crust (e.g. Wang et al., 2012) and mantle as well as possibly universal precursor activity (e.g. Bouchon et al., 2013) led to continuous refinement of the seismic-cycle concept. Finally, in recent years, plasticity theory has been formulated in the framework of seismic cycles, allowing the accumulation of permanent (i.e. tectonic) deformation through seismic cycles (e.g. Wang and Hu, 2006; Johnson, 2013). Observation both in nature (e.g. Wesson et al., 2015) and in experiments using seismotectonic scale models (e.g. Rosenau and Oncken, 2010) corroborates this new view on elastoplastic seismic-cycle deformation.

Seismic-cycle deformation using seismotectonic scale models have been realized using elastic (foam: Caniven et al., 2015), viscoelastic (gelatine: Corbi et al., 2013), and elastoplastic rheologies (rubber mix: Rosenau et al., 2009, 2010; Rosenau and Oncken, 2009). Seismotectonic scale models were able to reproduce the basic pattern of seismic cycles in subduction zones and strike-slip zones with alternating phases of stress build-up (analogue of the inter-seismic stage) and stress release (analogue of the coseismic stage) due to coseismic slip associated with uplift and subsidence in the order few micrometres (decimetres to metres if scaled to nature).

Caniven et al. (2015) developed crustal-scale three-layer brittle-ductile models by coupling frictional-plastic, elastic, and viscoelastic layers in a strike-slip setting. These models were intended to study the mechanical coupling between the layers with respect to seismic-cycle deformation. The models consist of three layers: a viscoelastic basal layer (PDMS) representing the lower crust, an elastic middle layer (polyurethane foam) with an embedded strike-slip fault (able 
(a)

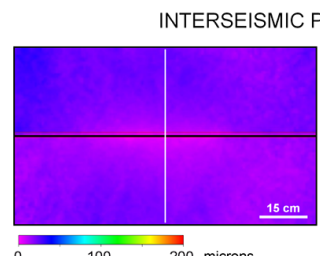

$100 \quad 200$ microns
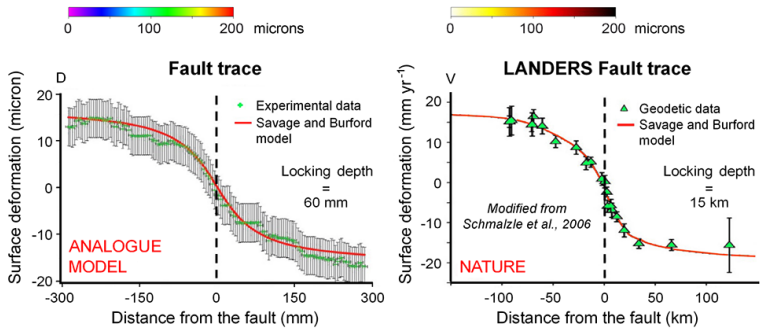

(c)
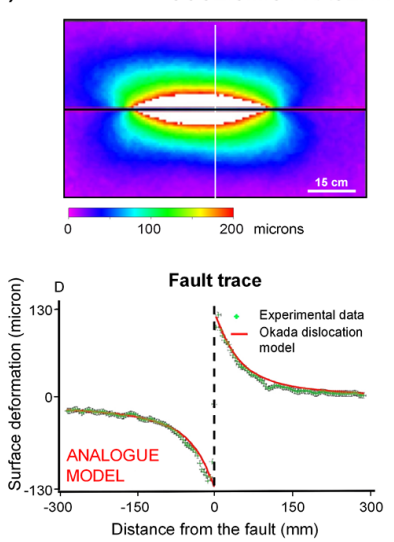

FAULT LOCKED

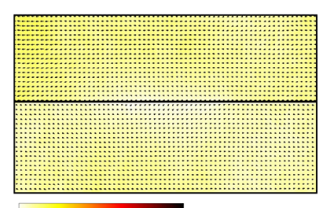

ENTAL FAULT SLIP
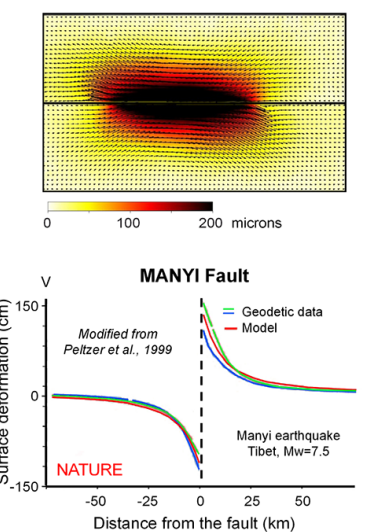

(b)
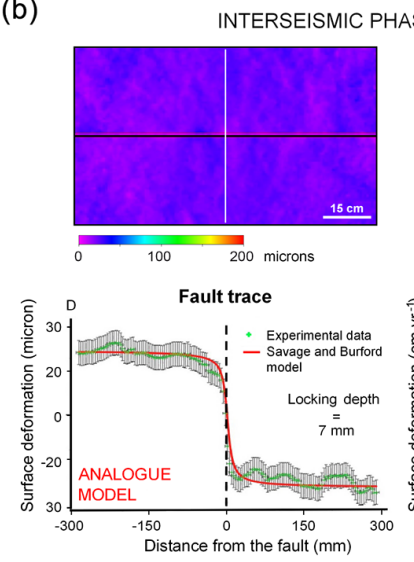

(d)
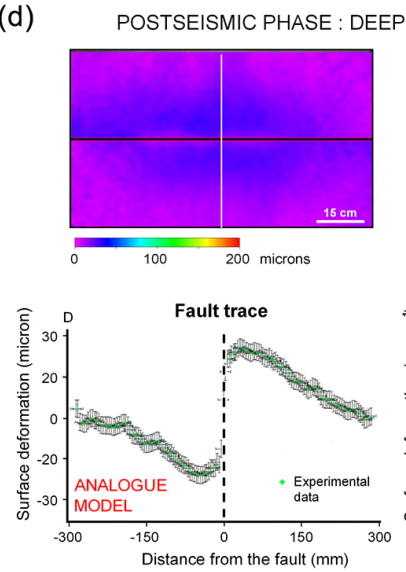
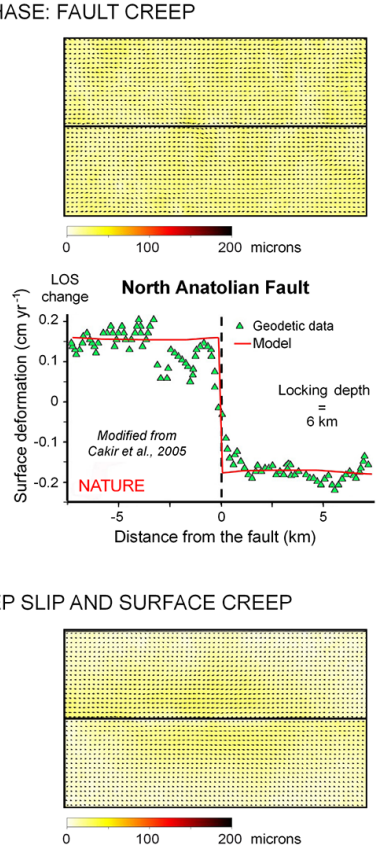

LoS LANDERS Fault trace

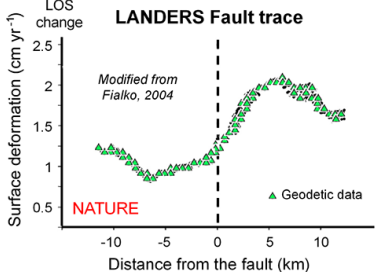

Figure 15. Seismic-cycle deformation as shown by multi-layer strike-slip fault models by Caniven et al. (2015): (a, b) inter-seismic (locked and creeping fault, respectively); (b) coseismic; (c) post-seismic phase (modified from Caniven et al., 2015).

to creep and stick-slip depending on treatment), and a thin cover of brittle-plastic granular material (mixture of silica and graphite or PVC plastic powder) representing the shallow aseismic crustal layer.

The model is loaded by applying both horizontal compression and shear at velocities in the order of micrometres per second. Model kinematic evolution is monitored using a high-performance optical system, based on sub-pixel correlation of high-definition digital images and enabling very accurate measurements of model deformations with a spatial resolution ranging from 1 to $5 \mathrm{~mm}$, an accuracy of a few micrometres (equivalent to a $1 \mathrm{~km}$ dense permanent GPS network), and a sample rate of $0.2 \mathrm{~Hz}$.

Caniven et al. (2015) used an average length scale of $L^{*}=4 \times 10^{-6}$ such that $1 \mathrm{~cm}$ in the model equals $2-3 \mathrm{~km}$ in nature. This scale was mainly imposed by the maximum size of the experimental box $(1 \mathrm{~m})$ and the dimensions of the studied geological prototype, i.e. a $200-300 \mathrm{~km}$ long strikeslip fault. The calculated stress scaling factor is very close to the length scaling factor and was estimated to be in the range of $\sigma *=5 \times 10^{-6}$ (taking into account that the normal stress was increased to compensate for the low density of the foam and a shear modulus scaling factor $G^{*}$ of $5 \times 10^{-6}$ ). The silicone oil used to model the ductile lower crust has a viscosity of $\eta=3-5 \times 10^{4} \mathrm{~Pa}$ s at $T=20^{\circ} \mathrm{C}$ for a mean strain rate of $\mathrm{d} \varepsilon / \mathrm{d} t=10^{-4} \mathrm{~s}^{-1}$ (Ten Grotenhuis et al., 2002; Rudolf et al., 2016a). Consequently, the viscosity scaling factor ranges between $\eta *=5 \times 10^{14}$ and $5 \times 10^{16}$ considering a viscosity of $10^{18}$ to $10^{20} \mathrm{~Pa}$ s for nature. Altogether, the resulting interseismic timescaling factor should be in the range of $10^{-8}$ to $10^{-10}$, which corresponds to a scaling in which $1 \mathrm{~s}$ is 3 to 300 years.

This experimental set-up by Caniven et al. (2015) succeeded in simulating realistic long-term tectonic loading along with seismic-cycle phases. In particular, inter-seismic loading (Fig. 15a) is either relaxed by slow and continuous, aseismic fault creep (Fig. 15b) or by successive instantaneous fault slip events (coseismic phase; Fig. 15c). After a seismic slip event low-amplitude, slow deformation occurs (post-seismic relaxation phase; Fig. 15d). The simulated kinematics of all stages can be directly compared with geodetic and seismological observations in nature. For 
each experiment, the evolution of the inter-seismic strain field is recorded semi-automatically by measuring surface deformation, calculating the evolution of the locking depth, quantifying the amount and location of aseismic creep, and analysing the spatial and temporal distribution of coseismic ruptures (surface rupture dimensions and geometries, coseismic slip profiles, earthquake magnitude, return period) and the post-seismic relaxation phase (surface deformation kinematics, decay of micro-earthquake activity). The model results are comparable to numerical simulations of strike-slip fault earthquakes in terms of seismic moment, slip gradients, and post-seismic response (e.g. Ben-Zion and Rice, 1997; Lapusta and Rice, 2003; Tullis et al., 2012a, b).

\subsection{Seismotectonic evolution of subduction zone forearcs: linking short and long timescales}

Lithospheric-scale elastoplastic models were used to study seismotectonic evolution of subduction zone forearcs (Rosenau et al., 2009; Rosenau and Oncken, 2009). Such models have helped to understand the relationship between earthquakes along the subduction megathrust and the structure and topography of the forearc wedge. Therefore, they are a valuable tool in understanding the links between short-term and long-term deformation processes, i.e bridging the timescales from single earthquakes to tectonic evolution.

The models of Rosenau et al. (2009) consist of a $200 \mathrm{~mm}$ thick granular wedge representing the brittle forearc lithosphere $(<60 \mathrm{~km}$ depth) made of a mixture of rubber pellets and sugar into which is embedded a seismogenic zone of rice grains. The whole model sits on top of a conveyer plate driven at a few millimetres per minute to simulate convergence. Kinematic monitoring occurred by the particle image velocimetry method able to detect displacements down to tens of micrometres at a $10 \mathrm{~Hz}$ resolution. While the resolution was good enough to monitor seismic-cycle deformation, it was too low to image the rupture process that occurred within less than $0.1 \mathrm{~s}$. Nevertheless, Rosenau et al. (2009) succeeded in simulating the main stages of the seismic cycle, namely the co-, post, and inter-seismic stage. The key issue in using this set-up was to study the accumulation of permanent (plastic, tectonic) deformation over several seismic cycles. Differentiating between elastic and plastic deformation on a seismic-cycle scale has been done by using elastic dislocation modelling to subtract the elastic deformation from the elastoplastic deformation seen.

According to 2-D models a few percent of plate convergence is converted into permanent across-strike shortening of the forearc wedge over several seismic cycles. Shortening localizes both at the updip and downdip limit of the seismogenic areas along the megathrust (Fig. 16a). At the updip limit of the seismogenic zone, coseismic compression is relaxed post-seismically by internal shortening accommodated by a splay fault in the models of Rosenau et al. $(2009,2010)$. This is consistent with theoretical predictions (Wang and $\mathrm{Hu}$,
2006) and observations in nature (e.g. Lieser et al., 2014). Vice versa, during the inter-seismic period compression occurs at the downdip limit of the seismogenic zone and may lead to uplift of the coast over multiple seismic cycles.

Results from 3-D experiments in the Rosenau et al. (2009) set-up suggest that a similar mechanism is active along-strike causing permanent shortening and uplift of coastal regions overlying aseismically slipping zones (barriers) along the megathrust (Fig. 16b, c).

In summary, analogue models suggested that permanent shortening is localized at the periphery of repeated great earthquakes (M8-M9) in subduction zones. In particular, a tectonically stable basin or platform evolves on top of the seismogenic areas along the megathrust. This leads to a morphotectonic segmentation of the wedge that directly reflects the pattern of seismic and aseismic slip along the megathrust. This mechanism could be responsible for the correlation of basins with source areas of megathrust earthquakes (Mogi, 1969; Nishenko and McCann, 1979; Wells et al., 2003) and peninsulas with barriers (e.g. Victor et al., 2011; Schurr et al., 2012; Saillard et al., 2017).

Rosenau and Oncken (2009) moreover suggest a feedback between forearc deformation and seismogenesis along the megathrust: accordingly, because the stable wedge part overlying the seismogenic zone in segmented forearcs deforms quasi-elastically, characteristic great earthquakes tend to occur fairly periodically as in simple spring-slider experiments and numerical simulations of the experiments (Pipping et al., 2016). In contrast, less segmented subduction zone forearcs have been predicted to show more random earthquake occurrence. This is in line with observations (Tormann et al., 2015) and numerical predictions (Fuller et al., 2006).

\section{Conclusions and outlooks}

Based on 2 centuries of development in experimental tectonics and seismology, analogue modelling has become an explorative simulation tool in the past decade to understand the link between short-term and long-term deformation processes, bridging the timescales from earthquake nucleation to tectonic evolution over multiple seismic cycles. This new across-scale modelling approach met needs for a better understanding of natural observations which have become available due to developments in seismological and geodetic monitoring techniques (GPS and InSAR) and an increase in the frequency of occurrences of large to great earthquakes in a variety of settings.

Here, we have presented an overview of experimental approaches to model earthquakes, seismic cycles, and seismotectonic deformation. The processes involved are multiscale posing the challenge to cross timescales from seconds (seismic deformation) to millions of years (tectonic deformations) both in natural observations and in simulations and experiments. Since natural observations are intrinsically 
(a)

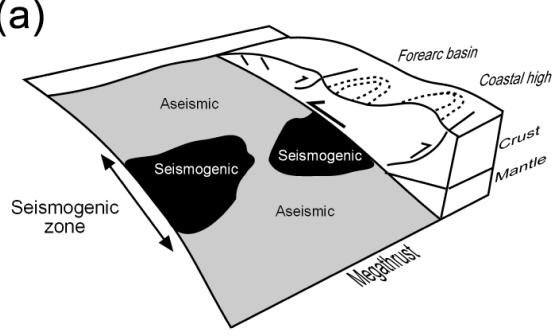

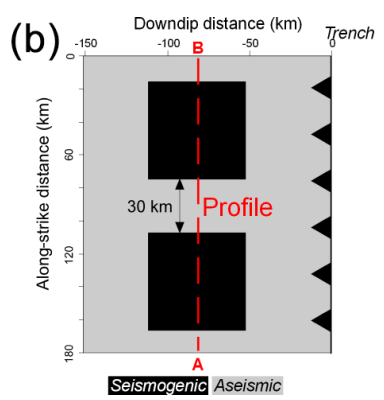

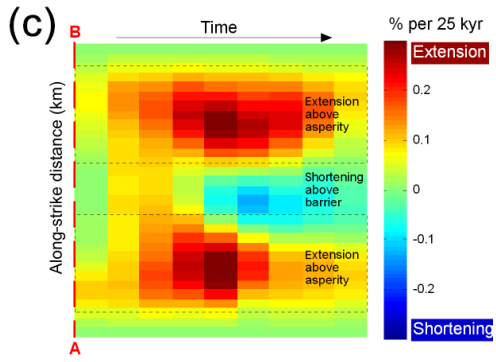

Figure 16. Seismotectonic evolution of subduction zone forearcs as suggested by elastoplastic subduction zone megathrust models: (a) spatial correlation between forearc topography and the seismogenic zone along subduction megathrust suggested by 2-D models of Rosenau and Oncken (2009). (b) Set-up of seismotectonic scale model with two seismogenic patches. (c) Evolution of along-strike strain emerging from the model shown in (b). Note the correlation between along-strike shortening and extension with aseismic and seismic areas along the megathrust.

limited in resolution and period of observation, simulations by means of analogue and numerical modelling are key to understanding multi-scale processes. An experimental approach to multi-scale problems seems most natural because experiments are physically self-consistent and happen in a time and space continuum. This is in contrast to numerical models, which need strong assumptions on the physical laws involved and need to be discretized.

Existing analogue earthquake models have been categorized as (1) spring-slider models, (2) fault block models, and (3) seismotectonic scale models according to their complexity, similarity, and applicability to the natural prototype. Seismotectonic scale models have been developed very recently, exploiting technological advances in material characterization and deformation monitoring techniques. Materials used in seismotectonic scale modelling studies include elastic, frictional-plastic, and viscoelastic rheologies. Monitoring techniques exist that allow us to monitor deformation in the lab accurately and precisely at high spatial and temporal resolution and with large coverage. Numerical modelling and inversion techniques adapted from geodesy and seismology allow us to infer hidden kinematic and dynamic parameters which are not directly observable (e.g. volumetric strain, material properties).

The key challenges and future developments we see are as follows:

1. New materials remain to be explored. Especially nonlinear rheologies both in brittle and viscoelastic regimes will contribute to more realistic analogue models in future. For example, the implementation of Burgers rheology in analogue models studying post-seismic mantle relaxation appears as a necessary step in the near future. A rigorous characterization of the material is prerequisite.

2. Monitoring techniques are developed continuously towards higher resolution both in space and time as well as full coverage. A key future challenge is handling the growing amount of image data thus derived. Adaptive imaging, i.e. adjusting the imaging rate to the deformation rate, is a way to reduce data production. Such adaptive imaging might be based on external triggering, e.g. by a combination with force measurement, or internal triggering, i.e. by applying fast (near real-time) image cross-correlation ("live strain gauge").

3. The coupling of analogue models with numerical models helps to overcome the respective limitations and leads to a better exploitation of the models' respective potentials. For example, numerical models can be used to infer quantities from the experiment that are not directly observable, such as small-scale details of rupture dynamics or unknown material properties. Numerical models also provide the means to better constrain boundary conditions and imposed artefacts in analogue models. On the other hand, experiments can help in validating numerical models by means of testing their predictions and thereby justifying the simplifications of the physical processes and parametrizations involved in numerical models. Cross-validation and benchmarking in general should be promoted in the respective communities.

4. Properly scaled analogue earthquake models may help to improve seismological and geodetic inversion techniques and overcome non-uniqueness of numerical solutions. They provide a large number of wellconstrained and self-consistent case studies which display both natural complexity and variability. Analogue earthquakes may thus serve to minimize the solution space and more adequately constrain slip variability, for example.

5. Finally, experimental techniques are a superb method for visualization and teaching complex processes. For example, simple spring-slider experiments equipped with force sensors and accelerometers are easy to realize 
and provide fascinating hands-on experience in relation to earthquakes.

Tackling the above challenges will enable analogue modellers and numerical modellers to develop more complex and realistic seismotectonic scenarios in terms of structure and rheology. Higher resolutions will shift the detection threshold for analogue earthquakes (i.e. the magnitude of completeness) further down from currently ca. $M 7$ to 8 . This will allow us to simulate transient processes more completely in the lab including slow earthquakes and fore- and aftershocks. Finally, longer and more complete experimental time series will provide further insight, especially into the link between short-term and long-term deformation processes. For example, new questions might arise about the link between megathrust seismogenesis and long-term sediment accretion at the forearc wedge toe or basal erosion processes in subduction zones or about the link between strike-slip seismogenesis and fault growth and linkage on a million-year timescale.

Data availability. Original data underlying the material presented here are published in an open access dataset by Rosenau et al. (2016).

Competing interests. The authors declare that they have no conflict of interest.

Acknowledgements. Fabio Corbi received funding from the European Union's Horizon 2020 research and innovation programme under the Marie Sklodowska-Curie grant agreement no. 658034 (AspSync). We thank Malte Ritter and Michael Rudolf for sharing their rock mechanical data compilations. We thank Kirsten Elger and GFZ Data Service for publishing the data. We thank Michele Cooke and an anonymous reviewer as well as the editor Susanne Buiter for very constructive comments.

Edited by: S. Buiter

Reviewed by: M. Cooke and one anonymous referee

\section{References}

Alshibli, A. K. and Roussel, L.: Experimental investigation of slipstick behaviour in granular materials, Int. J. Numer. Anal. Met., 30, 1391-1407, https://doi.org/10.1002/nag.517, 2006.

Abdelmalak, M. M., Bulois, C., Mourgues, R., Galland, O., Legland, J. B., and Gruber, C.: Description of new dry granular materials of variable cohesion and friction coefficient: Implications for laboratory modeling of the brittle crust, Special Issue on GeoMod 2014 - Modelling in Geoscience, 684, 39-51, 2016.

Abe, S. and Mair, K.: Effects of gouge fragment shape on fault friction: New 3-D modelling results, Geophys. Res. Lett., 36, L23302, https://doi.org/10.1029/2009g1040684, 2009.

Abe, Y. and Kato, N.: Complex Earthquake Cycle Simulations Using a Two-Degree-of-Freedom Spring-Block Model with a Rate- and State-Friction Law, Pure Appl. Geophys., 170, 745-765, https://doi.org/10.1007/s00024-011-0450-8, 2013.

Abe, S., Latham, S., and Mora, P.: Dynamic Rupture in a 3-D Particle-based Simulation of a Rough Planar Fault, Pure Appl. Geophys., 163, 1881-1892, https://doi.org/10.1007/s00024-0060102-6, 2006.

Adam, J., Oncken, O., Kukowski, N., Lohrmann, J., Hoth, S., Urai, J. L., van der Zee, W., Schmatz, J., Wieneke, B., and Pfeiffer, K.: Shear localisation and strain distribution during tectonic faulting - New insights from granular-flow experiments and highresolution optical image correlation techniques, J. Struct. Geol., 27, 183-301, https://doi.org/10.1016/j.jsg.2004.08.008, 2005.

Adam, J., Klinkmueller, M., Schreurs, G., and Wieneke, B.: Quantitative 3-D strain analysis in analogue experiments simulating tectonic deformation: Integration of X-ray computed tomography and digital volume correlation techniques, J. Struct. Geol., 55, 127-149, https://doi.org/10.1016/j.jsg.2013.07.011, 2013.

Aki, K.: Asperities, barriers, characteristic earthquakes and strong motion prediction, J. Geophys. Res., 89, 5867-5872, 1984.

Ampuero, J. P. and Ben-Zion, Y.: Cracks, pulses and macroscopic asymmetry of dynamic rupture on a bimaterial interface with velocity-weakening friction, Geophys. J. Int., 173, 674-692, https://doi.org/10.1111/j.1365-246X.2008.03736.x, 2008.

Andrews, D. J. and Ben-Zion, Y.: Wrinkle-like slip pulse on a fault between different materials, J. Geophys. Res., 102, 553-571, 1997.

Anooshehpoor, A. and Brune, J. N.: Foam rubber modeling of topographic and Dam interaction effects at Pacoima Dam, B. Seismol. Soc. Am., 79, 1347-1360, 1989.

Anooshehpoor, A. and Brune, J. N.: Frictional heat generation and seismic radiation in a foam rubber model of earthquakes, Pure Appl. Geophys., 142, 735-747, 1994.

Anooshehpoor, A. and Brune, J. N.: Wrinkle-like Weertman pulse at the interface between two blocks of foam rubber with different velocities, Geophys. Res. Lett., 26, 2025-2028, 1999.

Anooshehpoor, A. and Brune, J. N.: Study of Rupture Directivity in a Foam Rubber Physical Model, PEER Lifline Task 1D01 Report Pacific Earthquake Engineering Research Center College of Engineering University of California, Berkeley July, 2004.

Anthony, J. L. and Marone, C.: Influence of particle characteristics on granular friction, J. Geophys. Res., 110, B08409, https://doi.org/10.1029/2004JB003399, 2005.

Archuleta, R.J. and Brune, J. N.: Surface strong motion associated with a stick-slip event in a foam rubber model of earthquakes, B. Seismol. Soc. Am., 65, 1059-1071, 1975.

Aragon, L. E. and Jagla, E. A.: Spatial and temporal forecasting of large earthquakes in a spring-block model of a fault, Geophys. J. Int., 195, 1763-1772, https://doi.org/10.1093/gji/ggt330, 2013.

Baumberger, T., Heslot, F., and Perrin, B.,: Crossover from creep to inertial motion in friction dynamics, Nature, 367, 544-546, 1994.

Baumberger, T., Caroli, C., and Ronsin, O.: Self-healing slip pulses and the friction of gelatin gels, Eur. Phys. J. E, 11, 85-93, 2003.

Ben-Zion, Y.: Dynamic ruptures in recent models of earthquake faults, J. Mech. Phys. Solids, 49, 2209-2244, 2001.

Ben-Zion, Y.: Collective behavior of earthquakes and faults: Continuum-discrete transitions, progressive evolutionary changes, and different dynamic regimes, Rev. Geophys., 46, RG4006, https://doi.org/10.1029/2008rg000260, 2008. 
Ben-Zion, Y. and Rice, J. R.: Dynamic simulations of slip on a smooth fault in an elastic solid, J. Geophys. Res.-Sol. Ea., 102, 17771-17784, 1997.

Blanpied, M. L., Lockner, D. A., and Byerlee, J. D.: Fault stability inferred from granite sliding experiments at hydrothermal conditions, Geophys. Res. Lett., 18, 609-612, 1991.

Blanpied, M. L., Lockner, D. A., and Byerlee, J. D.: Frictional slip of granite at hydrothermal conditions, J. Geophys. Res., 100, 13045-13064, 1995.

Bouchon, M., Durand, V., Marsan, D., Karabulut, H., and Schmittbuhl, J.: The long precursory phase of most large interplate earthquakes, Nat. Geosci., 6, 299-302, https://doi.org/10.1038/ngeo1770, 2013.

Bouissou, S., Petit, J. P., and Barquins, M., Experimental evidence of contact loss during stick-slip: possible implications for seismic behaviour, Tectonophysics, 295, 341-350, 1998.

Boutelier, D.: TecPIV - A MATLAB-based application for PIVanalysis of experimental tectonics, Comput. Geosci., 89, 186199, 2016.

Boutelier, D., Schrank, C., and Cruden, A.: Power-law viscous materials for analogue experiments: New data on the rheology of highly-filled silicone polymers, J. Struct. Geol., 30, 341-353, https://doi.org/10.1016/j.jsg.2007.10.009, 2008.

Boutelier, D., Cruden, A., and Saumur, B.: Density and viscoelasticity of Natrosol $250 \mathrm{HH}$ solutions: Determining their suitability for experimental tectonics, J. Struct. Geol., 86, 153-165, 2016.

Brace, W. F.: Laboratory studies of stick-slip and their application to earthquakes, Tectonophysics, 14, 189-200, 1972.

Brace, W. F. and Byerlee, J. D.: Stick-Slip as a Mechanism for Earthquakes, Science, 153, 990, 1966.

Brietzke, G. B., Cochard, A., and Igel, H.: Dynamic rupture along bimaterial interfaces in 3-D, Geophys. Res. Lett., 34, L11305, https://doi.org/10.1029/2007gl029908, 2007.

Brietzke, G. B., Cochard, A., and Igel, H.: Importance of bimaterial interfaces for earthquake dynamics and strong ground motion, Geophys. J. Int., 178, 921-938, https://doi.org/10.1111/j.1365246X.2009.04209.x, 2009.

Brizzi, S., Funiciello, F., Corbi, F., Giuseppe, E. D., and Mojoli, G.: Salt matters: How salt affects the rheological and physical properties of gelatine for analogue modelling, Tectonophysics, 679, 88-101, 2016.

Brun, J.-P.: Deformation of the continental lithosphere: Insights from brittle-ductile models, edited by: De Meer, S., Drury, M. R., De Bresser, J. H. P., and Pennock, G. M., Deformation Mechanisms, Rheology and Tectonics, Current Status and Future Perspectives, Geological Society, London, Special Publications, 200, 355-370, https://doi.org/10.1144/GSL.SP.2001.200.01.20, 2002.

Brune, J. N.: Earthquake modeling by stick-slip along precut surfaces in stressed foam rubber, B. Seismol. Soc. Am., 63, 21052119, 1973.

Brune, J. N.: Particle motion in a physical model of shallow angle thrust faulting, Proc. Indian Acad. Sci. (Earth Planet. Sci.), 105, 197-206, 1996.

Brune, J. N. and Anooshehpoor, A.: Foam Rubber Modeling of the El Centro Terminal Substation Building, Earthquake Spectra, 7, 45-79, 1991a.
Brune, J. N. and Anooshehpoor, A.: Foam Rubber Modeling of the Lotung Large-Scale Seismic Experiment, Earthquake Spectra, 7, 165-178, 1991b.

Brune, J. N. and Anooshehpoor, A.: Frictional resistance of a fault zone with strong rotors, 24, 2071-2074, 1997.

Brune, J. N. and Anooshehpoor, A.: A physical model of the effect of a shallow weak layer on strong ground motion for strike-slip ruptures, B. Seismol. Soc. Am., 88, 1070-1078, 1998.

Brune, J. N. and Anooshehpoor, A.: Dynamic geometrical effects on strong ground motion in a normal fault model, J. Geophys. Res., 104, 809-815, 1999.

Brune, J. N., Johnson, P. A., and Slater, C.: Nucleation, predictability, and rupture mechanism in foam rubber models of earthquakes, J. Himalayan Geol., 1, 155-166, 1990.

Brune, J. N., Brown, S., and Johnson, P. A.: Rupture mechanism and interface separation in foam rubber models of earthquakes: a possible solution to the heat flow paradox and the paradox of large overthrusts, Tectonophysics, 218, 59-67, 1993.

Buckingham, E.: On Physically Similar Systems; Illustrations of the Use of Dimensional Equations, Phys. Rev., 4, 345-376, 1914.

Bürgmann, R.,and Dresen, G.: Rheology of the Lower Crust and Upper Mantle: Evidence from Rock Mechanics, Geodesy, and Field Observations, Annu. Rev. Earth Planet. Sc., 36, 531-567, 10.1146/annurev.earth.36.031207.124326, 2008.

Burridge, R. and Knopoff, L.: Model and theoretical seismicity, B. Seismol. Soc. Am., 57, 341, 1967.

Byerlee, J.: Friction of rocks, Pageoph, 116, 615-626, 1978.

Byerlee, J. D.: The mechanics of stick-slip, Tectonophysics, 9, 475486, 1970.

Cakir, Z., Akoglu, A. M., Belabbes, S., Ergintav, S., and Meghraoui, M.: Creeping along the Ismetpasa section of the North Anatolian fault (Western Turkey): Rate and extent from InSAR, Earth Planet. Sci. Lett., 238,225-234, doi:https://doi.org/10.1016/j.epsl.2005.06.044, 2005.

Caniven, Y., Dominguez, S., Soliva, R., Cattin, R., Peyret, M., Marchandon, M., Romano, C., and Strak, V.: A new multilayered visco-elasto-plastic experimental model to study strike-slip fault seismic cycle, Tectonics, 34, 232-264, https://doi.org/10.1002/2014tc003701, 2015.

Cao, T. and Aki, K.: Seismicity simulation with a mass-spring model and a displacement hardening-softening friction law, PAGEOPH, 122, 10-24, 1984.

Carlson, J. M. and Langer, J. S.: Mechanical model of an earthquake fault, Phys. Rev. A, 40, 6470-6484, 1989.

Carlson, J. M., Langer, J. S., Shaw, B. E., and Tang, C.: Intrinsic properties of a Burridge-Knopoff model of an earthquake, Phys. Rev. A, 44, 884-897, https://doi.org/10.1103/PhysRevA.44.884, 1991.

Chinnery, M. A.: The deformation of the ground around surface faults, B. Seismol. Soc. Am., 51, 355, 1961.

Coker, D., Lykotrafitis, G., Needleman, A., and Rosakis, A. J.: Frictional sliding modes along an interface between identical elastic plates subject to shear impact loading, J. Mech. Phys. Solids, 53, 884-922, 2005.

Cooke, M. L. and van der Elst, N. J.: Rheologic testing of wet kaolin reveals frictional and bi-viscous behavior typical of crustal materials, Geophys. Res. Lett., 39, L01308, https://doi.org/10.1029/2011g1050186, 2012. 
Corbi, F., Funiciello, F., Faccenna, C., Ranalli, G., and Heuret, A.: Seismic variability of subduction thrust faults: Insights from laboratory models, J. Geophys. Res., 116, B06304, https://doi.org/10.1029/2010jb007993, 2011.

Corbi, F., Funiciello, F., Moroni, M., van Dinther, Y., Mai, P. M., Dalguer, L. A., and Faccenna, C.: The seismic cycle at subduction thrusts: 1 . Insights from laboratory models, J. Geophys. Res.-Sol. Ea., 118, 1483-1501, https://doi.org/10.1029/2012jb009481, 2013.

Cruz, L., Malinski, J., Wilson, A., Take, W. A., and Hilley, G.: Erosional control of the kinematics and geometry of fold-and-thrust belts imaged in a physical and numerical sandbox, J. Geophys. Res.-Sol. Ea., 115, B09404, https://doi.org/10.1029/2010jb007472, 2010.

Daniels, K. E. and Hayman, N. W.: Force chains in seismogenic faults visualized with photoelastic granular shear experiments, J. Geophys. Res., 113, B11411, https://doi.org/10.1029/2008jb005781, 2008.

Das, S. and Scholz, C. H.: Why large earthquakes do not nucleate at shallow depth, Nature, 305, 621-623, 1983.

Day, S. M., Gonzalez, S. H., Anooshehpoor, R., and Brune, J. N.: Scale-Model and Numerical Simulations of Near-Fault Seismic Directivity, B. Seismol. Soc. Am., 98, 1186-1206, https://doi.org/10.1785/0120070190, 2008.

de Joussineau, G. Bouissou, G. S., Petit, J. P., and Barquins, M.: Experimental analysis of slip distribution along a fault segment under stick-slip and stable sliding conditions, Tectonophysics, 337, 85-98, https://doi.org/10.1016/S0040-1951(01)00058-0, 2001.

Di Giuseppe, E., Funiciello, F., Corbi, F., Ranalli, G., and Mojoli, G.: Gelatins as rock analogs: A systematic study of their rheological and physical properties, Tectonophysics, 473, 391-403, https://doi.org/10.1016/j.tecto.2009.03.012, 2009.

Di Giuseppe, E., Corbi, F., Funiciello, F., Massmeyer, A., Santimano, T. N., Rosenau, M., and Davaille, A.: Characterization of Carbopol hydrogel rheology for experimental tectonics and geodynamics, Tectonophysics, 642, 29-45, https://doi.org/10.1016/j.tecto.2014.12.005, 2015.

Dieterich, J. H.: Time-dependent friction as a possible mechanism for aftershocks, J. Geophys. Res., 77, 3771-3781, 1972a.

Dieterich, J. H.: Time-dependent friction in rocks, J. Geophys. Res., 77, 3690-3697, 1972b.

Dieterich, J. H.: Preseismic fault slip and earthquake prediction, J. Geophys. Res., 83, 3940-3948, 1978a.

Dieterich, J. H.: Time-dependent friction and the mechanics of stick-slip, Pageoph, 116, 790-806, 1978 b.

Dieterich, J. H.: Applications of Rate - and State-Dependent Friction to Models of Fault-Slip and Earthquake Occurrence, in: Treatise on Geophysics, Volume 4: Earthquake Seismology edited by: Kanamori, H., 107-129, https://doi.org/10.1016/B978-044452748-6/00065-1, 2007.

Dieterich, J. H. and Kilgore, B. D.: Direct observation of frictional contacts: New insights for state-dependent properties, PAGEOPH, 143, 283-302, 1994.

Dominguez, S., Malavieille, J., Mazzotti, S., Martin, N., Caniven, Y., Cattin, R., Soliva, R., Peyret, M., and Lallemand, S.: Modeling subduction megathrust earthquakes: Insights from a viscoelasto-plastic analog model, Geophysical Research Abstracts, 17, EGU2015-15200, 2015.
Erickson, B. A., Birnir, B., and Lavallee, D.: Periodicity, chaos and localization in a Burridge-Knopoff model of an earthquake with rate-and-state friction, Geophys. J. Int., 187, 178-198, https://doi.org/10.1111/j.1365-246X.2011.05123.x, 2011.

Eshelby, J. D.: The Determination of the Elastic Field of an Ellipsoidal Inclusion, and Related Problems, P. Roy. Soc. Lond. A Math., 241, 376, 1957.

Ferdowsi, B., Griffa, M., Guyer, R. A., Johnson, P. A., Marone, C., and Carmeliet, J.: Microslips as precursors of large slip events in the stick-slip dynamics of sheared granular layers: A discrete element model analysis, Geophys. Res. Lett., 40, 4194-4198, https://doi.org/10.1002/grl.50813, 2013.

Ferdowsi, B., Griffa, M., Guyer, R. A., Johnson, P. A., Marone, C., and Carmeliet, J.: Three-dimensional discrete element modeling of triggered slip in sheared granular media, Phys. Rev. E, 89, 042204, https://doi.org/10.1103/PhysRevE.89.042204, 2014.

Ferdowsi, B., Griffa, M., Guyer, R. A., Johnson, P. A., Marone, C., and Carmeliet, J. C. G. L.: Acoustically induced slip in sheared granular layers: Application to dynamic earthquake triggering, Geophys. Res. Lett., 42, 9750-9757, 2015.

Fuller, C. W., Willet, S. D., and Brandon, M. T.: Formation of forearc basins and their influence on subduction zone earthquakes, Geology, 34, 65-68, 2006.

Gabuchian, V., Rosakis, A. J., Lapusta, N., and Oglesby, D. D.: Experimental investigation of strong ground motion due to thrust fault earthquakes, J. Geophys. Res.-Sol. Ea., 119, 1316-1336, https://doi.org/10.1002/2013jb010409, 2014.

Gabuchian, V., Rosakis, A. J., Bhat, H. S., Madariaga, R., and Kanamori, H.: Experimental evidence that thrust earthquake ruptures might open faults, Nature, online first, 2017.

Galland, O., Bertelsen, H. S., Guldstrand, F., Girod, L., Johannessen, R. F., Bjugger, F., Burchardt, S., and Mair, K. C. J. B.: Application of open-source photogrammetric software MicMac for monitoring surface deformation in laboratory models, J. Geophys. Res.-Sol. Ea., 121, 2852-2872, 2016.

$\mathrm{Gu}$, Y. J. and Wong, T. F.: Effects of loading velocity, stiffness, and inertia on the dynamics of a single degree of freedom springslider system, J. Geophys. Res.-Sol. Ea., 96, 21677-21691, https://doi.org/10.1029/91jb02271, 1991.

Hamilton, T. and McCloskey, J.: Breakdown in power-law scaling in an analogue model of earthquake rupture and stick-slip, Geophys. Res. Lett., 24, 465-468, 1997.

Hamilton, T. and McCloskey, J.: The predictability of large earthquakes: Evidence from an analogue model of earthquake rupture, Pure Appl. Geophys., 152, 23-35, 1998.

Hartzell, S. H. and Archuleta, R. J.: Rupture propagation and focusing of energy in a foam rubber model of a stick slip earthquake, J. Geophys. Res., 84, 3623-3636, 1979.

Herbert, J. W., Cooke, M. L., Souloumiac, P., Madden, E. H., Mary, B. C. L., and Maillot, B.: The work of fault growth in laboratory sandbox experiments, Earth Planet. Sc. Lett., 432, 95-102, https://doi.org/10.1016/j.epsl.2015.09.046, 2015.

Herrendorfer, R., van Dinther, Y., Gerya, T., and Dalguer, L. A.: Earthquake supercycle in subduction zones controlled by the width of the seismogenic zone, Nat. Geosci., 8, 471-474, 2015.

Heslot, F., Baumberger, T., Perrin, B., Caroli, B., and Caroli, C.: Creep, stick.slip, and dry-friction dynamics: Experiments and a heuristic model, Phys. Rev., 49, 4973-4987, 1994. 
Hild, F. and Roux, S.: Digital image correlation: from displacement measurement to identification of elastic properties - a review, Strain, 42, 69-80, https://doi.org/10.1111/j.14751305.2006.00258.x, 2006.

Hirose, T. and Shimamoto, T.: Slip-Weakening Distance of Faults during Frictional Melting as Inferred from Experimental and Natural Pseudotachylytes, B. Seismol. Soc. Am., 95, 1666-1673, 2005.

Hubbert, M. K.: Theory of scale models as applied to the study of geological structures, Geol. Soc. Am. Bull., 48, 459-1520, 1937.

Jessop, H. T. and Harris, F. C.: Photoelasticity, principles and methods, Dover books on science, Dover Publications, 1960.

Johnson, P. A., Ferdowsi, B., Kaproth, B. M., Scuderi, M., Griffa, M., Carmeliet, J., Guyer, R. A., Le Bas, P. Y., Trugman, D. T., and Marone, C.: Acoustic emission and microslip precursors to stickslip failure in sheared granular material, Geophys. Res. Lett., 40, 5627-5631, https://doi.org/10.1002/2013gl057848, 2013.

Johnson, T., Wu, F. T., and Scholz, C. H.: Source Parameters for Stick-Slip and for Earthquakes, Science, 179, 278, 1973.

Johnson, K. M.: Slip rates and off-fault deformation in Southern California inferred from GPS data and models, J. Geophys. Res., 118, 5643-5664, 2013.

Kaneko, Y. and Ampuero, J. P.: A mechanism for preseismic steady rupture fronts observed in laboratory experiments, Geophys. Res. Lett., 38, L21307, https://doi.org/10.1029/2011g1049953, 2011.

Kaneko, Y., Avouac, J. P., and Lapusta, N.: Towards inferring earthquake patterns from geodetic observations of interseismic coupling, Nat. Geosci., 3, 363-U324, https://doi.org/10.1038/ngeo843, 2010.

Kavanagh, J., Menand, T., and Sparks, R.: An experimental investigation of sill formation and propagation in layered elastic media, Earth Planet. Sc. Lett., 245, 799-813, https://doi.org/10.1016/j.eps1.2006.03.025, 2006.

Kavanagh, J. L., Menand, T., and Daniels, K. A.: Gelatine as a crustal analogue: Determining elastic properties for modelling magmatic intrusions, Tectonophysics, 582, 101-111, https://doi.org/10.1016/j.tecto.2012.09.032, 2013.

King, C.-Y.: Model seismicity and faulting parameters, B. Seismol. Soc. Am., 65, 245-259, 1975.

King, C. Y.: Multicycle slip distribution along a laboratory fault, J. Geophys. Res., 96, 14377-14381, 1991.

King, C. Y.: Earthquake mechanism and predictability shown by a laboratory fault, PAGEOPH, 143, 457-482, 1994.

King, G. C. P., Stein, R. S., and Lin, J.: Static stress changes and the triggering of earthquakes, B. Seismol. Soc. Am., 84, 935-953, 1994.

King, J. L. and Brune, J. N.: Modeling the seismic response of sedimentary basins, B. Seismol. Soc. Am., 71, 1469-1487, 1981.

Klinkmuller, M., Schreurs, G., Rosenau, M., and Kemnitz, H.: Properties of granular analogue model materials: A community wide survey, Tectonophysics, 684, 23-38, https://doi.org/10.1016/j.tecto.2016.01.017, 2016.

Klotz, J., Khazaradze, G., Angermann, D., Reigber, C., Perdomo, R., and Cifuentes, O.: Earthquake cycle dominates contemporary crustal deformation in Central and Southern Andes, Earth Planet. Sc. Lett., 193, 437-446, 2001.

Knuth, M. and Marone, C.: Friction of sheared granular layers: Role of particle dimensionality, surface roughness, and material properties, Geochem. Geophy. Geosy., 8, Q03012, https://doi.org/10.1029/2006gc001327, 2007.

Krantz, R. W.: Measurements of friction coefficients and cohesion for faulting and fault reactivation in laboratory models using sand and sand mixtures, Tectonophysics, 188, 203-207, https://doi.org/10.1016/0040-1951(91)90323-k, 1991.

Kwiatek, G., Goebel, T. H. W., and Dresen, G. C. G. L.: Seismic moment tensor and $\mathrm{b}$ value variations over successive seismic cycles in laboratory stick-slip experiments, Geophys. Res. Lett., 41, 5838-5846, 2014.

Lapusta, N. and Liu, Y.: Three-dimensional boundary integral modeling of spontaneous earthquake sequences and aseismic slip, J. Geophys. Res., 114, https://doi.org/10.1029/2008jb005934, 2009.

Lapusta, N. and Rice, J. R. C.: Nucleation and early seismic propagation of small and large events in a crustal earthquake model, 108, 2205, https://doi.org/10.1029/2001JB000793, 2003.

Latour, S., Schubnel, A., Nielsen, S., Madariaga, R., and Vinciguerra, S.: Characterization of nucleation during laboratory earthquakes, Geophys. Res. Lett., 40, 5064-5069, $2013 \mathrm{a}$.

Latour, S., Voisin, C., Renard, F., Larose, E., Catheline, S., and Campillo, M.: Effect of fault heterogeneity on rupture dynamics: An experimental approach using ultrafast ultrasonic imaging, J. Geophys. Res.-Sol. Ea., 118, 5888-5902, https://doi.org/10.1002/2013JB010231, 2013b.

Lee, S.-J., Huang, B.-S., Ando, M., Chiu, H.-C., and Wang, J.-H.: Evidence of large scale repeating slip during the 2011 TohokuOki earthquake, Geophys. Res. Lett., 38, 1-6, 2011.

Lei, X. and Ma, S.: Laboratory acoustic emission study for earthquake generation process, Earthquake Science, 27, 627-646, 2014.

Leprince, S., Barbot, S., Ayoub, F., and Avouac, J. P.: Automatic and Precise Orthorectification, Coregistration, and Subpixel Correlation of Satellite Images, Application to Ground Deformation Measurements, IEEE T. Geosci. Remote, 45, 1529-1558, 2007.

Lieser, K., Grevemeyer, I., Lange, D., Flueh, E., Tilmann, F., and Contreras-Reyes, E.: Splay fault activity revealed by aftershocks of the 2010 M-w 8.8 Maule earthquake, central Chile, Geology, 42, 823-826, https://doi.org/10.1130/g35848.1, 2014.

Lin, J. and Stein, R. S.: Stress triggering in thrust and subduction earthquakes and stress interaction between the southern San Andreas and nearby thrust and strike-slip faults, J. Geophys. Res., 109, B02303, https://doi.org/10.1029/2003JB002607, 2004.

Lockner, D. A., Byerlee, J. D., Kuksenko, V., Ponomarev, A., and Sidorin, A.: Quasi-static fault growth and shear fracture energy in granite, Nature, 350, 39-42, 1991.

Lohrmann, J., Kukowski, N., Adam, J., and Oncken, O.: The impact of analogue material properties on the geometry, kinematics, and dynamics of convergent sand wedges, J. Struct. Geol., 25, 16911711, 2003.

Lu, X., Lapusta, N., and Rosakis, A. J.: Analysis of supershear transition regimes in rupture experiments: the effect of nucleation conditions and friction parameters, Geophys. J. Int., 177, 717732, https://doi.org/10.1111/j.1365-246X.2009.04091.x, 2009.

Lu, X., Rosakis, A. J., and Lapusta, N. C. B.: Rupture modes in laboratory earthquakes: Effect of fault prestress and nucleation conditions, J. Geophys. Res., 115, B12302, https://doi.org/10.1029/2009JB006833, 2010. 
Lykotrafitis, G., Rosakis, A. J., and Ravichandran, G.: Self-healing pulse-like shear ruptures in the laboratory, Science, 313, 17651768, 2006.

Ma, S. and Beroza, G. C.: Rupture Dynamics on a Bimaterial Interface for Dipping Faults, B. Seismol. Soc. Am., 98, 1642-1658, https://doi.org/10.1785/0120070201, 2008.

Mai, P. M., Spudich, P., and Boatwright, J.: Hypocenter locations in finite-source rupture models, B. Seismol. Soc. Am., 95, 965-980, 2005.

Mair, K. and Abe, S.: 3-D numerical simulations of fault gouge evolution during shear: Grain size reduction and strain localization, Earth Planet. Sc. Lett., 274, 72-81, https://doi.org/10.1016/j.epsl.2008.07.010, 2008.

Mair, K. and Hazzard, J.: Nature of stress accommodation in sheared granular material: Insights from 3-D numerical modeling, Earth Planet. Sc. Lett., 259, 469-485, https://doi.org/10.1016/j.epsl.2007.05.006, 2007.

Mair, K. and Marone, C.: Friction of simulated fault gouge for a wide range of velocities and normal stresses, J. Geophys. Res.-Sol. Ea., 104, 28899-28914, https://doi.org/10.1029/1999jb900279, 1999.

Mair, K., Frye, K. M., and Marone, C.: Influence of grain characteristics on the friction of granular shear zones, J. Geophys. Res.-Sol. Ea., 107, 2219, https://doi.org/10.1029/2001jb000516, 2002.

Mair, K., Renard, F., and Gundersen, O.: Thermal imaging on simulated faults during frictional sliding, Geophys. Res. Lett., 33, L19301, https://doi.org/10.1029/2006g1027143, 2006.

Marone, C.: Laboratory-derived friction laws and their application to seismic faulting, Annu. Rev. Earth Planet. Sc., 26, 643-696, 1998.

McLaskey, G. C. and Glaser, S. D.: Micromechanics of asperity rupture during laboratory stick slip experiments, Geophys. Res. Lett., 38, L12302, https://doi.org/10.1029/2011g1047507, 2011.

McLaskey, G. C., Thomas, A. M., Glaser, S. D., and Nadeau, R. M.: Fault healing promotes high-frequency earthquakes in laboratory experiments and on natural faults, Nature, 491, 101-114, https://doi.org/10.1038/nature11512, 2012.

McLaskey, G. C. and Kilgore, B. D.: Foreshocks during the nucleation of stick-slip instability, J. Geophys. Res., 118, 2982-2997, 2013.

Mello, M., Bhat, H. S., Rosakis, A. J., and Kanamori, H.: Identifying the unique ground motion signatures of supershear earthquakes: Theory and experiments, Tectonophysics, 493, 297-326, https://doi.org/10.1016/j.tecto.2010.07.003, 2010.

Mello, M., Bhat, H. S., Rosakis, A. J., and Kanamori, H.: Reproducing the supershear portion of the 2002 Denali earthquake rupture in laboratory, Earth Planet. Sc. Lett., 387, 89-96, https://doi.org/10.1016/j.epsl.2013.11.030, 2014.

Mello, M., Bhat, H. S., and Rosakis, A. J.: Spatiotemporal properties of Sub-Rayleigh and supershear rupture velocity fields: Theory and experiments, J. Mech. Phys. Solids, 93, 153-181, https://doi.org/10.1016/j.jmps.2016.02.031, 2016.

Mogi, B. K.: Relationship between the Occurrence of Great Earthquakes and Tectonic Structures, Bull. Earthqu. Res. Inst., 47, 429-451, 1969.

Moreno, M., Rosenau, M., and Oncken, O.: 2010 Maule earthquake slip correlates with pre-seismic locking of Andean subduction zone, Nature, 467, 198-202, https://doi.org/10.1038/nature09349, 2010.

Mori, T. and Kawamura, H.: Simulation study of the onedimensional Burridge-Knopoff model of earthquakes, J. Geophys. Res., 111, B07302, https://doi.org/10.1029/2005jb003942, 2006.

Mori, T. and Kawamura, H.: Simulation study of the two-dimensional Burridge-Knopoff model of earthquakes, J. Geophys. Res.-Sol. Ea., 113, B06301, https://doi.org/10.1029/2007jb005219, 2008.

Namiki, A., Yamaguchi, T., Sumita, I., Suzuki, T., and Ide, S.: Earthquake model experiments in a viscoelastic fluid: A scaling of decreasing magnitudes of earthquakes with depth, 119, 31693181, 2014.

Narkounskaia, G. and Turcotte, D. L.: A cellular-automata, sliderblock model for earthquakes: 1 . Demonstration of chaotic behavior for a low-order system, Geophys. J. Int., 111, 250-258, https://doi.org/10.1111/j.1365-246X.1992.tb00574.x, 1992.

Nasuno, S., Kudrolli, A., Bak, A., and Gollub, J. P.: Time-resolved studies of stick-slip friction in sheared granular layers, Phys. Rev. E, 58, 2161-2171, 1998.

Nielsen, S., Taddeucci, J., and Vinciguerra, S.: Experimental observation of stick-slip instability fronts, Geophys. J. Int., 180, $697-$ 702, 2010.

Nielsen, S. B.: Free surface effects on the propagation of dynamic rupture, Geophys. Res. Lett., 25, 125-128, 1998.

Nielsen, S. B., Carlson, J. M., and Olsen, K. B.: Influence of friction and fault geometry on earthquake rupture, J. Geophys. Res.-Sol. Ea., 105, 6069-6088, 2000.

Niemeijer, A., Marone, C., and Elsworth, D.: Healing of simulated fault gouges aided by pressure solution: Results from rock analogue experiments, J. Geophys. Res., 113, B04204, https://doi.org/10.1029/2007jb005376, 2008.

Niemeijer, A., Marone, C., and Elsworth, D.: Frictional strength and strain weakening in simulated fault gouge: Competition between geometrical weakening and chemical strengthening, J. Geophys. Res., 115, B10207, https://doi.org/10.1029/2009jb000838, 2010.

Nieuwland, D. A., Urai, J. L., and Knoop, M.: In-situ stress measurements in model experiments of tectonic faulting, in, Springer, Berlin Heidelberg, Berlin, Heidelberg, 155-166, 2000.

Nishenko, S. and McCann, W.: Large thrust earthquakes and tsunamis: Implications for the development of fore arc basins, J. Geophys. Res., 84, 573-584, 1979.

Oglesby, D. D., Archuleta, R. J., and Nielsen, S. B.: Earthquakes on dipping faults: The effects of broken symmetry, Science, 280, 1055-1059, 1998.

Oglesby, D. D., Archuleta, R. J., and Nielsen, S. B.: The threedimensional dynamics of dipping faults, B. Seismol. Soc. Am., 90, 616-628, 2000a.

Oglesby, D. D., Archuleta, R. J., and Nielsen, S. B.: Dynamics of dip-slip faulting: Explorations in two dimensions, J. Geophys. Res., 105, 13643-13653, https://doi.org/10.1029/2000JB900055, 2000b.

Ohnaka, M. and Kuwahara, Y.: Characteristic features of local breakdown near a crack-tip in the transition zone from nucleation to unstable rupture during stick-slip shear failure, Earthquake Source Processes, 175, 197-220, 1990.

Ohnaka, M. and Shen, L.-F.: Scaling of the shear rupture process from nucleation to dynamic propagation: Implications of geo- 
metric irregularity of the rupturing surfaces, J. Geophys. Res., 104, 817-844, 1999.

Okada, Y.: Surface deformation due to shear and tensile faults in a half-space, B. Seismol. Soc. Am., 75, 1135-1154, 1985.

Okada, Y.: Internal deformation due to shear and tensile faults in a half-space, B. Seismol. Soc. Am., 82, 1018-1040, 1992.

Okubo, P. G. and Dieterich, J. H.: Effects of physical fault properties on frictional instabilities produced on simulated faults, J. Geophys. Res., 89, 5817-5827, 1984.

Panien, M., Schreurs, G., and Pfiffner, A.: Mechanical behaviour of granular materials used in analogue modelling: insights from grain characterisation, ring-shear tests and analogue experiments, J. Struct. Geol., 28, 1710-1724, https://doi.org/10.1016/j.jsg.2006.05.004, 2006.

Passelègue, F. X., Schubnel, A., Nielsen, S., Bhat, H. S., and Madariaga, R.: From Sub-Rayleigh to Supershear Ruptures During Stick-Slip Experiments on Crustal Rocks, Science, 340, 1208-1211, https://doi.org/10.1126/science.1235637, 2013.

Passelègue, F. X., Schubnel, A., Nielsen, S., Bhat, H. S., Deldicque, D., and Madariaga, R. C. J. B.: Dynamic rupture processes inferred from laboratory microearthquakes, J. Geophys. Res., 121, 4343-4365, 2016.

Peltzer, G., Crampé, F., and King, G.: Evidence of nonlinear elasticity of the crust from Mw7.6 Manyi (Tibet) earthquake, Science, 286, 272-276, https://doi.org/10.1126/science.286.5438.272, 1999.

Peng, Z. G. and Gomberg, J.: An integrated perspective of the continuum between earthquakes and slow-slip phenomena, Nat. Geosci., 3, 599-607, https://doi.org/10.1038/ngeo940, 2010.

Pipping, E., Kornhuber, R., Rosenau, M., and Oncken, O.: On the efficient and reliable numerical solution of rate-andstate friction problems, Geophys. J. Int., 204, 1858-1866, https://doi.org/10.1093/gji/ggv512, 2016.

Pollard, D. D. and Segall, P.: 8 - Theoretical displacements and stresses near fractures in rock: with application to faults, joints, veins, dikes, and solution surfaces A2, edited by: Atkinson, B. K., Academic Press, London, 277-349, 1987.

Pollard, D. D. and Fletcher, R. C.: Fundamentals of Structural Geology, Cambridge Univ. Press, 2005.

Popov, V. L., Grzemba, B., Starcevic, J., and Popov, M.: Rate and state dependent friction laws and the prediction of earthquakes: What can we learn from laboratory models?, Tectonophysics, 532, 291-300, https://doi.org/10.1016/j.tecto.2012.02.020, 2012.

Ramberg, H.: Gravity, Deformation and the Earth's Crust, Academic Press, New York, 224 pp., 1967.

Reber, J. E., Hayman, N. W., and Lavier, L. L. C. G. L.: Stick-slip and creep behavior in lubricated granular material: Insights into the brittle-ductile transition, 41, 3471-3477, 2014

Reber, J. E., Lavier, L. L., and Hayman, N. W.: Experimental demonstration of a semi-brittle origin for crustal strain transients, Nat. Geosci., 8, 712-715, 2015.

Reid, H. F.: The elastic-rebound theory of earthquakes, Univ. Calif. Publ. Dept. Geol. Sci., 1911.

Renard, F., Mair, K., and Gundersen, O.: Surface roughness evolution on experimentally simulated faults, J. Struct. Geol., 45, 99-110, https://doi.org/10.1016/j.jsg.2012.03.009, 2012.

Rhie, J., Dreger, D., Burgmann, R., and Romanowicz, B.: Slip of the 2004 Sumatra-Andaman Earthquake from Joint Inversion of
Long-Period Global Seismic Waveforms and GPS Static Offsets, B. Seismol. Soc. Am., 97, S115-S127, 2007.

Ritter, M. C., Leever, K., Rosenau, M., and Oncken, O.: Scaling the sandbox-Mechanical (dis) similarities of granular materials and brittle rock, J. Geophys. Res.-Sol. Ea., 121, 6863-6879, https://doi.org/10.1002/2016JB012915, 2016.

Rosakis, A. J., Samudrala, O., and Coker, D.: Cracks faster than the shear wave speed, Science, 284, 1337-1340, 1999.

Rosakis, A. J., Xia, K., Lykotrafitis, G., and Kanamori, H.: 4.08 Dynamic Shear Rupture in Frictional Interfaces: Speeds, Directionality, and Modes A2 edited by: Schubert, G., Elsevier, Oxford, 183-213, 2007.

Rosenau, M. and Oncken, O.: Fore-arc deformation controls frequency-size distribution of megathrust earthquakes in subduction zones, J. Geophys. Res.-Sol. Ea., 114, B10311, https://doi.org/10.1029/2009jb006359, 2009.

Rosenau, M., Lohrmann, J., and Oncken, O.: Shocks in a box: An analogue model of subduction earthquake cycles with application to seismotectonic forearc evolution, J. Geophys. Res.-Sol. Ea., 114, B01409, https://doi.org/10.1029/2008jb005665, 2009.

Rosenau, M., Nerlich, R., Brune, S., and Oncken, O.: Experimental insights into the scaling and variability of local tsunamis triggered by giant subduction megathrust earthquakes, J. Geophys. Res.-Sol. Ea., 115, B09314, https://doi.org/10.1029/2009jb007100, 2010.

Rosenau, M., Corbi, F., Dominguez, S., Rudolf, M., Ritter, M., and Pipping, E.: Supplement to "Analogue earthquakes and seismic cycles: Experimental modelling across timescales" GFZ Data Services, https://doi.org/10.5880/GFZ.4.1.2016.008, 2016.

Rousseau, C.-E. and Rosakis, A. J.: Dynamic path selection along branched faults: Experiments involving sub-Rayleigh and supershear ruptures, J. Geophys. Res., 114, B08303, https://doi.org/10.1029/2008jb006173, 2009.

Roy, M., and Marone, C.: Earthquake nucleation on model faults with rate- and state-dependent friction: Effects of inertia, J. Geophys. Res.-Sol. Ea., 101, 13919-13932, https://doi.org/10.1029/96jb00529, 1996.

Rubino, V., Lapusta, N., Rosakis, A. J., Leprince, S., and Avouac, J. P.: Static Laboratory Earthquake Measurements with the Digital Image Correlation Method, Experimental Mechanics, 55, 77-94, https://doi.org/10.1007/s11340-014-9893-z, 2015.

Rubinstein, J. L., Ellsworth, W. L., Beeler, N. M., Kilgore, B. D., Lockner, D. A., and Savage, H. M.: Fixed recurrence and slip models better predict earthquake behavior than the time- and slip-predictable models: 2. Laboratory earthquakes, J. Geophys. Res.-Sol. Ea., 117, B02307, https://doi.org/10.1029/2011jb008723, 2012.

Rubinstein, S. M., Cohen, G., and Fineberg, J.: Detachment fronts and the onset of dynamic friction, Nature, 430, 1005, 2004.

Rubio, M. A. and Galeano, J.: Stick-slip dynamics in the relaxation of stresses in a continuous elastic medium, Phys. Rev. E, 50, 1000-1004, https://doi.org/10.1103/PhysRevE.50.1000, 1994.

Rudolf, M., Boutelier, D., Rosenau, M., Schreurs, G., and Oncken, O.: Rheological benchmark of silicone oils used for analog modeling of short- and long-term lithospheric deformation, Tectonophysics, 684, 12-22, https://doi.org/10.1016/j.tecto.2015.11.028, 2016a.

Rudolf, M., Rosenau, M., and Oncken, O.: Jelly Quakes - Characteristics of periodic slip events in an analog model of strike slip seis- 
motectonics using ballistic gelatin, Geophysical Research Abstracts, 18, EGU2016-3222, 2016b.

Ruina, A.: Slip instability and state variable friction laws, J. Geophys. Res., 88, 10359-10370, 1983.

Saillard, M., Audin, L., Rousset, B., Avouac, J.-P., Chlieh, M., Hall, S. R., Husson, L., and Farber, D. L.: From the seismic cycle to long-term deformation: linking seismic coupling and Quaternary coastal geomorphology along the Andean megathrust, Tectonics, 36, 241-256, https://doi.org/10.1002/2016TC004156, 2017.

Saito, T. and Matsukawa, H.: Size dependence of the BurridgeKnopoff model, Journal of Physics: Conference Series, 89, 012016, https://doi.org/10.1088/1742-6596/89/1/012016, 2007.

Savage, J. C. and Burford, R. O.: Geodetic determination of relative plate motion in central California, J. Geophys. Res., 78, 832-845, 1973.

Schallamach, A.: How does rubber slide?, Wear, 17, 301-312, 1971.

Schmalzle, G., Dixon, T., Malservisi, R., and Govers, R.: Strain accumulation across the Carrizo segment of the San Andreas Fault, California: Impact of laterally varying crustal properties, J. Geophys. Res., 111, B05403, https://doi.org/10.1029/2005JB003843, 2006.

Schmittbuhl, J., Vilotte, J.-P., and Roux, S.: A dissipation-based analysis of an earthquake fault model, J. Geophys. Res., 101, 27741-27764, 1996.

Scholz, C. and Molnar, P. J. T.: Detailed Studies of Frictional Sliding of Granite and Implications for the Earthquake Mechanism, J. Geophys. Res., 77, 6392-6406, 1972.

Scholz, C. H.: Earthquakes and friction laws, Nature, 391, 37-42, 1998.

Scholz, C. H.: The Mechanics of Earthquakes and Faulting, 2nd Edn., Cambridge University Press, Cambridge, 2002.

Schorlemmer, D., Wiemer, S., and Wyss, M.: Variations in earthquake-size distribution across different stress regimes, Nature, 437, 539-542, 2005.

Schubnel, A., Nielsen, S., Taddeucci, J., Vinciguerra, S., and Rao, S.: Photo-acoustic study of subshear and supershear ruptures in the laboratory, Earth Planet. Sc. Lett., 308, 424-432, https://doi.org/10.1016/j.epsl.2011.06.013, 2011.

Schulze, D.: Entwicklung und Anwendung eines neuartigen Ringschergerätes, Aufbereitungstechnik, 35, 524-535, 1994.

Schulze, D.: Time- and velocity-dependent properties of powders effecting slip-stick oscillations, Chemical Engineering Technology, 26, 1047-1051, 2003.

Schurr, B., Asch, G., Rosenau, M., Wang, R., Oncken, O., Barrientos, S., Salazar, P., and Vilotte, J. P.: The 2007 M7.7 Tocopilla northern Chile earthquake sequence: Implications for along-strike and downdip rupture segmentation and megathrust frictional behavior, J. Geophys. Res.-Sol. Ea., 117, B05305, https://doi.org/10.1029/2011jb009030, 2012.

Scuderi, M. M., Carpenter, B. M., Johnson, P. A., and Marone, C. C. J. B.: Poromechanics of stick-slip frictional sliding and strength recovery on tectonic faults, J. Geophys. Res.-Sol. Ea., 120, 68956912, 2015.

Shi, B. and Brune, J. N.: Characteristics of near-fault ground motions by dynamic thrust faulting: Two dimensional lattice particle approaches, B. Seismol. Soc. Am., 95, 2525-2533, 2005.

Shi, B., Anooshehpoor, A., Brune, J. N., and Zeng, Y.: Dynamics of thrust faulting: 2d lattice model, B. Seismol. Soc. Am., 88, 1484-1494, 1998.
Shi, B., Brune, J. N., Zeng, Y., and Anooshehpoor, A.: Dynamics of Earthquake Normal Faulting: Two-Dimensional Lattice Particle Model, B. Seismol. Soc. Am., 93, 1179, 2003.

Souloumiac, P., Leroy, Y. M., Maillot, B., and Krabbenhoft, K.: Predicting stress distributions in fold-and-thrust belts and accretionary wedges by optimization, J. Geophys. Res.-Sol. Ea., 114, B09404, https://doi.org/10.1029/2008jb005986, 2009.

Spagnuolo, E., Nielsen, S., Violay, M., and Di Toro, G. C. G.: An empirically based steady state friction law and implications for fault stability, Geophys. Res. Lett., 43, 3263-3271, 2016.

Stierle, E., Vavryčuk, V., Kwiatek, G., Charalampidou, E.-M., and Bohnhoff, M.: Seismic moment tensors of acoustic emissions recorded during laboratory rock deformation experiments: sensitivity to attenuation and anisotropy, Geophys. J. Int., 205, 38-50, 2016.

Sugiura, N., Hori, T., and Kawamura, Y.: Synchronization of coupled stick-slip oscillators, Nonlin. Processes Geophys., 21, 251267, https://doi.org/10.5194/npg-21-251-2014, 2014.

Sutton, M. A., Orteu, J. J., and Schreier, H.: Image Correlation for Shape, Motion and Deformation Measurements: Basic Concepts, Theory and Applications, Springer US, 2009.

Sveen, J. K.: An introduction to MatPIV v.1.6.1, Eprint no. 2. ISSN 0809-4403, Department of Mathematics, University of Oslo, available at: http://urn.nb.no/URN:NBN:no-27806 (last access: 4 May 2017), 2004.

Tchalenko, J. S.: Similarities between Shear Zones of Different Magnitudes, Geol. Soc. Am. B., 81, 1625, 1970.

Templeton, E. L., Baudet, A., Bhat, H. S., Dmowska, R., Rice, J. R., Rosakis, A. J., and Rousseau, C.-E.: Finite element simulations of dynamic shear rupture experiments and dynamic path selection along kinked and branched faults, J. Geophys. Res., 114, B08304, https://doi.org/10.1029/2008jb006174, 2009.

ten Grotenhuis, S. M., Piazolo, S., Pakula, T., Passchier, C. W., and Bons, P. D.: Are polymers suitable rock analogs?, Tectonophysics, 350, 35-47, https://doi.org/10.1016/s00401951(02)00080-x, 2002.

Thielicke, W. and Stamhuis, E. J.: PIVlab, Towards User-friendly, Affordable and Accurate Digital Particle Image Velocimetry in MATLAB, Journal of Open Research Software, 2, https://doi.org/10.5334/jors.bl, 2014.

Thompson, B. D., Young, R. P., and Lockner, D. A. C. L.: Observations of premonitory acoustic emission and slip nucleation during a stick slip experiment in smooth faulted Westerly granite, Geophys. Res. Lett., 32, L10304, https://doi.org/10.1029/2005GL022750, 2005.

Thompson, B. D., Young, R. P., and Lockner, D. A.: Fracture in Westerly Granite under AE Feedback and Constant Strain Rate Loading: Nucleation, Quasi-static Propagation, and the Transition to Unstable Fracture Propagation, Pure Appl. Geophys., 163, 995-1019, 2006.

Thompson, B. D., Young, R. P., and Lockner, D. A.: Premonitory acoustic emissions and stick-slip in natural and smoothfaulted Westerly granite, J. Geophys. Res., 114, B02205, https://doi.org/10.1029/2008jb005753, 2009.

Toda, S. and Stein, R. S.: Response of the San Andreas fault to the 1983 Coalinga-Nuñez Earthquakes: An application of interaction-based probabilities for Parkfield, J. Geophys. Res., 107, 2126, https://doi.org/10.1029/2001JB000172, 2002. 
Tormann, T., Enescu, B., Woessner, J., and Wiemer, S.: Randomness of megathrust earthquakes implied by rapid stress recovery after the Japan earthquake, Nat. Geosci., 8, 152-158, https://doi.org/10.1038/ngeo2343, 2015.

Tullis, T. E., Richards-Dinger, K., Barall, M., Dieterich, J. H., Field, E. H., Heien, E. M., Kellogg, L. H., Pollitz, F. F., Rundle, J. B., Sachs, M. K., Turcotte, D. L., Ward, S. N., and Yikilmaz, M. B.: A Comparison among Observations and Earthquake Simulator Results for the allcal2 California Fault Model, Seismol. Res. Lett., 83, 994-1006, 10.1785/0220120094, 2012a.

Tullis, T. E., Richards-Dinger, K., Barall, M., Dieterich, J. H., Field, E. H., Heien, E. M., Kellogg, L. H., Pollitz, F. F., Rundle, J. B., Sachs, M. K., Turcotte, D. L., Ward, S. N., and Yikilmaz, M. B.: Generic Earthquake Simulator, Seismol. Res. Lett., 83, 959, 2012b.

Turcotte, D. L. and Schubert, G.: Geodynamics, Cambridge University Press, 456 pp., 2002.

van Dinther, Y., Gerya, T. V., Dalguer, L. A., Corbi, F., Funiciello, F., and Mai, P. M.: The seismic cycle at subduction thrusts: 2. Dynamic implications of geodynamic simulations validated with laboratory models, J. Geophys. Res.-Sol. Ea., 118, 1502-1525, https://doi.org/10.1029/2012jb009479, 2013a.

van Dinther, Y., Gerya, T. V., Dalguer, L. A., Mai, P. M., Morra, G., and Giardini, D.: The seismic cycle at subduction thrusts: Insights from seismo-thermo-mechanical models, J. Geophys. Res.-Sol. Ea., 118, 6183-6202, https://doi.org/10.1002/2013jb010380, 2013b.

van Otterloo, J. and Cruden, A. R.: Rheology of pig skin gelatine: Defining the elastic domain and its thermal and mechanical properties for geological analogue experiment applications, Tectonophysics, 683, 86-97, 2016.

Varamashvili, N., Chelidze, T., and Lursmanashvili, O.: Phase synchronization of slips by periodical (tangential and normal) mechanical forcing in the spring-slider model, Acta Geophys., 56, 357-371, 10.2478/s11600-008-0006-1, 2008.

Victor, P., Sobiesiak, M., Glodny, J., Nielsen, S. N., and Oncken, O.: Long-term persistence of subduction earthquake segment boundaries: Evidence from Mejillones Peninsula, northern Chile, J. Geophys. Res., 116, B02402, https://doi.org/10.1029/2010jb007771, 2011.

Voisin, C., Renard, F., and Grasso, J.-R.: Long term friction: From stick-slip to stable sliding, Geophys. Res. Lett., 34, L13301, https://doi.org/10.1029/2007g1029715, 2007.

Voisin, C., Grasso, J.-R., Larose, E., and Renard, F.: Evolution of seismic signals and slip patterns along subduction zones: Insights from a friction lab scale experiment, Geophys. Res. Lett., 35, L08302, https://doi.org/10.1029/2008g1033356, 2008.

Wang, J. H.: Some Intrinsic Properties of the Two-Dimensional Dynamical Spring-Slider Model of Earthquake Faults, B. Seismol. Soc. Am., 102, 822-835, https://doi.org/10.1785/0120110172, 2012.

Wang, K. and Hu, Y.: Accretionary prisms in subduction earthquake cycles: The theory of dynamic Coulomb wedge, J. Geophys. Res., 111, B06410, https://doi.org/10.1029/2005JB004094, 2006.

Wang, K. L., Hu, Y., and He, J. H.: Deformation cycles of subduction earthquakes in a viscoelastic Earth, Nature, 484, 327-332, https://doi.org/10.1038/nature11032, 2012.
Weertman, J.: Unstable slippage across a fault that separates elastic media of different elastic constants, J. Geophys. Res., 85, 14551461, 1980.

Weijermars, R. and Schmeling, H.: Scaling of Newtonian and nonNewtonian fluid dynamics without inertia for quantitative modelling of rock flow due to gravity (including the concept of rheological similarity), Phys. Earth Planet. Int., 43, 316-330, 1986.

Weijermars, R., Jackson, M. P. A., and Vendeville, B.: Rheological and tectonic modelling of salt provinces, Tectonophysics, 217, 143-174, https://doi.org/10.1016/0040-1951(93)90208-2, 1993.

Weldon, R., Scharer, K., Fumal, T., and Biasi, G.: Wrightwood and the earthquake cycle: What a long recurrence record tells us about how faults work, GSA Today, 14, 4-10, https://doi.org/10.1130/10525173(2004)014<4:watecw>2.0.co;2, 2004.

Wells, R. E., Blakely, R. J., Sugiyama, Y., Scholl, D. W., and Dinterman, P. A. C.: Basin-centered asperities in great subduction zone earthquakes: A link between slip, subsidence, and subduction erosion?, J. Geophys. Res., 108 2507, https://doi.org/10.1029/2002JB002072, 2003.

Wesson, R. L., Melnick, D., Cisternas, M., Moreno, M., and Ely, L. L.: Vertical deformation through a complete seismic cycle at Isla Santa Maria, Chile, Nat. Geosci., 8, 547-551, https://doi.org/10.1038/ngeo2468, 2015.

Wood, H. O.: The elastic-rebound theory of Earthquakes, B. Seismol. Soc. Am., 2, 98-100, 1912.

Wu, F. T., Thomson, K. C., and Kuenzler, H.: Stick-slip propagation velocity and seismic source mechanism, B. Seismol. Soc. Am., 62, 1621-1628, 1972.

Xia, K., Rosakis, A. J., and Kanamori, H.: Laboratory Earthquakes: The Sub-Rayleigh-to-Supershear Rupture Transition, Science, 303, 1859-1861, 2004.

Xia, K., Rosakis, A. J., Kanamori, H., and Rice, J. R.: Geophysics: Laboratory earthquakes along inhomogenous faults: Directionality and supershear, Science, 308, 681-684, 2005.

Yamaguchi, T., Morishita, M., Doi, M., Hori, T., Sakaguchi, H., and Ampuero, J.-P. C. B.: Gutenberg-Richter's law in sliding friction of gels, J. Geophys, Res., 116, B12306, https://doi.org/10.1029/2011JB008415, 2011.

Yoshida, S., Kato, A., Kato, N., and Nakatani, M.: Interpretation of various slip modes on a plate boundary based on laboratory and numerical experiments, Earth Planets Space, 56, 795-801, 2004.

Zang, A., Christian Wagner, F., Stanchits, S., Dresen, G., Andresen, R., and Haidekker, M. A.: Source analysis of acoustic emissions in Aue granite cores under symmetric and asymmetric compressive loads, Geophys. J. Int., 135, 1113-1130, 1998.

Zang, A., Wagner, F. C., Stanchits, S., Janssen, C., and Dresen, G.: Fracture process zone in granite, J. Geophys. Res., 105, 2365123661, 2000.

Zigone, D., Voisin, C., Larose, E., Renard, F., and Campillo, M.: Slip acceleration generates seismic tremor like signals in friction experiments, Geophys. Res. Lett., 38, L01315, https://doi.org/10.1029/2010gl045603, 2011. 